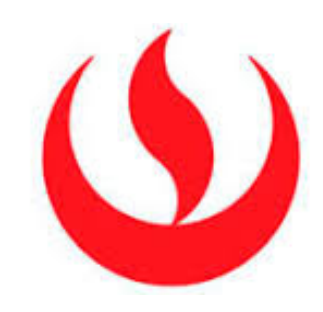

UNIVERSIDAD PERUANA DE CIENCIAS APLICADAS

ESCUELA DE POSGRADO

MAESTRIA EN FINANZAS CORPORATIVAS

\title{
VALORIZACION DE EMPRESA MILPO S.A.A. (NEXA RESOURCES PERU S.A.A.) POR EL METODO: FLUJO DE CAJA DESCONTADOS
}

\author{
TRABAJO DE INVESTIGACIÓN \\ PARA OPTAR EL GRADO ACADEMICO DE MAESTRO EN \\ FINANZAS CORPORATIVAS
}

AUTOR:

Ugarte Portuondo, Walter Antonio (0000-0001-5040-9785)

ASESOR

Paredes Minaya, Percy (0000-0002-0702-3729)

Lima, 30 de Julio de 2018 
Dedico el presente trabajo a mi familia, profesores y amigos por su apoyo incondicional. 


\section{RESUMEN EJECUTIVO}

El objetivo de este trabajo es presentar los Resultados de la valorización económica realizado a la Empresa Milpo S.A.A. al cierre del 31 de Diciembre de 2017. Para este propósito se han analizado los datos históricos de la Empresa, así como sus estimaciones de ingresos, gastos e inversiones por un período de diez años. Adicionalmente se han planteado supuestos utilizados en las metodologías de valorización aplicadas a fin de sensibilizar los datos obtenidos.

Como conclusión, se han obtenido que el valor fundamental de la Empresa es de miles de USD $\$ \mathbf{1 , 7 9 7 , 9 0 4}$ y el precio por acción es de S/. 4.458. Dicho resultado se ha obtenido sobre la base de información tanto pública y de la propia Empresa, artículos obtenidos sobre la industria, búsqueda de fuentes confiables, así como en el uso de herramientas financieras.

La experiencia de la Empresa utilizando bajos costos y flexibilidad para priorizar su inversión, le permite llevarla con mucha eficiencia ante la volatilidad de los precios de los metales en el mercado internacional. Como consecuencia de ello, la Compañía Minera Milpo tiene un gran soporte financiero.

Finalmente, debemos mencionar que el valor obtenido resulta conservador, debido a que no se está considerando la puesta en marcha de nuevos proyectos mineros. Además, durante el presente trabajo, los precios de los metales están en proceso de recuperación. Sin embargo, he creído conveniente que se considere un precio moderado tomando como base las proyecciones del Banco Mundial publicadas en Abril del 2018.

Palabras clave : Valorización ; Flujo de Caja Descontado ; Sensibilidad 


\begin{abstract}
The purpose of this work is to present the results of the economic valuation made to The Milpo S.A.A. Company at the close of December 31, 2017. For this purpose, the historical data of this company, as well as its estimates of income, expenses and investments for a period of ten years have been analyzed. In addition, the assumptions used in the valuation methodologies applied in order to raise awareness of the data obtained have been raised.
\end{abstract}

In conclusion, we have obtained that the fundamental value of the Company is of miles of dollars USD \$ 1,797,904 and the price per share is S/. 4.458. This result has been obtained on the basis of information both public and the company, articles obtained on the industry, in the search of reliable sources, as well as in the use of finantial tools.

Experience of the Company using low costs and flexibility to prioritize its investments, allows it to be carried out with great efficiency in the face of the volatility of metals prices in the international marketplace. As a consequence, The Milpo Mining Company has great finantial support.

Finally, we must mention that the value obtained is conservative, this is because the startup of new mining projects is not to be considered. In addition, in the present work, the prices of metals are in process of recovery. However, I thought it convenient that taking a moderate price based on World Bank projections published in April 2018.

Keywords : Valuation ; Discount Cash Flow ; Sensibility 


\section{Indice de Contenido}

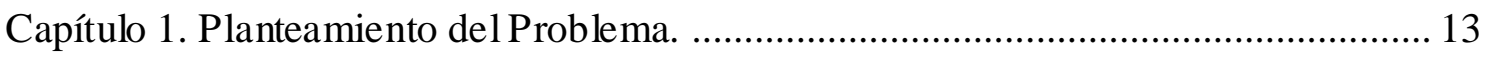

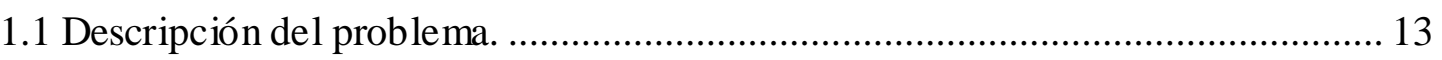

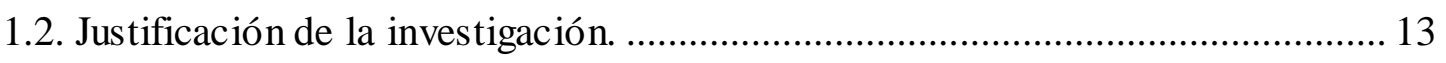

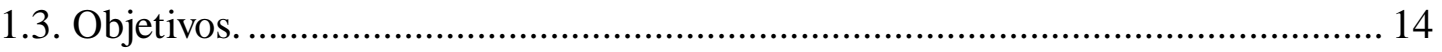

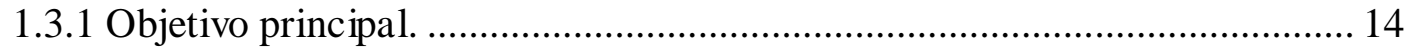

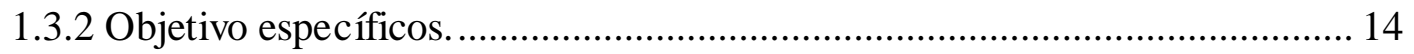

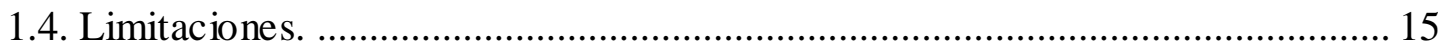

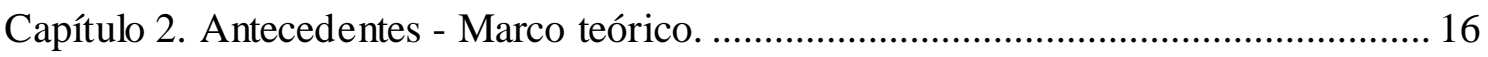

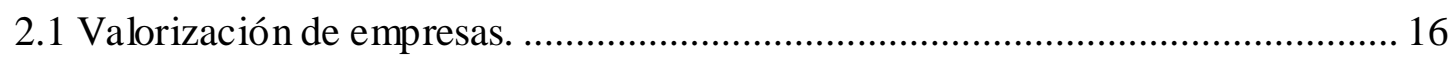

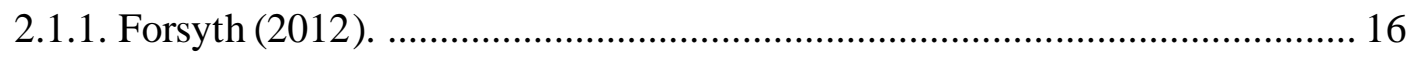

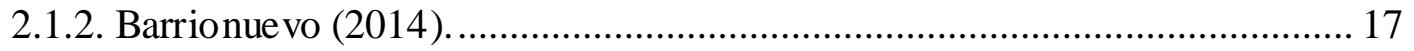

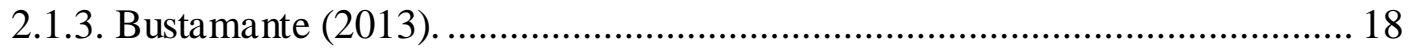

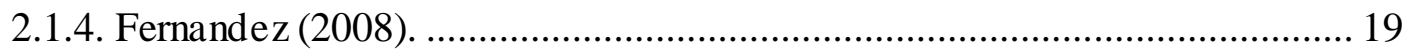

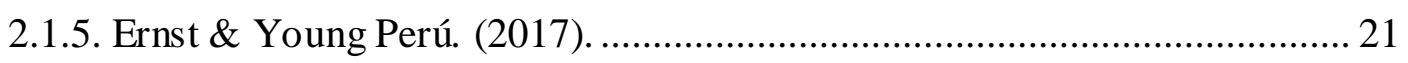

2.1.6. Copeland, Koller y Murrin (2004)........................................................... 23

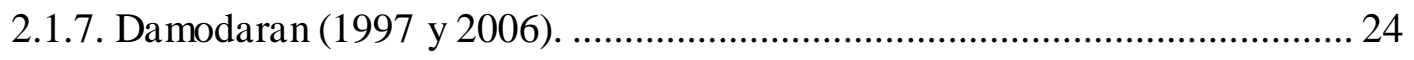

2.2. Metodologías en la determinación de la Tasa de descuento COK...................... 26

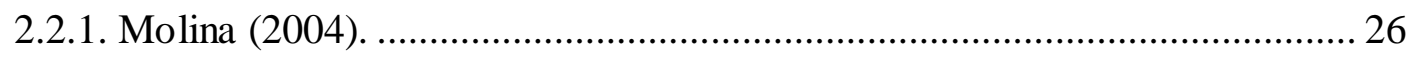

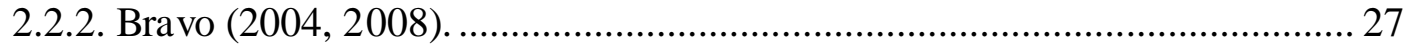

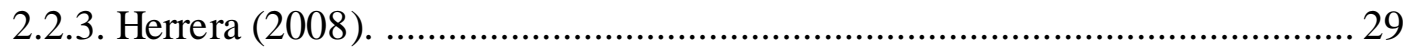

2.2.4. Ibboton, Kaplan y Peterson (1997)............................................................ 30

2.3 Metodologías para la estimación de los flujos de caja, VAN y el modelo de

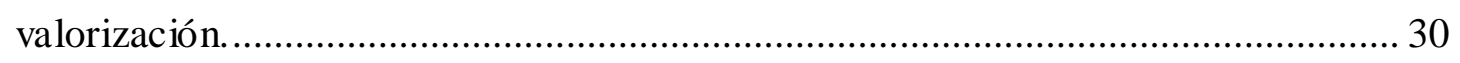

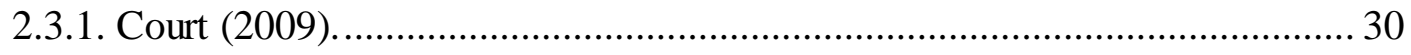

2.3.2. Monserrat Casanova, Pol Santandreu (2012). .......................................... 35

Capítulo 3. Descripción general del negocio y Análisis de la industria. ......................... 36

3.1. Antecedentes de la Empresa Milpo SAA. .......................................................... 36

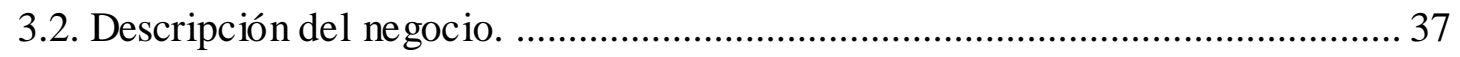

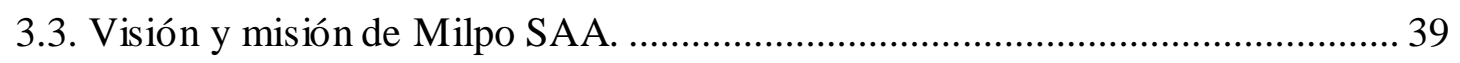

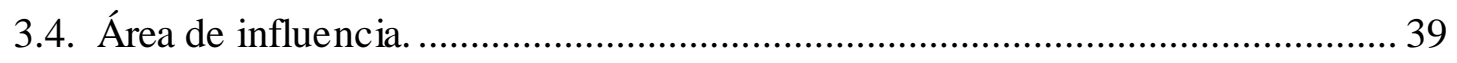

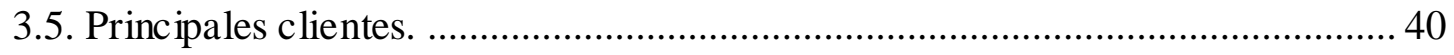


3.6. Regulación actual del sector Minero. ................................................................ 40

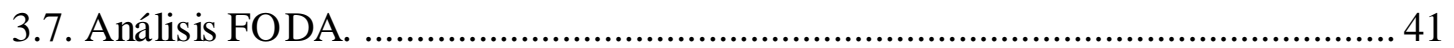

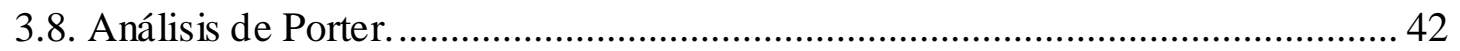

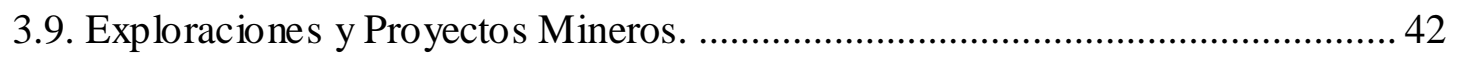

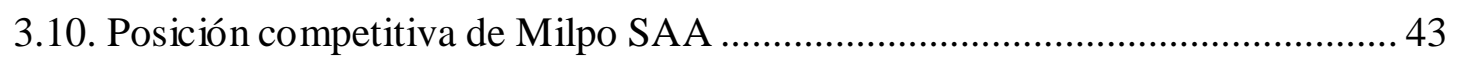

3.11. Perspectivas de crecimiento económico del sector, nacional y mundial. .......... 43

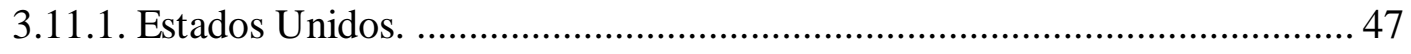

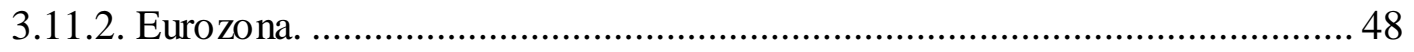

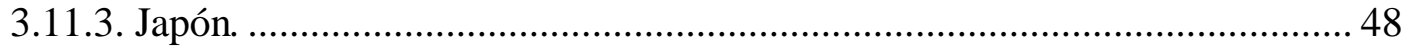

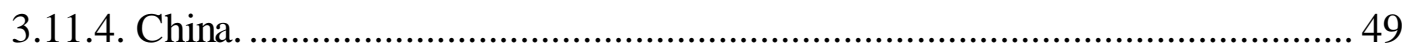

3.11.5. América Latina. .............................................................................. 49

3.11.6. Perú. ….......................................................................................... 51

3.11.6.1. Sector Agropec uario. .............................................................. 51

3.11.6.2. Sector Pesca. .......................................................................... 52

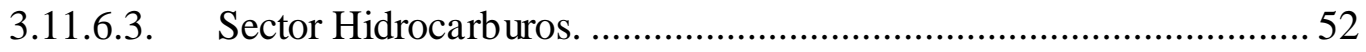

3.11.6.4. Manufactura No Primaria. ........................................................... 52

3.11.6.5. Sector Minería Metálica. ............................................................. 52

3.12. El Sector Minero en el Perú y su Entorno Internacional. .................................57

3.12.1. Producción, usos y perspectivas del zinc...................................................58

3.12.2. Producción, usos y perspectivas del plomo. .............................................. 59

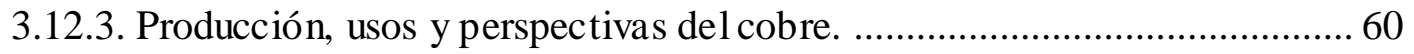

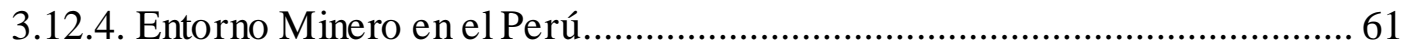

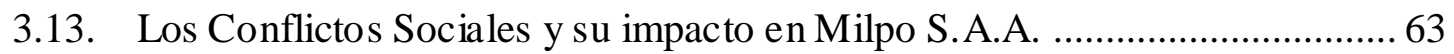

Capítulo 4. Análisis financiero Milpo S.A.A. y estimación de la tasa de descuento. .... 65

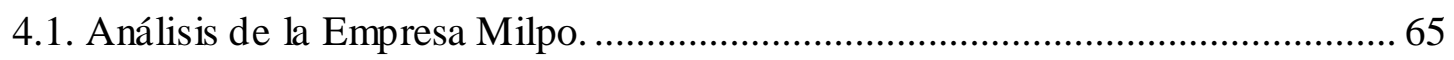

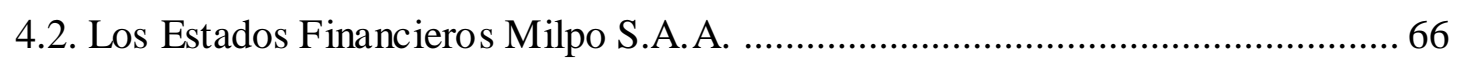

4.3. Análisis del Ebitda, Ebit, Patrimonio, Depreciación y Amortización. ................. 69

4.4. Análisis financiero: Ratios de Liquidez, de Gestión y Rentabilidad. ................. 69

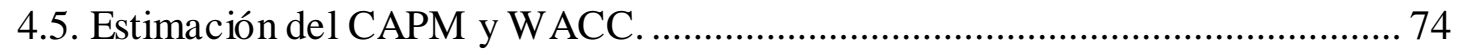

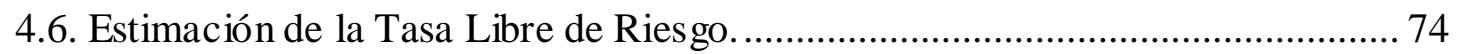

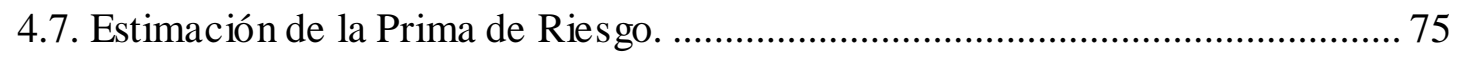

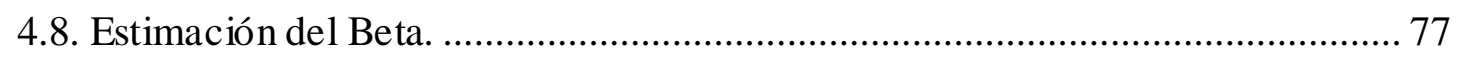

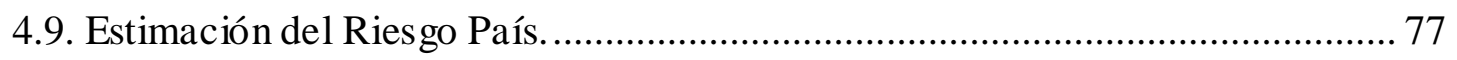

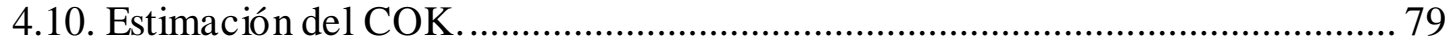




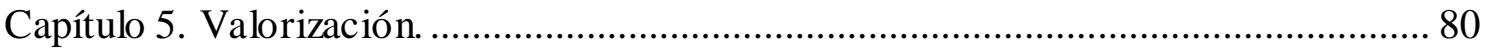

5.1. Supuestos y sustentos para las proyecciones. ....................................................... 80

5.1.1. Proyección de las Ventas. ............................................................................ 80

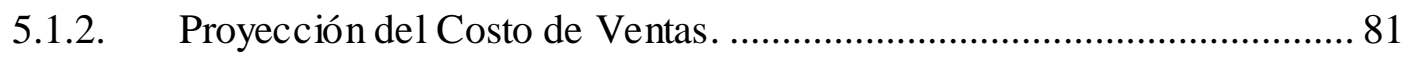

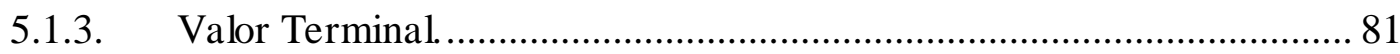

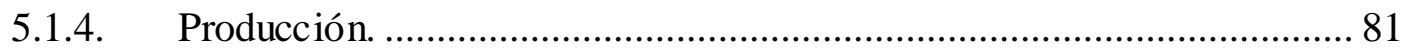

5.1.5. Cierre de Mina y Pasivos Ambientales................................................... 82

5.2. Estimación de los Gastos Administrativos y de Ventas. ...................................... 82

5.2.1. Estimación de los Gastos Administrativos. ................................................... 82

5.2.2. Estimación de los Gastos de Ventas. ............................................................ 83

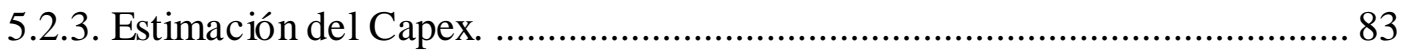

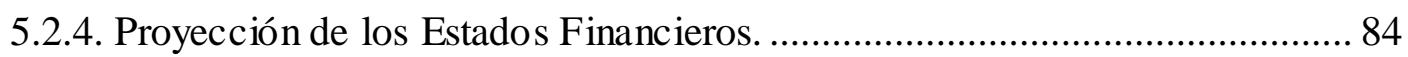

5.2.4.1. Proyección del Estado de Resultados .................................................... 84

5.2.4.2. Indicadores Financieros obtenidos luego de la proyección ..................... 85

5.2.4.3. Proyección del Estado de Situación Financiera (Balance General) ........ 86

5.2.4.4. Proyección del Flujo de Efectivo........................................................... 86

5.2.4.5. Estimación de la perpetuidad para la valorización .................................. 87

5.2.5. Valorización de la empresa Milpo S.A.A. ..................................................... 87

5.2.5.1. Estimación del Free Cash Flow para la Compañía ................................... 87

5.2.5.2. Resultados de la Valorización: ............................................................... 88

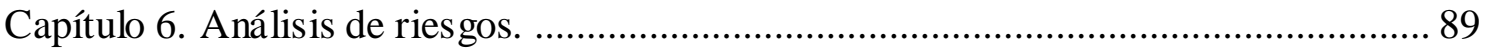

6.1. Análisis de Sensibilidad de la Valorización. ………………………………........ 89

6.1.1. Sensibilidad del precio de los metales. .......................................................... 89

6.1.2. Sensibilidad de la tasa de descuento........................................................... 90

6.1.3. Sensibilidad de la tasa de crecimiento. ........................................................... 91

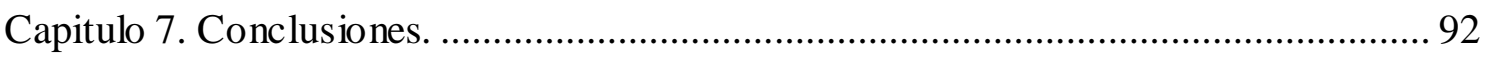

Capítulo 8. Recomendaciones y conceptos adicionales. ……………………………..... 93

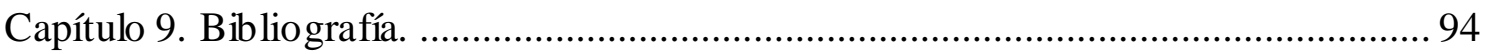




\section{Indice de Tablas}

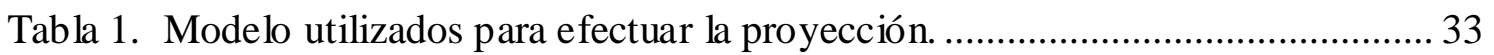

Tabla 2. Modelo de Balance General Proyectado. ........................................................ 34

Tabla 3. Modelo de Resultados Proyectados del Modelo................................................ 34

Tabla 4. Historia de la Compañía Minera Milpo SAA. ................................................... 36

Tabla 5. Evolución de los recursos y reservas Milpo SAA. ........................................... 38

Tabla 6. Distribución de Ingresos Milpo SAA 2017 por Unidad Minera. ...................... 38

Tabla 7. Participación Porcentual de reservas y recursos Milpo SAA 2017. ................. 39

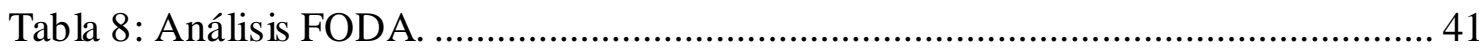

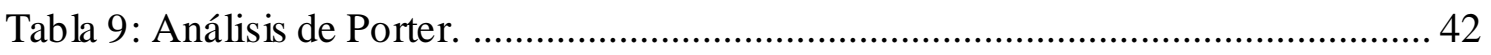

Tabla 10. Evolución de la acción Milpo vs. el índice SPBLGPT de la BVL. ................. 45

Tabla 11: Posición del Perú en el ranking de reservas metálicas. ...................................58

Tabla 12. Composición de Ventas Milpo S.A.A. (2014-2017)..................................... 65

Tabla 13. Composición de la Venta por Unidad Minera Milpo S.A.A. (2014-2017). .. 66

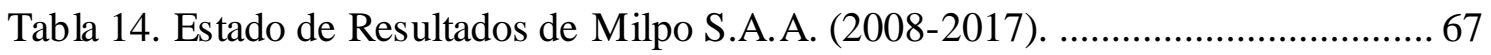

Tabla 15. Estado de Situación Financiera de Milpo S.A.A. (2008-2017)........................ 68

Tabla 16. Indicadores Financieros de Rentabilidad Milpo SAA (2008-2017)............... 69

Tabla 17. Ratios Financieros de Liquidez-Rentabilidad y Endeudamiento de Milpo SAA

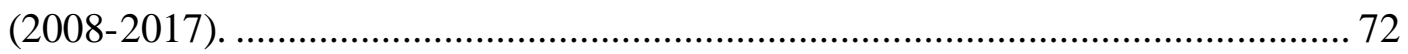

Tabla 18. Ratios de Creación de Valor de Milpo S.A.A. (2012-2016). ......................... 73

Tabla 19. Determinación delCAPM de Milpo S.A.A....................................................... 74

Tabla 20. Determinación del W ACC de Milpo S.A.A. .................................................. 74

Tabla 21. Información de la Rentabilidad de los T-Bonds de los últimos 30 años. Adaptado de Información financiera del Dr. Aswath Damodaran en su web

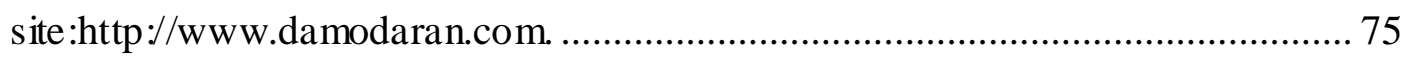

Tabla 22. Determinación de la prima de riesgo de mercado. Adaptada de la Información financiera del Dr. Aswath Damodaran en su web site:http://www.damodaran.com.

Tabla 23. Datos finales de la prima de riesgo de mercado y la tasa libre de riesgo. ...... 76 
Tabla 24. Determinación del Beta desapalancado de la Empresa Milpo SAA. 77

Tabla 25. Determinación del Riesgo País (Perú). ........................................................... 78

Tabla 26. Proyección de los Precios de los Commodities período 2018-2027. .............. 80

Tabla 27. Proyección del Costo de Ventas período 2018-2027...................................... 81

Tabla 28. Proyección de la Producción de Metales período 2018-2027 de Milpo SAA. 82

Tabla 29. Proyección de los Gastos Administrativos período 2018-2027 de Milpo SAA.

Tabla 30. Proyección de los Gastos de Ventas período 2018-2027 de Milpo SAA....... 83

Tabla 31. Proyección de las Inversiones en Activos Fijos (Capex) período 2018-2027 de Milpo SAA.

Tabla 32. Proyección del Estado de Resultados Anual período 2018- 2027 de Milpo SAA.

Tabla 33. Indicadores Financieros Proyectados período 2018- 2027 de Milpo SAA. ... 85

Tabla 34. Proyección del Estado de situación Financiera período 2018- 2027 de Milpo SAA. .86

Tabla 35. Proyección delFlujo de Efectivo período 2018- 2027 de Milpo SAA. ......... 86

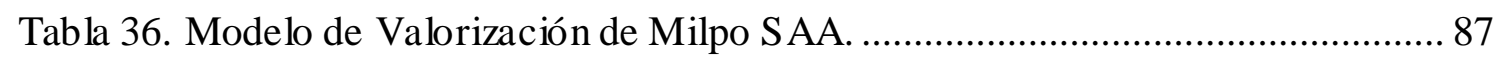

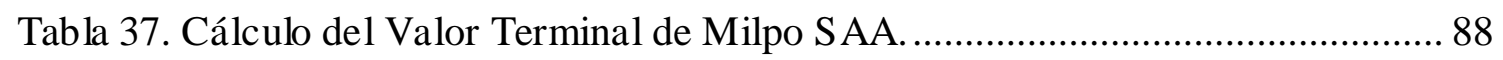

Tabla 38. Cálculo del Valor Final de Milpo SAA. ......................................................... 88

Tabla 39. Determinación del Margen con Relación al Valor de Mercado de la Acción

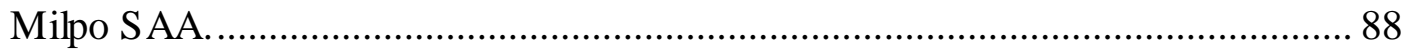

Tabla 40. Sensibilidad en el Precio del Cobre. ................................................................ 89

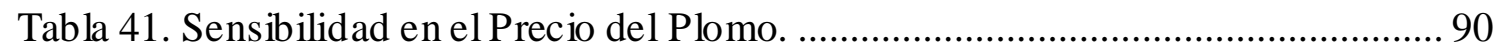

Tabla 42. Sensibilidad en el Precio del Zinc. .................................................................. 90

Tabla 43. Sensibilidad en el Costo Promedio Ponderado del Capital. ............................ 90

Tabla 44. Sensibilidad en la tasa de Crecimiento. ....................................................... 91 


\section{Indice de Figuras}

Figura 1. Indice Global de la Minería vs. Indices Bursátiles FTSE y Dow Jones - Extraído de GPAE Osimergmin.

Figura 2. Crecimiento Mundial (Variaciones Porcentuales Anuales), adaptado de BCRP Junio 2018. 46

Figura 3. Crecimiento del PBI mundial (variación porcentual anual) - Adaptado de: BCRP, Marzo 2018.

Figura 4. Variación porcentual anual del PBI de Estados Unidos, adaptado de: BCRP, Marzo 2018.

Figura 5. Crecimiento del PBI en América Latina (Variación porcentual), adaptado de: Reporte de Inflación BCRP, Junio 2018 ......................................................... 50

Figura 6. Inflación América Latina (2018 -2019), adaptado de: BCRP Reporte de Inflacion, Junio 2018. 50

Figura 7. Variaciones Porcentuales Producción Minera, adaptado de : BCRP, Junio 2018.

Figura 8. Proyectos de Inversión por Sectores, adaptado de : BCRP, Junio 2018. .53

Figura 9. Variaciones porcentuales reales del PBI por sectores económicos, adaptado de:

BCRP, segundo trimestre 2018. 54

Figura 10. PBI (variación \% interanual), adaptado de: BBVA Research, Junio 2018. . 55

Figura 11. Proyección de variables macroeconómicas Perú, adaptado de: BBVA Research, segundo trimestre 2018. .55

Figura 12. Tipo de Cambio Perú, adaptado de: BBVA Research, Junio 2018. 56

Figura 13. Principales Indicadores Económicos (variación porcentual real), adaptado de:

Estudios Económicos-Scotiabank, Reporte Semanal Julio 2018. 57

Figura 14. Estadística de la producción de la minería metálica anual (var \% real), adaptado de INEI y MINEM. 57

Figura 15. Evolución del precio del zinc en los últimos 05 años. Adaptado de Market Business Insider, Julio 2018. .58 
Figura 16. Evolución del Precio del Zinc en los últimos 05 años (USD x libra). Adaptado de london exchang market.com, Julio 2018. ....................................................... 59

Figura 17. Evolución del precio del plomo en los últimos 05 años. Adaptado de www.bolsamania.com, Julio 2018. 60

Figura 18. Evolución del precio del cobre en los últimos 05 años. Fuente: www.bolsamania.com, Julio 2018. 61

Figura 19. Variación Anualizada del Valor Bruto de la Producción del Sector Minería e Hidrocarburos: 2016-2017, adaptado de: Instituto Nacional de Estadística e Informática, Diciembre 2017. 62

Figura 20. Conflictos sociales por Región y tipos de conflictos. Adaptado de Defensoría del Pueblo 2016. 64 


\section{Introducción}

El presente trabajo tiene como objetivo realizar la valoración de la empresa MILPO S.A.A. mediante el método de flujo de caja descontados. Con esta valorización se busca determinar el precio de la acción que refleje los fundamentos de la empresa y su capacidad de generación de ingresos. Se busca como resultado un enfoque más preciso del estado actual de la compañía así como sustentar con estos resultados las metodologías utilizadas Para el análisis se utilizará información de los estados financieros, proyecciones y datos internos proporcionados por la empresa así como información recopilada de diversos autores para la metodología.

El presente trabajo se divide en siete capítulos. En el capítulo uno comienzo con el planteamiento del problema, donde menciono la descripción del problema, la justificación de la investigación, los objetivos principal y específicos, y por último las limitaciones.

En el capítulo dos paso a sustentar las metodologías según el marco teórico y algunos casos como ejemplos.

En el capítulo tres hago una descripción del negocio y un análisis de la industria, colocando las perspectivas de crecimiento nacional y mundial.

En la cuarta sección se realiza el análisis financiero y las estimación de la tasa de descuento.

En el capítulo cinco analizo los supuestos y sustentos de las proyecciones, así como las estimaciones de costos, dando como resultado la valorización de la empresa.

En la sexta sección realizo el análisis de sensibilidad de la valorización, viendo la sensibilidad del precio de los metales, la tasa de descuento y el valor de perpetuidad, con sus respectivos análisis de escenarios de cada uno.

Finalmente paso a las conclusiones y recomendaciones del presente caso. 


\section{Capítulo 1. Planteamiento del Problema.}

\subsection{Descripción del problema.}

En el presente trabajo de tesis se busca encontrar el valor fundamental de la empresa Milpo S.A.A., importante firma del rubro de la minería del Grupo Votoramtim Metais. Milpo con el paso del tiempo ha incrementado su portafolio de inversiones a nivel nacional, éstas inclusive a traspasado fronteras, convirtiéndose en una empresa con proyección internacional.

El incremento de las necesidades de las empresas de diversificar sus inversiones para satisfacer la demanda sobre todo, internacional, para una gestión eficiente de sus negocios, además de la constante inversión en Capex, han generado una constante búsqueda de nuevas fuentes de recursos (brownfield) en el sector minería en nuestro país, esto a su vez ha provocado que las empresas se encuentren en un constante cambio en sus modelos de negocios, adaptándose a los requerimientos de un mundo globalizado de innovación y demanda constante.

Es por ello que el objetivo principal de la investigación es obtener como resultado el valor de mercado de la empresa Milpo, investigación que contemplará analizar y encontrar la metodología más eficiente que nos permita dar con un valor razonable, que recoja a profundidad el nuevo modelo de negocio de la empresa y su estrategia, entendiendo su mercado y dónde están sus elementos de creación de valor.

\subsection{Justificación de la investigación.}

La valorización de una empresa se puede dar por diferenctes circunstancias, ya sea por necesidad de valorarla para fines comerciales, como adquisiciones y ventas. También se puede dar por cambios coyunturales de la industria minera, así como también por cambios en sus fundamentos estructurales. Valorar una empresa involucra hacer un pronóstico de sus rendimientos futuros, por tal motivo la valorización de Milpo S.A.A. engloba distintos fundamentos que permitirán a futuros inversionistas conocer si el precio en el mercado 
está sobrevalorado o no, además de conocer la situación patrimonial y financiera, revisar su situación estratégica en el negocio, su situación de riesgo vs. rentabilidad, su posición de deuda con acccionistas propios y terceros, entre otras diversas.

\subsection{Objetivos.}

\subsubsection{Objetivo principal.}

El objetivo principal de la presente investigación será:

- Encontrar el valor fundamental de mercado de la empresa Milpo S.A.A. utilizando la metodologías de Valorización por Flujo de Caja Descontados.

\subsubsection{Objetivo específicos.}

- Análisis de la industria y del entorno competitivo de la empresa. Entendimiento de los key drivers del negocio.

- Análisis de Estados Financieros y entendimiento de las cuentas contables, administración tributaria y laboral. Análisis de evolución histórica de ingresos y costos operativos. Análisis de márgenes de rentabilidad y revisión del Ebitda.

- Construcción del modelo financiero: estructura circular del Estado de Resultados, el Balance General y el Estado de Flujo de Efectivo. Proyección de los ingresos, costos, gastos y Capex. Cálculo del Flujo de Caja Libre y construcción de la tasa de descuento. Identificar y proyectar la depreciación y amortización para los próximos 5 años.

- Analizar el gasto financiero y su impacto en la rentabilidad de la empresa, así como también las futuras necesidades de financiamiento para Capital de Trabajo y Capex.

- Determinar la tasa de descuento (WACC) para descontar los flujos futuros del negocio.

- Estimación del Capital de Trabajo necesario para solventar la operatividad del negocio para los próximos 10 años.

- Cálculo del Flujo de Caja Libre. 


\subsection{Limitaciones.}

La presente investigación parte de la siguiente información proporcionada por la empresa, información que será indispensable para poder realizar una correcta valorización:

- Estados financieros (auditados) 2008, 2009, 2010, 2011, 2012, 2013, 2014, 2015, 2016, 2017 y a Marzo del 2018.

- Ingresos y costos por línea de negocio durante los últimos 10 años.

- Proyección de ingresos por parte del área de planeamiento estratégico y marketing.

- Plan de inversiones (Capex).

- Cronogramas de deuda financieras.

- Detalle de la depreciación de activo fijo y amortización de intangibles.

- Detalle y tratamiento de los activos de la empresa (para proyección del balance).

- Estructura de costos y gastos operativos.

- En caso de no contar con la información requerida se procederá a determinar y estimar de manera razonable y con la data pública obtenida (Dictámenes de Auditoría, Estados Financieros y Memorias de la Empresa obtenidas de la web de la SMV e informes de Gerencia de Milpo) los inputs necesarios para la elaboración del modelo. 


\section{Capítulo 2. Antecedentes - Marco teórico.}

\subsection{Valorización de empresas.}

\subsubsection{Forsyth (2012).}

En su libro "Finanzas empresariales: Rentabilidad y Valor" explica sus observaciones y definiciones con relación a la valorización de empresas. En tal sentido, refiere que cuando uno valora una empresa o negocio, lo que está realmente se está ejecutando es la determinación del valor de los flujo de caja futuros. Para ello, la principal herramienta financiera que emplea es el VAN - Valor actual Neto, o sea, el método que actualizará los flujos futuros a una tasa de descuento determinada.

El autor menciona que la empresa se puede ver como un conjunto de activos que generan caja, por lo que, al valorizarla, estamos determinando el valor de estos activos (p, 197).

Comentario aparte merece señalar dos puntos bastante importantes, referidos a la recomendación de que en estas valorizaciones debemos separar los aquellos activos que no guardan relación con el negocio que se esta evaluando (salvo los que están dentro de la evaluación los posibles flujos futuros que genera la empresa relacionados con su giro del negocio), más la posible capacidad de generación de caja con otras inversiones ajenas al core del negocio. Estos otros activos se deben excluir en la generación de caja y valorizarlos de forma independiente (en este caso recomienda realizar la valorización a valor de mercado). El segundo tema que menciona el autor es el relacionado con el periodo que comprende dicha valorización, el cual sugiere que el mismo debe establecerse teniendo en cuenta la realidad actual del negocio, tomando en consideración el plazo en la cual se considere oportuno que la empresa alcanzará la estabilidad en sus operaciones, en algunos casos a criterio del evaluador del proyecto. Además de ello, también podrá plantear opciones de plazos diferentes por conocimientos sobre un mayor crecimiento en algún año en particular, razón por el cual se debe tomar que ese año debería ser evaluado de forma independiente al proyecto, sin tenerlo en cuenta como perteneciente de un valor residual. 
Además, el tipo de flujo de caja que el autor sugiere para valorizar una empresa es el flujo de caja económico, ya que este flujo de caja toma en consideración los movimientos asociados con la parte operatividad del negocio sin importar la forma en la que las inversiones fueron financiadas. En resumen, el flujo de caja será el mismo independientemente de la forma de que la empresa ha financiado sus activos, sus deudas o recursos propios. Para ello citamos lo siguiente:

«Las empresas generan caja operativa tomando en cuenta la bondad de sus activos y no la forma en que estos han sido financiados. En un entorno eficiente donde están disponibles los recursos rentables, no tiene mucho sentido concluir que una empresa venderá más por el hecho de que emite deuda o decide financiarse con recursos propios » (p.203).

\subsubsection{Barrionuevo (2014).}

En su investigación «Teoría y Comportamientos Organizativos » publicado por la Fundación Novasoft en España, nos entrega un panorama sobre los criterios a considerar en el momento de valorar una empresa. Nos indica que la valoración es emitir una opinión, un juicio que siempre es subjetivo. Y como cualquier opinión, puede estar o no bien fundamentada. Por ello sugiere que una valorizaación correcta es aquella que esté bien realizada técnicamente, que se fundamenta en supuestos razonables y que tiene en cuenta la perspectiva subjetiva bajo la que se lleva a cabo la valoración (valor para qué, valor para quién, valor en qué circunstancias).

El autor considera también que, en forma categórica los métodos correctos desde su óptica son los basados en el descuento de flujos de caja, ya que es el método más popular y conceptualmente correcto, porque vé a la Empresa como un generador de flujo de efectivo $\mathrm{y}$, por lo tanto, evaluable como un activo financiero.

Por último, el autor menciona los criterios que utiliza para considerar el método de flujo de caja descontado como el preferido por los analistas, y son los siguientes :

- Considera el valor del negocio en función de su capacidad para generar recursos financieros a futuro.

- Incorpora el concepto del riesgo, tanto del negocio como financiero.

- Contempla el valor temporal del dinero. 
- Considera las inversiones requeridas para la generación de recuros.

\subsubsection{Bustamante (2013).}

El autor en un acercamiento al trabajo de investigación actual, en su investigación «Métodos de Valorización de Empresas Mineras : un análisis para el caso peruano 20082013 » sostiene que la valorización por el método del flujo de caja libre descontado a una tasa de descuento es el método más completo, y para fundamentar su crítica hace un análisis de los siguientes métodos de valorización :

- El método basado en el Balance, el cual radica principalmente en su balance o en sus activos, lo cual arroja un valor que es estático en el tiempo. Por consiguiente, no considera otras variables como por ejemplo, la evolución futura de la empresa o escenarios que podrían afectarla, tales como el anális is del sector, dificultades de la organización, etc.

- El método basado en la cuenta de resultados, el cual trata de determinar el valor de la empresa a través de la magnitud de beneficios, de los dividendos , de la venta o de otro indicador, el mismo que es comparado con el obtenido de otras empresas similares o del sector. Este metodo es mayormente conocido como el método de los múltiplos comparables. El principal problema de este método radica en que se asume implícitamente que la empresa de la que se ha tomado el múltiplo de referencia y la empresa que se está valorando tienen similares características.

- Método basado en el valor llave o Goodwill, el cual es el valor que recibe la empresa por encima de su valor contable ajustado y corresponde a un conjunto de fortalezas de la firma, la cuales no se ven revalados en la contabilidad ajustada. Este método se fundamenta en el valor que tiene la empresa por encima de su valor contable, considerando los elementos intangible (ejemplo el valor de la marca). El principal problema de esta valoración es que no existe una regla lo suficiente clara de cómo realizar ese cálculo.

- Por último el método del flujo de caja descontado, el cual considera la generación de los flujos de dinero que se generarán en el futuro, para luego ser descontado a la tasa más apropiada, tomando en consideración el riesgo de dichos flujos 


\subsubsection{Fernandez (2008).}

El autor hace un análisis previo en su investigación «Métodos de Valoración de empresas » publicado en la Universidad de Navarra nos da en primer lugar una definición clara de valor desde el punto de vista del comprador y del vendedor, argumentando de que las posturas de ambos varía dependiendo del interés que tengan cada una de las partes. Así tenemos por ejemplo: mientras para un comprador extranjero valorará la marca del producto en el mercado nacional, mientras que para el vendedor de una empresa nacional incidirá principalmente en sus recursos materiales y en la posibilidad de seguir produciendo. Entre ambas valoraciones se llegaría inevitablemente a un punto medio.

El autor también señala que las valorizaciones sirven para varios propósitos tales como: Operaciones de compra-venta, Valorización de empresas cotizadas en Bolsa, Salidas a Bolsa, Herencias y testamentos, identificación de los value drivers como conductores de la creación o destrucción de valor en una compañía, para la toma de decisiones estratégicas de la empresa, para propósitos de planificación estratégica y procesos de arbitraje, entre otros.

En un análisis similar al investigador Bustamante (2013), también comenta sobre los diferente métodos que existen para poder realizar una valorización, haciendo incluso una explicación con ejemplos con los cuales demuestra las ventajas y/o desventajsa de utilizar cada uno de ellos, entre los cuales menciona:

- Métodos basados en el balance (valor patrimonial): metodologías que tratan de estimar el rango de valor de una empresa en base al valor de su patrimonio, el cual se realiza desde una perspectiva estática, sin considerar evolución futura de la empresa, el valor temporal del dinero, situación actual de la industria, entre otros.

- Métodos basados en la cuenta de resultados: En este caso se trata de estimar el valor de una empresa en función al valor de las utilidades generadas por la empresa, beneficios como el EBIT, el Ebitda, dividendos, entre otros. Existen 
varios, entre los principales métodos tenemos: Valor de los beneficios- PER, Valor de los dividendos y Múltiplo de las ventas. En este tipo de valorizaciones se caracteriza principalmente básicamente en dos aspectos : el primero que se utiliza masivamente cuando el autor recomienda su uso sólo para fines de aproximación (si se requiere una valorización rápida o si los cash flow son muy inciertos o como contraste del valor obtenido por descuento de flujos). El segundo aspecto radica en que el múltipo que utiliza relaciona una magnitud de mercado con otra puramente contable.

- Métodos Mixtos basados en el goodwill: En este tipo de valorización se trata de estimar el valor de los elementos inmateriales de la empresa, el cual muchas veces no aparece reflejado en el balance. Es en general el valor que tiene la empresa por encima de su valor contable o por encima del valor contable ajustado. No existe una metodología clara o convencional del método, para el autor son considerados muy arbitrarios, porque utiliza coeficientes con poca base estadística.

- Métodos basado en el descuento de flujos de fondos: Para el autor es la metodología aceptada y utilizada a nivel mundial, método que se basa en el pronóstico detallado y cuidadoso, para cada período, de cada una de las partidas financieras vinculadas a la generación de los cash flow correspondientes a las operaciones de la empresa. Así mismo, se determina una tasa de descuento teniendo en cuenta el riesgo, volatilidades históricas y tipos de descuento mínimo a considerar.

Por otra parte, el autor señala que el flujo correcto para poder estimar el rango de valor de la empresa es el Flujo de caja libre (con tasa de descuento WACC).

También señala que la metodología aceptada para poder estimar el costo de oportunidad del accionista (COK) es el CAPM, el cual menciona que indica que la rentabilidad exigida por el accionistas se calcula de la siguiente forma:

$$
\mathrm{Ke}=\mathbf{R f}+\mathbf{b}^{*} \mathbf{P M}
$$


En donde :

- Ke: rentabilidad exigida por el accionista

- RF: tasa libre de riesgo

- B: Beta de la acción

- PM: Prima de riesgo

\subsubsection{Ernst \& Young Perú. (2017).}

Esta firma de auditores internacional con representación en el Perú hizo por primera vez una encuesta sobre las principales prácticas de valorización aplicada en nuestro país. Dicho estudio extrae la opinión de las principales empresas de diversos sectores en nuestro país. El artículo de nombre: “¿Su empresa está al tanto de las últimas prácticas de valorización en el mercado?” apareció en junio 2017 y tuvo como principal objetivo conocer sobre las metodologías de valorización comúnmente utilizadas y los desafíos que mantiene los especialistas para estimar la tasa de descuento apropiada.

Para realizar esta investigación, E\&Y realizó una serie de consultas vía encuestas a distintos profesionales que laboran con todo lo relacionado a valorización de empresas y la determinación del costo de capital.

Así tenemos que de un total de 44 participantes de diversas empresas del sector se pudo obtener lo siguiente:

- $90 \%$ de los participantes considera al enfoque de ingresos como su principal enfoque de valorización.

- $85 \%$ de los participantes considera al flujo de caja libre para la firma como la metodología principal dentro del enfoque de ingresos.

- $59 \%$ de los participantes opina que la transparencia y contenido de información financiera de las empresas representa uno de los mayores retos al momento de realizar valorizaciones.

- $12-18 \%$ es el rango estimado para el retorno exigido a los recursos propios, de acuerdo a la opinión del $64 \%$ de los participantes. 
Así mismo, en cuanto a los métodos de la valorización nos indica en principio que no existe un método único aplicado en el Perú, de acuerdo a lo recogido en la muestra. Existe, por lo tanto diversas fórmulas y métodos generalmente empleados y aceptados por los profesionales para poder establecer parámetros del valor de una firma. De acuerdo a los resultados obtenidos, nos indican que existen 3 enfoques de valorización:

1. El 90\% considera el enfoque de ingresos: Flujo de caja de la firma (FCFF) y Flujo de caja del accionista (FCA), Modelo de dividendos y el Valor presente ajustado.

2. El 56\% considera el enfoque de mercado: Múltiplo de cotizaciones y Múltiplo de Transacciones

3. El $11 \%$ considera el enfoque basado en activos: Liquidación ordinaria y Liquidación forzada

Así mismo, el $82 \%$ de los participantes indican que utilizan el flujo de caja para la firma como el método principal de valorización, y en segundo lugar el $49 \%$ utiliza el flujo de caja para el accionista.

De los dos enfoques de flujo de caja utilizados con mayor frecuencia los participantes señlaron como principal tasa de descuento los siguientes:

1. Flujo de caja para la firma : Tasa de descuento (Costo promedio ponderado de capital)

2. Flujo de caja para el accionista: Tasa de descuento COK-Costos del patrimonio

El estudio revela también que el $66 \%$ de los participantes prefiere como al "Modelo de Gordon" para la estimación del valor a perpetuidad y el $45 \%$ utiliza la tasa de crecimiento del PBI a largo plazo para la perpetuidad.

Así también, en dicha investigación el 74\% de los encustados considera el Capital Asset Pricing Model (CAPM) es el método más utilizado para estimar el rendimiento exigido por el accionista (COK).

En cuanto a la determinación de la tasa libre de riesgo no se llega a un consenso, arrojando los siguientes resultados: 
A la pregunta de cómo deriva usualmente la tasa libre de riesgo, respondieron lo siguiente:

1. Un 39\% toma la tasa libre de riesgo promedio de un período mayor de un año.

2. Un $36 \%$ toma la tasa libre de riesgo spot del último día disponible.

3. Un $18 \%$ toma la tasa libre de riesgo promedio del último año.

4. Un $7 \%$ toma la tasa libre de riesgo promedio del último mes.

A la pregunta de cuál es plazo típico de su tasa libre de riesgo, respondieron lo siguie nte :

1. Un $61 \%$ toma el plazo de 10 años.

2. Un $18 \%$ toma el plazo de 20 años.

3. Un $18 \%$ toma el plazo de 30 años.

4. Un $4 \%$ toma la tasa libre de riesgo al mismo plazo de la duración de los flujos de caja.

Por ultimo, para el método de valorización por el método de múltiplos comparables, el $82 \%$ de los participantes siempre considera el uso del EV/EBITDA al momento realizar una valorización, distanciándose de otras alternativas.

\subsubsection{Copeland, Koller y Murrin (2004).}

Basándonos en su libro «Valoración: Medición y Gestión del Valor », nos menciona que el método de valorización basado en el descuento de flujos de caja es la forma más apropiada para hacer los análisis pertinentes, debido q que vincula en forma directa el valor de la empresa con las rentabilidades a generar en el futuro.

Además, mantienen que el principal objetivo es la maximización del valor de las acciones de una empresa, lo cual es lo adecuado para el conjunto de la economía a largo plazo.

Para sostener esta idea, proporcionan pruebas empíricas que demuestran la validez del enfoque sobre valorización basado en el descuento de cash flows. Para complementar la valorización hace una descripción de cómo analizar los rendimientos históricos, hacer la proyección del cash flow libre, estimar el coste de capital, identificar las fuentes generadoras de valor e interpretar los resultados. 
Así mismo, en el libro cita a otros autores como Heer y Koller (2000) en su artículo «Valuing Cyclical Companies » (The Mckinsey Quarterly - 2000 number 2) quienes sugieren que para la valorización de compañías cíclicas como aerolíneas, químicas, papel y acero, se utilice el modelo de flujo de efectivo descontado basado en probabilidades para obtener estimaciones razonables.

También hace mención en otra parte de su libro a Mimi James y Tim Koller con su obra «Valuation in Emerging Markets » (The Mckinsey Quarterly - 2000 number 4) quienes mencionan que son iguales en cualquier lugar los procedimientos para descontar los flujos de efectivo futuros al costo de capital promedio ponderado, pero en los mercados emergentes los riesgos son mayores ya que la valuación se vuelve más compleja porque los compradores y vendedores encaran mayores riesgos (tales como los altos niveles de inflación, volatilidad macroeconómica, cambios políticos, etc.).

\subsubsection{Damodaran (1997 y 2006).}

Para el autor ya había planteado en 1997 que en última instancia, es importante mencionar que para algunos escenarios la valorización por el método del flujo de caja descontado puede presentar algunas implicaciones y necesidad de adaptaciones, tal es el caso para aquellas empresas de capitales cerrados, que señalan dos problemas en su aplicación (en la estimación del costo de capital y la estimación de flujos de caja), teniendo como alternativa utilizar el grado de riesgo de empresas similares con acciones en bolsa, o relacionar el riesgo a variables contables la empresa.

En su libro «Damodaran on Valuation (2006) - Security Analysis for Investment and Corporate Finance », detalla y analiza sobre la forma de cómo debemos asumir los datos obtenidos en una valorización. Así tenemos que si bien es cierto que los modelos son cuantitativos, no necesariamente la valorización será objetiva. También nos explica que el valor obtenido de cualquier modelo está afecto al flujo constante de información, con lo cual el valor cambiará a medida de que la nueva información de los mercados sea revelada. Y así nos detalla entre estas y otras particularidades y sesgos que se dan en una valorización, el autor nos indica que la valorización con $\mathrm{DCF}$, se tendrá que tomar en cuenta para realizada correctamente. Para ello requiere que los analistas entiendan el 
negocio que están valorando y que hagan las preguntas sobre la sostenibilidad de los flujos de efectivo y el riesgo.

En su investigación el autor indica que la valorización descontada del flujo de liquidez se hace desde el punto de vista del inversionista, a fin de conocer los flujos esperados a recibir por su colocación y saber los beneficios del equity. Sin embargo, el autor sugiere una valorización comparativa en función a un valor de capital utilizando empresas comparables a fin de evaluar mejor la compañía al encontrarse situaciones como la siguiente : si los precios de las acciones suben desproporcionadamente en relación con las ganancias subyacentes y los flujos de efectivo, es probable que los modelos de DCF encuentren existencias sobrevaluadas y, si caen desproporcionadamente, los modelos de DCF consideran que las acciones están infravaloradas.

Por lo tanto, las valoraciones de DCF pueden ser manipuladas para generar estimaciones de valor que no tienen relación con el valor propio del negocio. O sea, necesitamos información adicional para valorar a una empresa con modelos DCF, ya que tenemos que estimar los flujos de efectivo, las tasas de crecimiento y las tasas de descuento.

Por otra parte, en entrevista realizada a Daodaran por Sintetia.com (https://www.sintetia.com/aswath-damodaran-stern-finance/) hace énfasis en el hecho de que lo difícil en una valorización se encuentra en la estimación de los flujos de caja futuros, por lo que lo complicado es medir la incertidumbre.

También menciona en la misma entrevista que las empresas recurren a errores comunes en la valorización de las empresas como las como las siguientes:

1. «Asumir que el crecimiento es muy barato o es gratis. En muchos trabajos es un supuesto muy habitual. Los especialistass tienden a incrementar las tasas de crecimiento empujados por su optimismo sobre ellas. No casi no tienen en cuenta qué inversiones tienen que acometer esas empresas para poder afrontar esa expectativa de crecimiento ».

2. «No descontar la dificultad que las empresas y sus modelos de negocio escalen. A medida que las empresas se hacen más grandes es más difícil mantener las tasas de crecimiento y rentabilidad. Por esto es que el crecimiento se desvanece en la mayoría de las empresas a medida que se hacen más grandes ». 
3. «El mezclar la macro con la micro. Cuando se hacen valorizaciones de forma individual (micro), se asumen ciertos supuestos sobre los tipos de interés u otras variables macro y al final se dificulta discernir qué parte de la valoración se debe a los factores micro y qué parte se debe a los pronósticos que se hacen sobre la evolución de la economía en sí ».

\subsection{Metodologías en la determinación de la Tasa de descuento COK.}

\subsubsection{Molina (2004).}

En su artículo «La Tasa de Descuento en la Evaluación de Proyectos y Negocios Empresariales » menciona en principio que en la evaluación de inversiones se pueden encontrar excelentes ideas de proyectos y planes de negocios, pero que a veces no se ven valorados por una aplicación inadecuada de fórmulas en la estimación de la tasa de descuento o costo de capital que dejan de lado algunos conceptos básicos. El concepto más importante para dicha evaluación es el CAPM, en el cual el riesgo de la inversión se divide en riesgo sistemático o de mercado (no diversificable) y el riesgo no sistemático (diversificable) o riesgo específico de una empresa.

El autor menciona que para ambos riesgos considerados en el CAPM, el primero está medido por su coeficiente beta, el cual relaciona el exceso de rendimiento de la acción respecto a la tasa libre de riesgo y el exceso de rendimiento de mercado respecto a la tasa libre de riesgo. En cuanto al riesgo diversificable surge por aspectos como litigios, huelgas, programas de comercialización con o sin éxito y otros eventos que son únicos en una empresa o industria en particular. 


\subsubsection{Bravo $(2004,2008)$.}

En su libro «Teoría Financiera y Costo de Capital »sostiene que para la determinación de los parámetros del CAPM se inclina por la utilización de horizontes de largo plazo debido a dos razones :

a) porque es parte de las metodologías de los más reconocidos servicios financieros que se dedican a la determinación del COK, y

b) porque la mayoría de los autores adoptan un horizonte de largo plazo, esto con el propósito de aislar el efecto de los ciclos económicos.

Anteriormente a este trabajo, en el año 2004, en su libro «El Costo de capital en Sectores Regulados y Mercados Emergentes » menciona tres métodos de cálculo del COK para empresas de sectores regulados en mercados emergentes, haciendo un breve comentario acerca de la conveniencia de aplicar el S\&P 500 en la prima de riesgo de mercado en un mercado emergente, esto debido a que, según el autor, el mercado local es pequeño en comparación con el mercado de países desarrollados.

El autor considera que el COK es apropiado para una ampresa específica u otra con riesgo similar. Sin embargo, este cálculo se realizaría con empresas que cotizan sus acciones en la bolsa de valores de NY, no sería el mismo aplicable para un país emergente con una mayor volatilidad derivada de la inestabilidad de las instituciones. Para ello, el autor sugiere que para calcular el COK de un país emergente se debe considerar el riesgo adicional que la misma representa, adicionando al COK al mercado aplicable al mercado desarrollado una prima de riesgo país.

Así mismo, el autor hace un desdoblamiento del COK, en el cual, se da lo siguiente :

\section{Retorno Esperado = Tasa libre de Riesgo + Prima de Riesgo Económico + Prima de Riesgo Financiero}

El autor propone que si se desea conocer cuál es el rendimiento exigido solamente por el riesgo negocio, lo que se debe hacer es desapalancar el beta financiero- bE (convertirlo en económico) y con esto se encontrará el COK o retorno esperado económico : 


\section{Koa $=$ rf + b oa $*($ Prima de Riesgo de mercado $)$}

De donde:

- Koa: Retorno esperado económico

- rf: Tasa libre de riesgo

- be : beta no apalancado

- boa: $\beta E /\left[1+(1-t)^{*}(1-p p)^{*} \quad D / C\right]$ (formula para desapalancar beta)

De esta fórmula, en la relación (1-pp) es aplicable para países en la cual la legislación obliga a las empresas a repartir utilidades a los trabajadores. En cuanto a las dos relaciones (1-t )x(1-ppt ) incorporan los efectos de los escudos tributarios que producen los gastos financieros derivados del apalancamiento financiero.

En suma, para la determinación del boa, es el beta económico que resulta de extraer el efecto del apalancamiento financiero (riesgo financiero) al beta patrimonial $\mathrm{Eb}$.

En resumen, se parte del Beta apalancado (con efecto económico y financiero) y luego quedarse solamente con el impacto económico del retorno esperado al desapalancar el beta.

Para obtener la tasa libre de riesgo, se obtiene un promedio histórico de los retornos de los bonos del tesoro americano, siendo el considerado en la investigación al promedio aritmético como el indicado para su correcto cálculo. Cabe resaltar que otros autores como Damodaran opinan lo contrario, pues recomiendan el uso de un promedio geométrico.

Con respecto al riesgo país el autor nos manifiesta se debe establecer un ajuste por el factor de exposición de la empresa al riesgo país, factor conocido como (lambda), este ajuste dependerá de cada empresa y su exposición a los factores del riesgo país.

El autor sugiere que con respecto a la tasa libre de riesgo (horizontes de tiempo desde 1928 en adelante), se debería sustentar la utilización de horizontes de largo plazo tomando en consideración de que la utilización de horizontes de corto plazo no separa el efecto de los ciclos económicos en el momento de la determinación del COK. 
El autor también menciona que el principio básico para el cálculo de la tasa libre de riesgo será el utilizar a los T-Bills y los T-Bonds como tasas libres de riesgo, haciendo la salvedad de que si se utiliza una de ellas como tasa libre de riesgo, también deberá replicarse la misma tasa cuando se calcule la prima por riesgo.

En cuanto a cuál tasa utilizar existen diversas opiniones, aunque el autor menciona que en ambos casos producirá similares resultados, dependiendo de los horizontes temporales de datos que se determinen para la tasa libre de riesgo y el retorno del mercado. El autor además hace mención de que toda la información para el cálculo del COK y las tasa de descuento es pública para permitir una actualización permanente y que sugiere la utilización de betas móviles para el análisis del negocio.

Finalmente, el coeficiente beta es un índice que mide el riesgo de mercado de ese activo financiero, y cuyo rango de valores que va desde cero a más de uno.

\subsubsection{Herrera (2008).}

Investigadora peruana en su artículo «Acerca de la Tasa de Descuentos en Proyectos » publicado por Quipukamayoc y Finanzas S. XXI de la Universisdad de San Marcos, menciona que en la elección de la tasa de descuento se debe obtener un flujo de fondos que refleje el riesgo, lo que significa de que la tasa de descuento debe incluir el riesgo. Para obtener la tasa de descuento existen tres modalidades :

a) La manera más fácil es utilizar la tasa de rentabilidad de proyectos similares o que pertenezca a la misma actividad sectorial, con lo cual se debería establecer rentabilidad esperada de proyectos similares o de la misma industria.

b) La segunda modalidad más sofisticada es la aplicación de modelos de valorización de activos financieros que incorporan la relación entre rentabildiad y riesgo, o sea el CAPM y el WACC.

c) La tercera modalidad es incorporarle un factor de corrección por riesgo a la tasa de mercado. Sin embargo, esta opción no se recomienda por dos razones : la tasa de mercado ya tiene incluído un factor de riesgo, y lo 
segundo es que los factores de corrección subjetivos tienden a castigar los proyectos,ya que agregan arbitrariamente un mayor costo de oportunidad.

\subsubsection{Ibboton, Kaplan y Peterson (1997).}

Investigadores acerca del mercado de portafolio de inversiones, hacen una especial mención a la elección del beta sectorial al considerar el siguiente criterio : un enfoque común para aumentar la precisión del beta sectorial es estimar el beta para un cartera de empresas que operan únicamente en la misma línea de negocio que la empresa, división o proyecto a evaluar. El beta de la cartera se usa luego para determinar el costo de capital para una inversión.

\subsection{Metodologías para la estimación de los flujos de caja, VAN y el modelo de valorización.}

\subsubsection{Court (2009).}

Investigador y catedrático de CENTRUM en su libro «Aplicaciones para Finanzas Empresariales » en el capítulo 11 nos describe el método para realizar una valorización basándose en el modelo de Flujo de Caja Descontado (FCD). En su libro menciona la determinación de dos sistemas :

a) El Flujo de Caja Libre (FCL) generado por la operaciones de la Empresa, sin considerar la deuda financiera, después de los impuestos. A este método se le aplica el WACC como tasa de descuento, basado en las características del negocio. Si bien este método se basa en la información económico financiera de la empresa, recomienda no utilizar aquellos rubros cuya metodología responde únicamente a criterios contables (como por ejemplo el principio del devengado, o asignación de ingresos y gastos arbitrarios). 
b) El Flujo de Caja para el Accionista (FCFE) es el generado después de haber cumplido con todas las obligaciones financieras, incluyendo los pagos de deuda, los gastos de capital y de financiar las inversiónes.

Para llegar al FCFE se aplica la siguiente fórmula :

\section{FCFE = Ingresos Netos $-($ Gastos de Capital - Deprec. + Var. Capital de Trab. - Pago Principal + Nueva Deuda)}

El costo del equity es el CAPM (tasa libre de riesgo, beta y prima de riesgo).

El autor también detalla los pasos para poder llegar a valorizar una empresa mediante el desarrollo de un modelo (capítulo 13 del libro), el cual contiene entre otras cosas, la siguiente información importante:

- Fondo de Maniobra: Se calculan las necesidades iniciales de caja y las variaciones anuales que afectan a los flujos netos de efectivo.

- Inversiones: Se desglosan las inversiones necesarias diferenciando (también conocido como CAPEX).

- Cuenta de costos: Se ingresan los costos fijos y variables por línea de producto. Se utiliza parámetros de cálculo para cada año como índice de precios del consumidor anual e inflación.

- Ingresos: Se han considerado factores de incremento a nivel de precios y unidades .

- Financiación: Se calculan las variables más relevantes de financiación. Para calcular la cuantía de cada una de las tres fuentes establecidas (capital, subvención y deuda).

- Balance general por línea de producto: se muestra el comportamiento del fondo de maniobra de cada una de las líneas de producto y el balance del negocio al inicio de la valorización.

- Balance Final: Balance del negocio teniendo en cuenta las inversiones realizadas, la financiación de estas y la evolución de los resultados en los años de operación. Los cálculos realizados alimentarán a la cuenta caja para la determinación del capital de trabajo. 
- Cuenta de resultados: Se recogen los ingresos y gastos que tiene la empresa durante el ejercicio económico; la diferencia de estos nos dará la utilidad o pérdida de la empresa

- Análisis: se pueden visualizar los ratios financieros y económicos principales con datos procedentes de la "Cuenta de resultados" y del "Balance general", tales como: rentabilidad económica y comercial, rotación sobre activos, punto de equilibrio, apalancamientos operativo y financiero, ratio de liquidez y la prueba ácida, entre otros.

- Rentabilidad: Se identifica las variables de rentabilidad del proyecto y del capital. Parte de los flujos netos de caja obtenidos y se obtiene el VAN.

- Estados Financieros: Se construye el balance general y el estado de ganancias y pérdidas. Así también se obtiene el valor de las necesidades operativas de fondos así como los beneficios antes y después de impuestos.

- Tasa de descuento: Se muestra el cálculo de la rentabilidad mínima exigida por la empresa sin apalancar y apalancada, así como sus respectivos betas (B) y WACC.

- Escenarios: Se deberá visualizar tres escenarios para las principales variables, tales como inversión, volumen de actividad, precio, costo, crecimiento. Se pueden ingresar los porcentajes que considera necesarios para la simulación en escenarios pesimista u optimista.

Todos estos cuadros se podrían considerar como modelos sugeridos a utilizar para metodologias para esimaciones de flujos de caja y modelos de valorización. 
Tabla 1. Modelo utilizados para efectuar la proyección.

\begin{tabular}{|c|c|c|c|c|c|c|c|c|c|c|c|}
\hline BALANCE & & Año 1 & Año 2 & Año 3 & Año 4 & Año 5 & Año 6 & Año 7 & Año 8 & Año 9 & Año 10 \\
\hline Efectivo & \% sobre el CV & $17.0 \%$ & $17.0 \%$ & $17.0 \%$ & $17.0 \%$ & $17.0 \%$ & $17.0 \%$ & $17.0 \%$ & $17.0 \%$ & $17.0 \%$ & $17.0 \%$ \\
\hline Cuentas $\mathrm{x}$ cobrar comerciales & \% sobre V & $12 \%$ & $12 \%$ & $12 \%$ & $12 \%$ & $12 \%$ & $12 \%$ & $12 \%$ & $12 \%$ & $12 \%$ & $12 \%$ \\
\hline Otras cuentas $x$ cobrar & \% sobre V & $0.9 \%$ & $0.9 \%$ & $0.9 \%$ & $0.9 \%$ & $0.9 \%$ & $0.9 \%$ & $0.9 \%$ & $0.9 \%$ & $0.9 \%$ & $0.9 \%$ \\
\hline Existencias & \% sobre el CV & $12.0 \%$ & $12.0 \%$ & $12.0 \%$ & $12.0 \%$ & $12.0 \%$ & $12.0 \%$ & $12.0 \%$ & $12.0 \%$ & $12.0 \%$ & $12.0 \%$ \\
\hline Gastos diferidos & \% sobre el CV & $0.5 \%$ & $0.5 \%$ & $0.5 \%$ & $0.5 \%$ & $0.5 \%$ & $0.5 \%$ & $0.5 \%$ & $0.5 \%$ & $0.5 \%$ & $0.5 \%$ \\
\hline Inversiones previstas en activo fijo & & 10.000 & 30.000 & 0 & 0 & 0 & 0 & 0 & 0 & 0 & 0 \\
\hline Depreciación (D) & Tasa de depreciación & $10.0 \%$ & $10.0 \%$ & $10.0 \%$ & $10.0 \%$ & $10.0 \%$ & $10.0 \%$ & $10.0 \%$ & $10.0 \%$ & $10.0 \%$ & $10.0 \%$ \\
\hline Activos intagibles & & 0 & 0 & 0 & 0 & 0 & 0 & 0 & 0 & 0 & 0 \\
\hline Proveedores & \% sobre el CV & $20 \%$ & $20 \%$ & $20 \%$ & $20 \%$ & $20 \%$ & $20 \%$ & $20 \%$ & $20 \%$ & $20 \%$ & $20 \%$ \\
\hline Otras cuentas $\mathrm{x}$ pagar $\mathrm{CP}$ & & 0 & 0 & 0 & 0 & 0 & 0 & 0 & 0 & 0 & 0 \\
\hline Otras cuentas $x$ pagar $L P$ & & 0 & 0 & 0 & 0 & 0 & 0 & 0 & 0 & 0 & 0 \\
\hline Incrementos de capital & & 0 & 0 & 0 & 0 & 0 & 0 & 0 & 0 & 0 & 0 \\
\hline GANANCIAS Y PERDIDAS & & Año 1 & Año 2 & Año 3 & Año 4 & Año 5 & Año 6 & Año 7 & Año 8 & Año 9 & Año 10 \\
\hline Incremento anual de ventas $(\mathrm{V})$ & & $5 \%$ & $5 \%$ & $5 \%$ & $5 \%$ & $5 \%$ & $5 \%$ & $5 \%$ & $5 \%$ & $5 \%$ & $5 \%$ \\
\hline Costo de las ventas (CV) & \% sobre las ventas & $55 \%$ & $55 \%$ & $55 \%$ & $55 \%$ & $55 \%$ & $55 \%$ & $55 \%$ & $55 \%$ & $55 \%$ & $55 \%$ \\
\hline Gastos administrativos & \% sobre las ventas & $4 \%$ & $4 \%$ & $4 \%$ & $4 \%$ & $4 \%$ & $4 \%$ & $4 \%$ & $4 \%$ & $4 \%$ & $4 \%$ \\
\hline Gastos de ventas & \% sobre las ventas & $3 \%$ & $3 \%$ & $3 \%$ & $3 \%$ & $3 \%$ & $3 \%$ & $3 \%$ & $3 \%$ & $3 \%$ & $3 \%$ \\
\hline Ingresos financieros & $\%$ sobre las ventas & $0.3 \%$ & $0.3 \%$ & $0.3 \%$ & $0.3 \%$ & $0.3 \%$ & $0.3 \%$ & $0.3 \%$ & $0.3 \%$ & $0.3 \%$ & $0.3 \%$ \\
\hline
\end{tabular}

Nota: Información proveniente de: E. Court - "Aplicaciones para Finanzas Empresariales" 
Tabla 2. Modelo de Balance General Proyectado.

\begin{tabular}{|c|c|c|c|c|c|}
\hline Balance general & 2008 & 2009 & 2010 & 2011 & 2012 \\
\hline Caja & 29,082 & 29,082 & 29,082 & 29,082 & 0 \\
\hline Cuentas por cobrar comerciales & 110,140 & 110,140 & 110,140 & 110,140 & 0 \\
\hline Inventarios & 56,899 & 56,899 & 56,899 & 56,899 & 0 \\
\hline Activo fijo bruto & $3,251,777$ & $3,251,777$ & $3,251,777$ & $3,251,777$ & $3,251,777$ \\
\hline Amortización & 650,355 & 650,355 & 650,355 & 650,355 & 650,355 \\
\hline (-) Amortizción acumulada & 650,355 & $1,300,711$ & $1,951,066$ & $2,601,422$ & $3,251,777$ \\
\hline Activo fijo neto & $2,601,422$ & $1,951,066$ & $1,300,711$ & 650,355 & 0 \\
\hline TOTAL ACTIVO & $2,797,543$ & $2,147,187$ & $1,496,832$ & 846,476 & 0 \\
\hline Cuentas por cobrar comerciales & 150,572 & 150,5724 & 150,572 & 150,572 & 0 \\
\hline Deuda & 859,923 & 429,962 & 107,490 & 0 & 0 \\
\hline Capital & $1,787,048$ & $1,566,654$ & $1,238,769$ & 695,904 & 0 \\
\hline TOTAL PASIVO & $2,797,543$ & $2,147,187$ & $1,496,832$ & 846,476 & 0 \\
\hline NOF & 45,549 & 45,549 & 45,549 & 45,549 & 0 \\
\hline Estado de ganancias y pérdidas & 2008 & 2009 & 2010 & 2011 & 2012 \\
\hline Ventas & $1,100,000$ & $1,155,000$ & $1,212,750$ & $1,273,388$ & $1,337,057$ \\
\hline Costo de ventas & 770,000 & 808,500 & 848,925 & 891,371 & 935,940 \\
\hline Gastos operativos & 44,000 & 46,200 & 48,510 & 50,936 & 53,482 \\
\hline Utilidad de operación & 286,000 & 300,300 & 315,315 & 331,081 & 347,635 \\
\hline Intereses & 78,540 & 58,905 & 29,452 & 7,363 & 0 \\
\hline BAT & 207,460 & 241,395 & 285,863 & 323,718 & 347,635 \\
\hline Impuestos (30\%) & 62,238 & 72,419 & 85,759 & 97,115 & 104,290 \\
\hline BDT & 145,222 & 168,977 & 200,104 & 226,602 & 243,344 \\
\hline (+) Amortización & 650,355 & 650,355 & 650,355 & 650,355 & 650,355 \\
\hline (+) Variación de deuda & $-286,641$ & $-429,962$ & $-322,471$ & $-107,490$ & 0 \\
\hline (-) Variación de NOF & 0 & 0 & 0 & 0 & $-45,549$ \\
\hline Cface & 508,937 & 389,371 & 527,988 & 769,467 & 939,249 \\
\hline FCF & 850,555 & 860,565 & 871,076 & 882,112 & 939,249 \\
\hline
\end{tabular}

Nota: Información provenente de de: E. Court - "Aplicaciones para Finanzas Empresariales".

Tabla 3. Modelo de Resultados Proyectados del Modelo.

\begin{tabular}{|c|c|c|c|c|c|c|}
\hline \multicolumn{7}{|c|}{ RESULTADOS DEL MODELOO } \\
\hline Datos hallados & & 2008 & 2009 & 2010 & 2011 & 2012 \\
\hline $\mathbf{K}_{u}$ & $10.00 \%$ & $10.00 \%$ & $10.00 \%$ & $10.00 \%$ & $10.00 \%$ & $10.00 \%$ \\
\hline $\mathbf{B}_{\mathrm{d}}$ & 0.2841 & 0.2841 & 0.2841 & 0.2841 & 0.2841 & 0.2841 \\
\hline$E=\operatorname{VAN}\left(K_{\varpi} ; D^{\prime} K_{\varpi}\right)$ & $2,242,509$ & & & & & \\
\hline B. & 1.256224 & 1.217305 & 1.118978 & 1.036555 & 1.000000 & \\
\hline $\mathrm{K}_{\mathrm{e}}$ & $11.13 \%$ & $10.96 \%$ & $10.52 \%$ & $10.16 \%$ & $10.00 \%$ & \\
\hline WACC & $8.985 \%$ & $9.093 \%$ & $9.424 \%$ & $9.796 \%$ & $10.000 \%$ & \\
\hline$E=$ VAN (Wacc; Fcf) - D & $2,242,509$ & & & & & \\
\hline \multicolumn{7}{|l|}{ Beneficio económico: } \\
\hline$B . E .=B F O t-K_{e} \times V C t-1$ & & $-94,101$ & $-26,815$ & 35,237 & 100,733 & 173,754 \\
\hline$V A\left(B_{e} ; K_{e}\right)$ & & 196,058 & 244,353 & 234,830 & 157,958 & 0 \\
\hline MVA $=$ VAN $\left(B_{a} ; K_{e}\right)$ & 91,747 & & & & & \\
\hline
\end{tabular}

Nota: Información proveniente de: E. Court - "Aplicaciones para Finanzas Empresariales" 
De esta forma el autor nos indica los pasos técnicos que llevarán a poder crear el modelo de valorización para una empresa en marcha.

\subsubsection{Monserrat Casanova, Pol Santandreu (2012).}

Investigadores y autores de la obra «Guía Práctica de Valoración de Empresas », hacen una recopilación de conceptos de varios autores e investigadores, en la cual mencionan inicialmente que la valorización se se deberá considerar dependiendo de la situación, si la misma deberá contemplar la totalidad o de una parte de la compañía (la cual origina sinergias que podrían afectar el valor de la suma de las partes), así como también se deberá considerar el entorno en la cual se realiza (entorno social, cultural, legal, medioambiental y económico concreto).

Además de ello, hace mención a diversos autores como Brealey y Myers, Ross, Penman y Copeland para argumentar y recomendar el método de descuento de flujos de caja. Además menciona que la aplicación de la misma tiene las siguientes ventajas :

- El método de flujo de caja considera variables fundamentales y claves del negocio.

- Estima el valor intrínseco del negocio en términos absolutos, lo que facilita más precisión respecto al valor.

- Permite y recomienda utilizar diferentes tasas de crecimiento a corto y largo plazo, lo que le dá mayor sensibilidad al valor final.

- Obliga también a realizar una provisión a largo plazo, lo cual conlleva a planificar la gestión de los aspectos fundamentales del negocio.

También menciona inconvenientes en este método, como por ejemplo la aplicación del método para empresas de crecimiento reciente o con corta vida, y la estimación del valor residual podría inrementar más aún la incertidumbre sobre todo si éste es determinante en el valor final. 


\section{Capítulo 3. Descripción general del negocio y}

\section{Análisis de la industria.}

\subsection{Antecedentes de la Empresa Milpo SAA.}

La Compañía minera Milpo S.A.A. es una subsidiaria indirecta de Votoramtim S.A.

(Brasil) y además parte del conglomerado VM Holding S.A. (Luxemburgo). Milpo S.A.A. surge en el año 1949 dando actividad a la actividad minera polimetálica en la localidad de Pasco - Perú.

A lo largo de los años, como se podrá apreciar en el cuadro siguiente, resume la evolución de las operaciones de Milpo en los últimos años, la cual ha estado caracterizada por un constantes incremento de la producción.

Tabla 4. Historia de la Compañía Minera Milpo SAA.

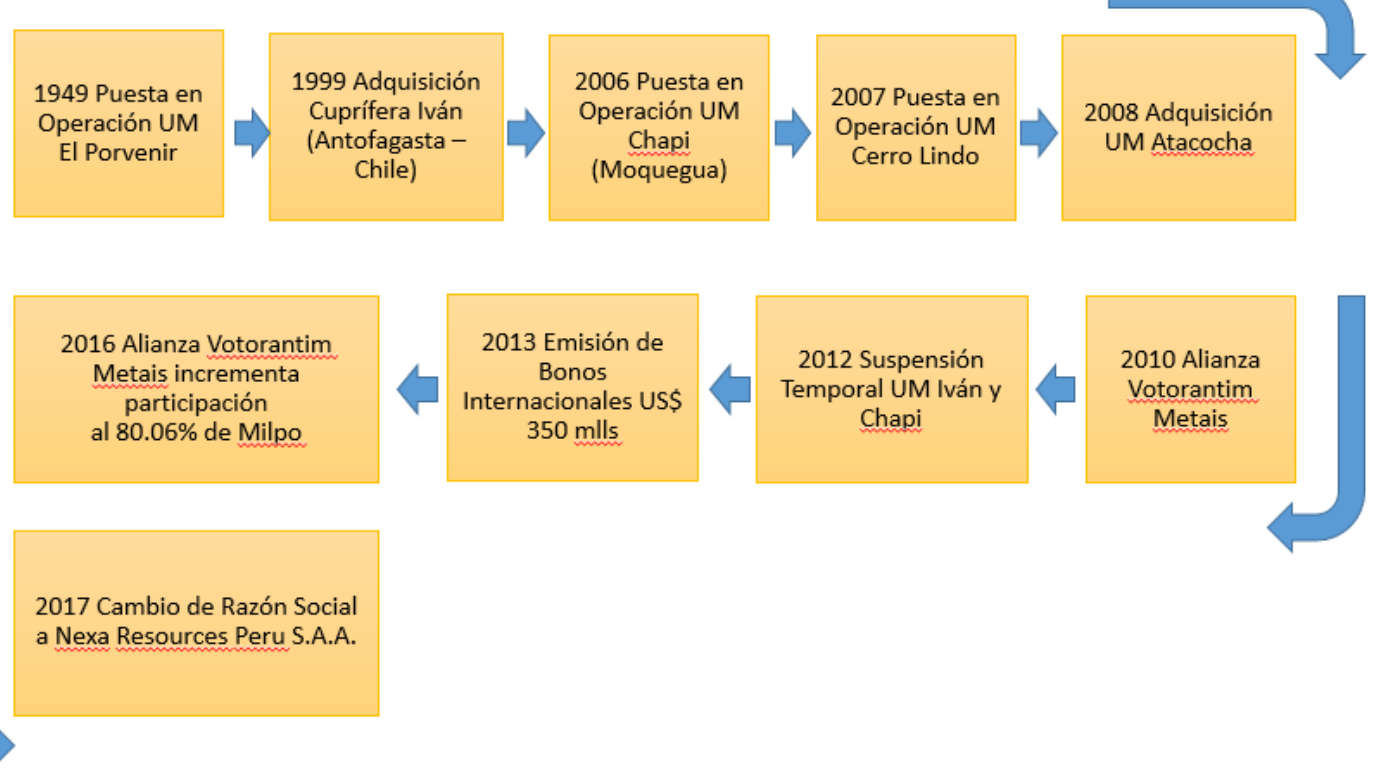

Nota: Elaboración propia en base a Memorias Mipo SAA 


\subsection{Descripción del negocio.}

La Compañía minera Milpo actualmente desarrolla tres unidades mineras : Atacocha, El Porvenir y Cerro Lindo. Cuenta además con una interesante cartera de proyectos Greenfield de cobre y de zinc (Magistral, Pukaqaqa, Chapi, Iván, Aripuaná, Shalipayco, Hilarión y Bongará). Estos proyectos aseguran de alguna forma el futuro de la Compañía. A continuación describiremos cada una de las unidades mineras (UM) actuales :

a. UM Atacocha está ubicada en el distrito de San Francisco de Asis, en la provincia y departamento de Pasco, a 4,000 m.s.n.m. y se caracteriza por ser una mina subterránea. En la UM Atacocha se realizaron trabajos de exploración con el fin de incrementar las reservas y recursos. Como resultado incrementó en 3.0 millones de toneladas sus reservas de mineral de Diciembre 2017 en comparación a lo estimado a Junio del mismo año. Por consiguiente, la vida útil de la mina se prolongó hasta el año 2036 (incluyendo recursos medidos e indicados).

b. UM El Porvenir está ubicada en en el distrito de San Francisco de Asis, en la provincia y departamento de Pasco, a 4,100 m.s.n.m. Al igual que la UM Atacocha es una mina subterránea. En esta mina realizó actividades de exploración en la zona intermedia del yacimiento, lo que le permitió acceder a nuevas zonas mineralizadas, y además de ello expandió su zona de relaves y de una nueva línea de transmisión, permitie ndo un incremento de su vida útil hasta el año 2036 (incluyendo recursos medidos e indicados).

c. UM Cerro Lindo está ubicada en el distrito de Chavín, provincia de Chincha, departamento de Ica, a 1,820 m.s.n.m. En esta UM se realizaron trabajos de sondeo de recursos, arrojando como resultado una reposición de reservas y recursos, con lo que incrementa las expectativas por encontrar mineral. Sin embargo, se debe mencionar que el fenómeno del Niño Costero produjo un efecto negativo, en cuanto a producción, pero que fue compensado en la recuperación de precios internaconales del cobre. A pesar de ello, con los programas de exploración y reclasificación de minerales (incremento de reservas de 52.4 a 55.6 mill. De ton), hace que mantenga su vida útil hasta el año 2028 (incluyendo recursos medidos e indicados). 
En cuanto a producción, Milpo depende principalmente del zinc, cobre y plomo respectivamente. Así mismo, en términos de ingresos, la UM Cerro Lindo es la más importante, ya que contribuye con el $69 \%$ de participación en los ingresos de la compañía, y un $48 \%$ del total de reservas y recursos.

Tabla 5. Evolución de los recursos y reservas Milpo SAA.

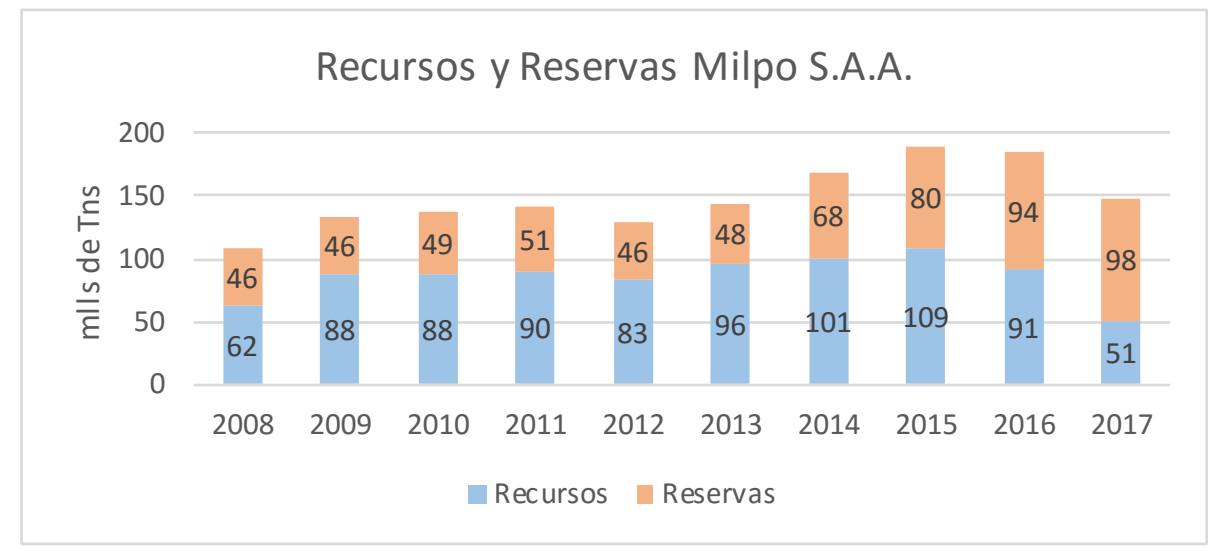

Nota: Elaboración propia en base a Memorias Milpo SAA (Tns=Tonelada Métrica Seca)

Tabla 6. Distribución de Ingresos Milpo SAA 2017 por Unidad Minera.

\section{INGRESOS POR UNIDAD MINERA}

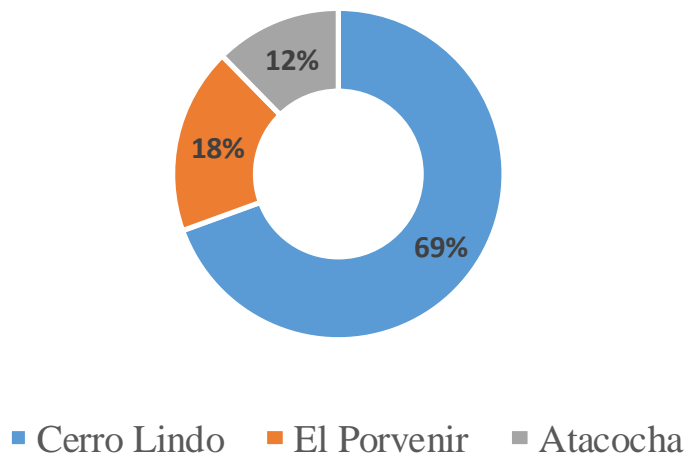

Nota: Elaboración propia en base a Memoria Milpo 2017 
Tabla 7. Participación Porcentual de reservas y recursos Milpo SAA 2017.

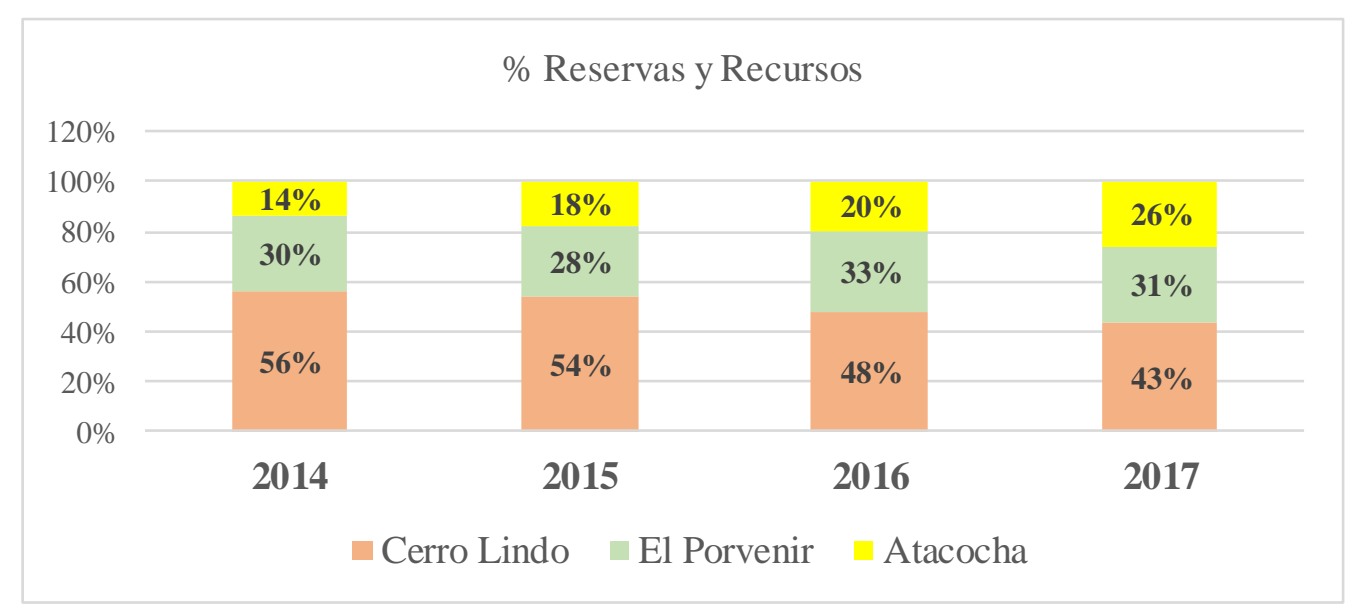

Nota: Elaboración propia en base a Memorias Milpo SAA

\subsection{Visión y misión de Milpo SAA.}

La empresa tiene como misión de negocio: "Liderar en la concepción, ejecución y operación de proyectos minero-metalúrgicos, a fin de crear valor de manera responsable para sus accionistas, comunidades, trabajadores, clientes y socios de negocio."

Por otro lado, la empresa tiene como visión de negocio: "Ser uno de los principales productores de metales industriales en el mundo (zinc, cobre y plomo), cuya estrategia de crecimiento sostenido se basa en modelo transparente e innovador que genere valor para todos de manera responsable."

\section{4. Área de influencia.}

Actualmente la principal estrategia de la Compañía es básicamente realizar las actividades relacionadas con el desarrollo de los proyectos Greenfield, cupríferos y polímetálicos, así como también con sus principales prospectos de exploración minera.

Actualmente Milpo cuenta con un portafolio de más de 1,000 concesiones mineras distribuidos en los departamentos de Amazonas, Ancash, La Libertad, Junin, Huancavelica y Moquegua. 


\subsection{Principales clientes.}

Milpo tiene segmentado su mercado de la siguiente manera:

- Los principales clientes de zinc están Votoramtin Metais - Cajamarquilla S.A. y traders con gran prestigio internacional que exportan a las principales refinería del mundo como por ejemplo Glencore y Trafigura.

- Los principales clientes de cobre y plomo son Glencore, Trafigura, Transamine y Louis Dreyfus.

\subsection{Regulación actual del sector Minero.}

La minería en el Perú es regulado actualmente por el Texto Unico Ordenado de la Ley General de Minería, aprobado por Decreto Supremo N $^{\circ}$ 014-92-EM. Anteriormente existían otras regulaciones que, con la legislación actual destaca básicamente en la normativa de 03 aspectos principales : el régimen de los títulos habilitantes (concesiones), los derechos y obligaciones de los habilitantes, y por último la intervención del Estado en la actividad minera. La legislación actual a la par de las reformas estructurales del Estado que se produjo desde inicio de la década de los noventa, estuvo orientada hacia un rol menos preponderante del Estado y al inicio de procesos de privatizaciones, a fin de dar incentivo a la inversión de la actividad minera. Con la introducción del Decreto Legislativo $\mathrm{N}^{\circ} 708$ incorporó un marco regulatorio adicional en la promoción de la inversión privada, estableciéndose aspectos básicos como beneficios básicos, normas y medidas promocionales. También existe la ley $\mathrm{N}^{\circ}$ 26821, Ley Orgánica de Aprovechamiento de los Recursos Naturales, orientado básicamente a asegurar que la utilización de recursos renovables y no renovables se realice sin poner en peligro el aprovechamiento para generaciones futuras.

En cuanto a instituciones públicas los organismos supervisores son el Ministerio de Energía y Minas y Osinergmin. La primera es el ente rector y normativo mediante la formuación, dirección y supervisión del cuplimiento de la política sectorial alineado con la política del Estado. En cuanto a Osinergmin es el ente encargado de supervisar y fiscalizar el cumplimiento de las disposiciones legales y normas técnicas en las actividades del sector, como infraestructura, instalaciones y gestión de operaciones. 
Las funciones específicas de OSINERGMIN son:

a. Función Supervisora.- verificación del cumplimiento de las obligaciones contenidas en las normas vigentes. También ejerce supervisión de la seguridad en el desarrollo de las actividades mineras.

b. Función Normativa.- Se elaboran propuestas normativas para presentarlas ante los órganos competentes.

c. Función Fiscalizadora y Sancionadora.- se refiere a la imposición de sanciones ante el incumplimiento de las normas legales y/o técnicas.

d. Función de Solución de Reclamos de Usuarios.- OSINERGMIN tiene como competencia adicional la atención de denuncias ante la existencia de alguna vulneración de las normales legales y técnicas del sector correspondiente.

e. Función de Solución de Controversias.- OSINERGMIN atiende solicitudes de reconsideración y apelación de las Empresas mineras supervisadas.

\subsection{Análisis FODA.}

Actualmente, a raíz de la diversificación de nuevos proyectos y aprovechamiento de sinergias en los costos operativos de dos de las tres UM existentes, y además por ser parte del conglomerado Votorantin, se busca fortalecer su posición competitiva frente a otras compañías como productor polimetálico. Y como tal, busca el liderazgo en crecimiento y con excelente capacidad financiera y operativa. Analizando la Matriz FODA se tiene los siguiente:

Tabla 8: Anális is FODA.

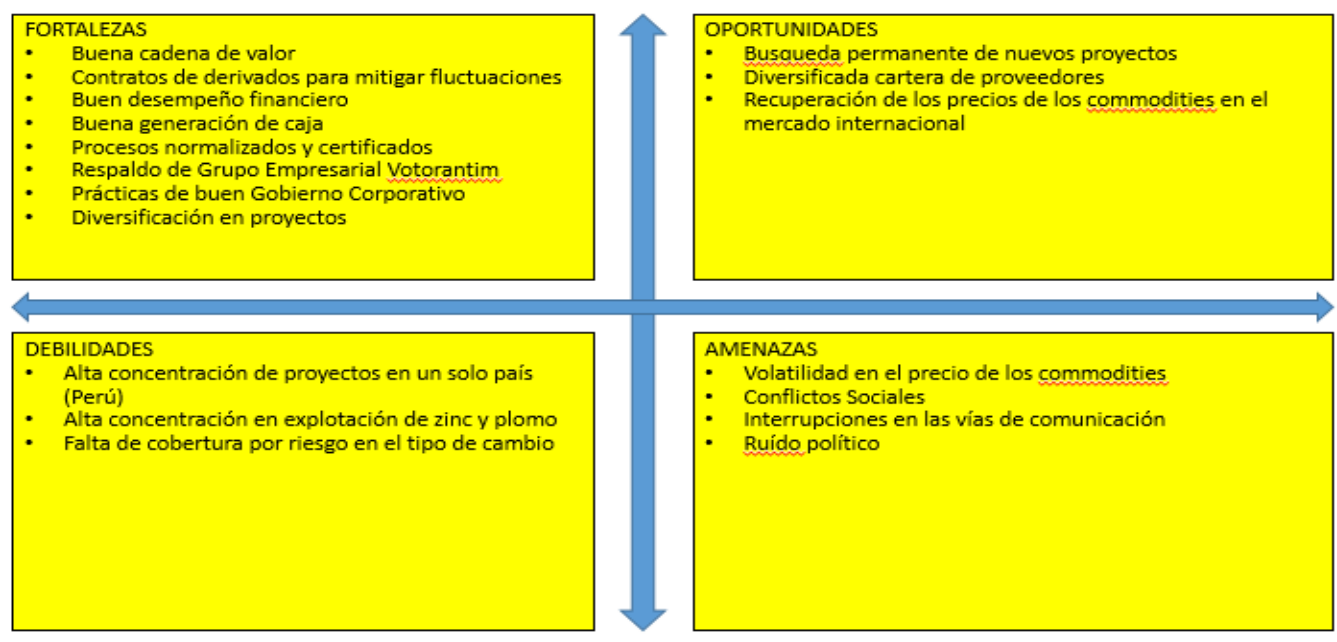




\subsection{Análisis de Porter.}

La compañía Milpo posee varias concesiones mineras con una vida útil no menor de 10 años sin la necesidad de realizar mayores inversiones. A pesar de ello, la empresa tiene la posibilidad de seguir con sus proyectos mineros y de exploración, lo cual ya indica un potencial desarrollo. Mencionado esto, del análisis de Porter se desprende lo siguiente:

Tabla 9: Anális is de Porter.

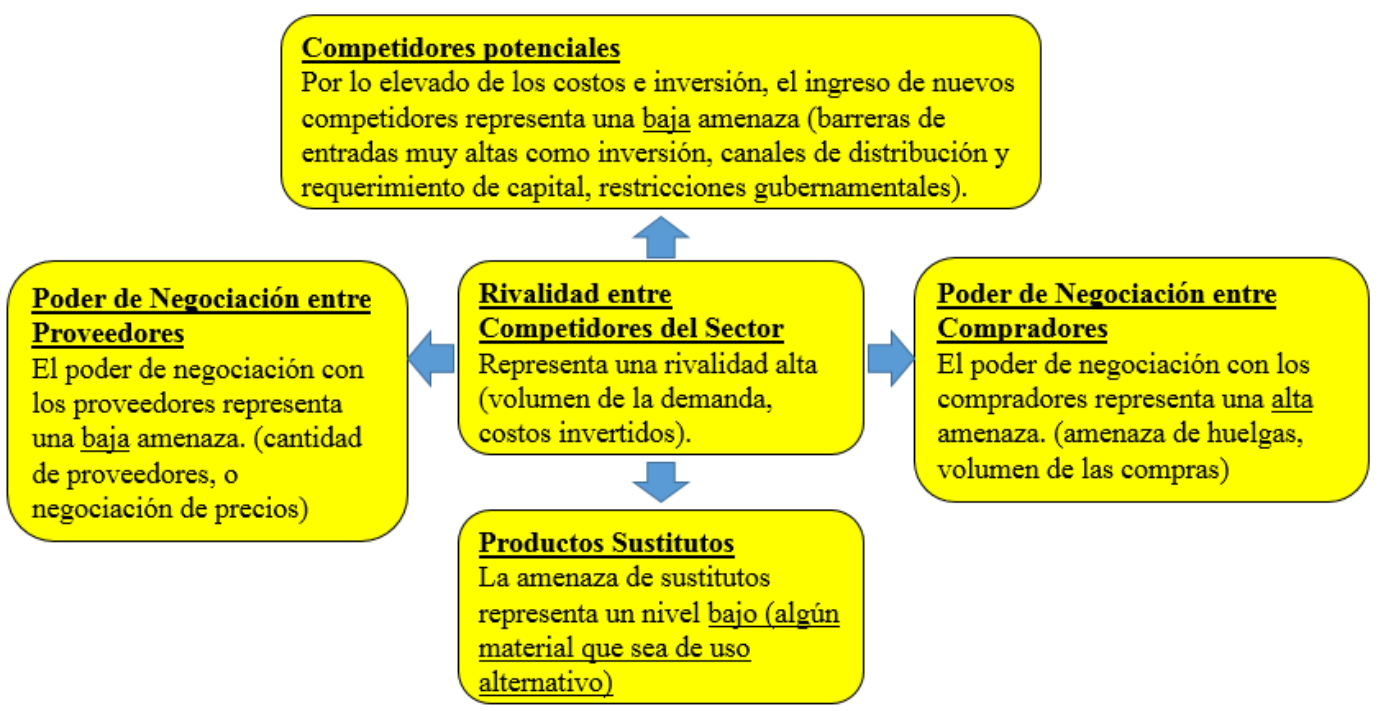

Nota: Elaboración propia, 2017

\subsection{Exploraciones y Proyectos Mineros.}

Actualmente, la principal estrategia de la Compañía es básicamente realizar las actividades relacionadas con el desarrollo de los proyectos Greenfield, cupríferos y polimetálicos, así como también con sus principales prospectos de exploración minera. De igual forma, continuar con la búsqueda de otros proyectos y operaciones que permitan aportar sinergias con la cartera actual de unidades mineras, como por ejemplo la integración operativa de las UM El Porvenir y UM Atacocha. Estas unidades muy cercanas unas de otras, producirán sinergias que conllevarán a una reducción considerable en sus costos, tanto en el ámbito energético como logístico. 
Además de eso, Milpo continúa con la búsqueda de otros proyectos y/u operaciones que puedan generar sinergias potenciales con los ya existentes a fin de lograr la reducción de los costos operativos y la minimización de riesgos relacionado a dichas operaciones. De todas las concesiones mineras que tiene la compañía, incluye también hacia Brasil a través del proyecto Aripuaná, en el estado de Matto Grosso. Todas estas nuevas concesiones mineras adquiridos y/o existentes no forman parte ni motivo de análisis en la presente valorización, considerándose solamente las UM Atacocha, Cerro Lindo y El Porvenir.

\subsection{Posición competitiva de Milpo SAA}

La empresa tiene que competir con las principales empresas polimetálicas en el mercado local. Sus principales competidores en el mercado local son, entre otras, los siguientes:

- Sociedad Mineral El Brocal: zinc, cobre, plomo, plata

- Compañía Minera Antamina: zinc, cobre, plomo, plata, oro

- Compañía Minera Volcán: zinc, cobre, plomo, plata

\subsection{Perspectivas de crecimiento económico del sector, nacional y mundial.}

En el mercado mundial, la determinación de los precios de los metales son muy inestables y por lo tanto eso hace difícil predecir, ya que, como ocurre en la ciencia económica, los pronósticos se basan en las expectativas, las mismas que pueden verse influe nciada por la susceptibilidad de los inversionistas y de los mercados (inestabilidad política, pánico financiero, entre otros). Después de haber obtenidos altos precios entre los años 2006 hasta el año 2010, empezó un período de desaceleración que ocasionó una disminución de los precios más o menos desde el año 2011 hasta el año 2016, a partir del 2017 empieza un crecimiento de los precios hasta la fecha. En general, los precios en los últimos 20 años se ha incrementado básicamente es la volatilidad de los precios. 


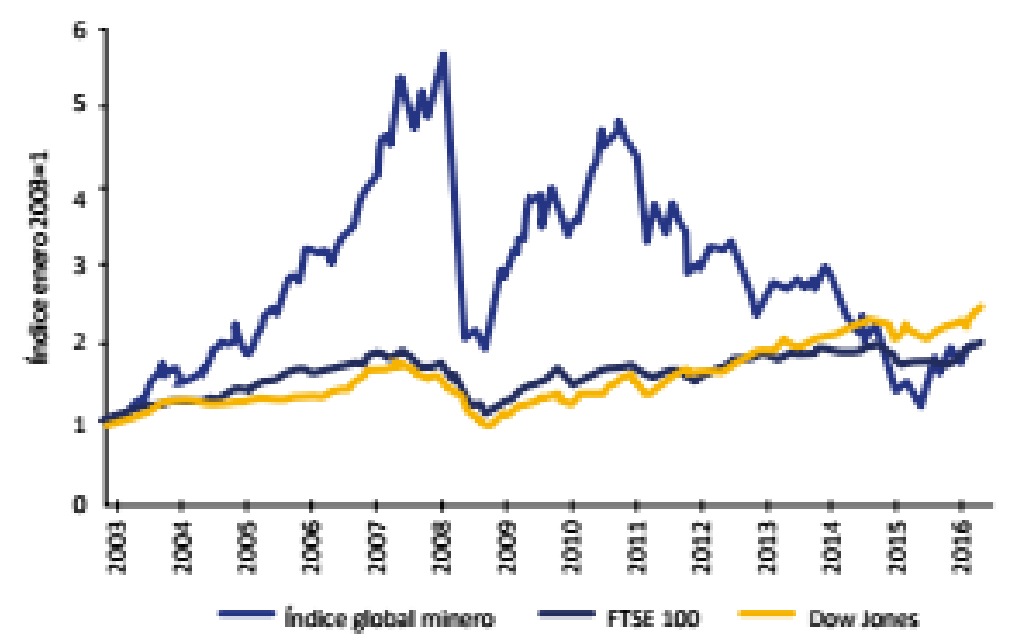

Figura 1. Indice Global de la Minería vs. Indices Bursátiles FTSE y Dow Jones - Extraído de GPAE Osimergmin.

Cabe mencionar que, en comparación con el índice SPBLGPT (SP/BVL Perú General Index) que se reporta en Standar \& Pools Dow Jones Index, sí existe una correlación entre el crecimiento del país y el crecimiento del sector. Para el caso en particular de las acciones de la empresa, hay una correlación entre la cotización de MILPO vs. el índice SPBLGPT, en la cual se puede observar en el siguiente gráfico. 
Tabla 10. Evolución de la acción Milpo vs. el índice SPBLGPT de la BVL.

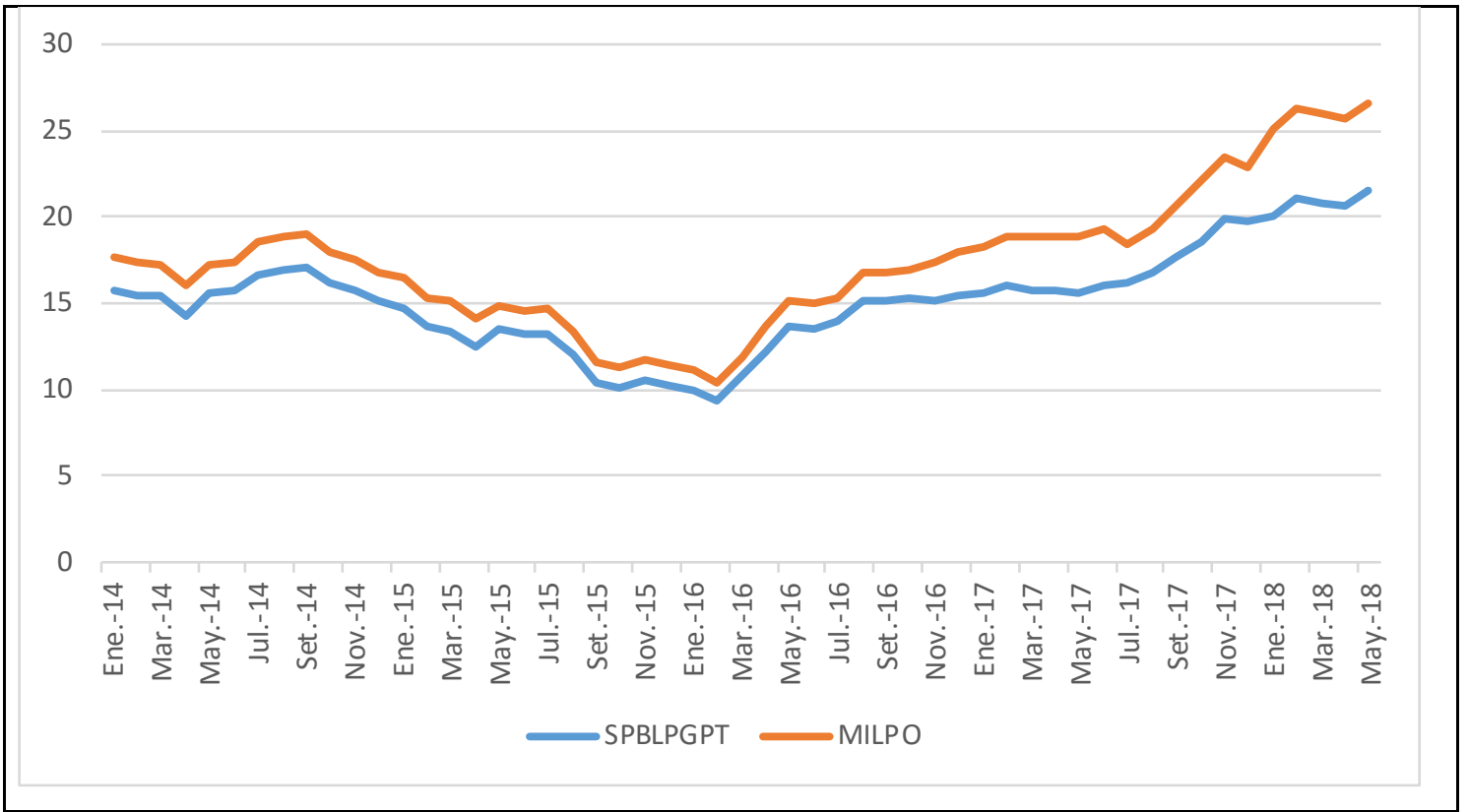

Nota: Elaboración propia en base a BVL y Bloomberg.

En cuanto a la perspectivas de la economía en general, según Reporte de Inflación al mes de Diciembre 2017 del BCRP, obtenemos un modesto crecimiento de alrededor del $3.7 \%$ en el 2017, considerando esta tasa más alta de los últimos 05 años anteriores, mantenie ndo la tendencia tanto para países desarrollados como en vías en desarrollo (estos últimos se han visto favorecidas debido a estímulos monetarios y recuperación de los precios de los metales en el mercado internacional) . El estudio también muestra un mantenimiento de las tendencias en el 2018 y 2019 a razón de 3.8\% y 3.7\% anual respectivamente. 


\begin{tabular}{|c|c|c|c|c|c|c|c|c|}
\hline \multicolumn{9}{|c|}{$\begin{array}{c}\text { Cuadro } 1 \\
\text { CRECIMIENTO MUNDIAL } \\
\text { (Variaciones porcentuales anuales) }\end{array}$} \\
\hline & \multirow{2}{*}{ PPP\%" } & \multirow{2}{*}{$\begin{array}{l}\text { Comercio } \\
\text { Perú \%v }\end{array}$} & \multirow{2}{*}{2016} & \multirow{2}{*}{$2017^{*}$} & \multicolumn{2}{|c|}{$2018^{*}$} & \multicolumn{2}{|c|}{ 2019* } \\
\hline & & & & & RI Dic.17 & RI Mar.18 & RI Dic 17 & RI Mar. 18 \\
\hline $\begin{array}{l}\text { Economias desarrolladas } \\
\text { De las cuales: }\end{array}$ & 41,9 & 47,3 & 1,7 & 2,3 & 2,0 & 2,3 & 1,9 & 2,0 \\
\hline 1. Estados Unidos & 15,5 & 18,0 & 1,5 & 2,3 & 2,3 & 2,7 & 2,0 & 2,2 \\
\hline 2. Eurozona & 11,8 & 11,2 & 1,8 & 2,5 & 2,1 & 2,3 & 1,8 & 2,0 \\
\hline 3. Japón & 4,4 & 3,1 & 1,0 & 1,7 & 1,1 & 1,3 & 1,0 & 1,0 \\
\hline 4. Reino Unido & 2,3 & 1,2 & 1,8 & 1,8 & 1,3 & 1,4 & 1,3 & 1,4 \\
\hline $\begin{array}{l}\text { Economias en desarrollo } \\
\text { De las cuales: }\end{array}$ & 58,1 & 52,7 & 4,2 & 4,7 & 4,9 & 4,9 & 4,9 & 4,9 \\
\hline 1. Asia emergente y en desarrollo & 31,6 & 28,0 & 6,4 & 6,5 & 6,5 & 6,5 & 6,4 & 6,5 \\
\hline China & 17,8 & 22,9 & 6,7 & 6,9 & 6,4 & 6,5 & 6,2 & 6,3 \\
\hline India & 7,2 & 2,4 & 7,1 & 6,7 & 7,6 & 7,4 & 7,9 & 7,8 \\
\hline 2. Comunidad de Estados Independientes & 4,5 & 0,6 & 0,4 & 2,2 & 2,2 & 2,2 & 2,2 & 2,2 \\
\hline Rusia & 3,2 & 0,5 & $-0,2$ & 1,8 & 1,7 & 1,7 & 1,7 & 1,7 \\
\hline 3. América Latina y el Caribe & 7,9 & 21,9 & $-0,5$ & 1,4 & 2,4 & 2,2 & 2,7 & 2,7 \\
\hline & 2,6 & 4,5 & $-3,4$ & 1,0 & 2,5 & 2,5 & 2,4 & 2,4 \\
\hline Chile & 0,4 & 3,0 & 1,7 & 1,5 & 2,9 & 3,0 & 2,7 & 3,0 \\
\hline Colombia & 0,6 & 2,6 & 1,6 & 1,8 & 2,9 & 2,9 & 3,0 & 3,0 \\
\hline México & 1,9 & 2,9 & 2,4 & 2,1 & 2,0 & 2,2 & 2,5 & 2,5 \\
\hline Perú & 0,3 & - & 4,0 & 2,5 & 4,2 & 4,0 & 4,2 & 4,0 \\
\hline Economía Mundial & 100,0 & 100,0 & $\underline{3.1}$ & $\underline{3.7}$ & 3.7 & 3,8 & 3,6 & 3.7 \\
\hline \multirow{2}{*}{$\begin{array}{l}\text { Nota: } \\
\text { Socios Comerciales }{ }^{1 / 2 s}\end{array}$} & & & & & & & & \\
\hline & 64,8 & & 2,8 & 3,5 & 3,5 & 3,6 & 3,3 & 3,4 \\
\hline
\end{tabular}

Figura 2. Crecimiento Mundial (Variaciones Porcentuales Anuales), adaptado de BCRP Junio 2018.

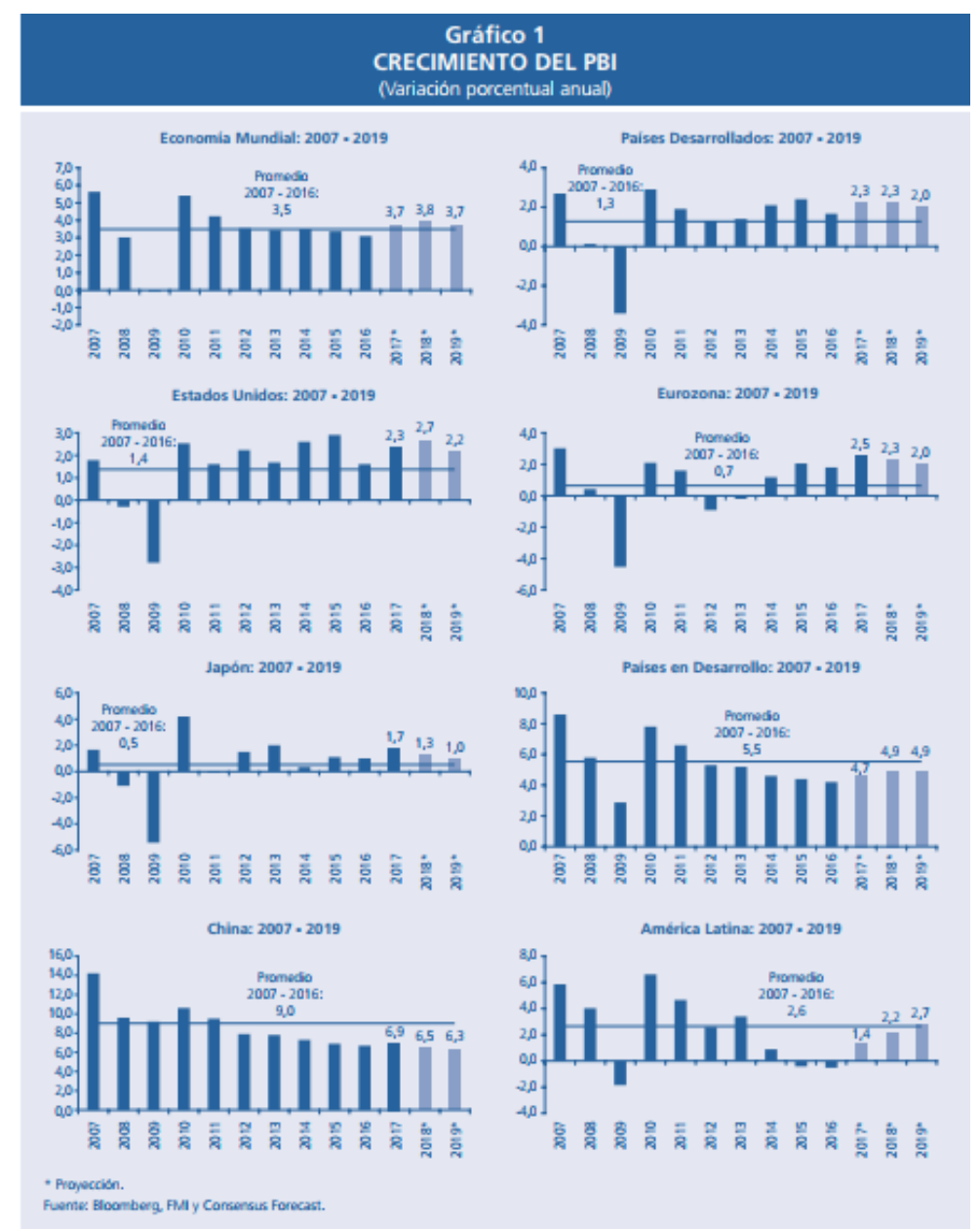


Figura 3. Crecimiento del PBI mundial (variación porcentual anual) - Adaptado de: BCRP, Marzo 2018.

\subsubsection{Estados Unidos.}

La economía de Estados Unidos pese al ruido político existente, se mantiene con la proyección al alza, superando sus expectativas de mercado, se estima que su economía crezca $2.3 \%$ a $2.7 \%$ en 2018 , y de $2.0 \%$ a $2.2 \%$ en 2019 . Este crecimiento se debe a las reformas tributarias aprobadas en Diciembre 2017, con lo cual estimulará el crecimie nto de la economía. De acuerdo a especialistas, podría haber algún impacto debido a la guerra comercial con China.

En el segundo trimestre el PBI creció 3.0\%, la mejora se debió principalmente a un mayor crecimiento del consumo privado (3.3\%) y de la inversión privada (3.6\%). El mayor consumo contribuyó en 2.3 puntos al PBI mientras que la inversión privada contribuyó en 0.6 puntos.

\begin{tabular}{|c|c|c|c|c|c|c|c|}
\hline \multicolumn{8}{|c|}{$\begin{array}{c}\text { EUA: PBI } \\
\text { (Nariación porcentual anual) }\end{array}$} \\
\hline & \multirow{2}{*}{2015} & \multirow{2}{*}{2016} & \multicolumn{5}{|c|}{2017} \\
\hline & & & 1 & II & III & IV & Año \\
\hline Consumo personal & 2,5 & 2,7 & 1,9 & 3,3 & 2,2 & 3,8 & 2,7 \\
\hline Inversión privada bruta & 0,9 & $-1,6$ & $-1,2$ & 3,9 & 7,3 & 3,5 & 3,2 \\
\hline Inversión no residencial & 2,3 & $-0,6$ & 7,2 & 6,7 & 4,7 & 6,6 & 4,7 \\
\hline Variación de inventarios * & 0,2 & $-0,4$ & $-1,5$ & 0,1 & 0,8 & $-0,7$ & $-0,1$ \\
\hline Exportaciones & 0,1 & $-0,3$ & 7,3 & 3,5 & 2,1 & 7,1 & 3,4 \\
\hline Importaciones & $-0,8$ & 1,3 & 4,3 & 1,5 & $-0,7$ & 14,0 & 3,9 \\
\hline Gasto de gobierno & 0,3 & 0,8 & $-0,6$ & $-0,2$ & 0,7 & 2,9 & 0,1 \\
\hline PQ1 & $\underline{2,9}$ & 1.5 & 1,2 & $\underline{3.1}$ & $\underline{3.2}$ & 2,5 & $\underline{2.3}$ \\
\hline
\end{tabular}

Figura 4. Variación porcentual anual del PBI de Estados Unidos, adaptado de: BCRP, Marzo 2018.

Esta mejora también se ve reflejada en el mercado laboral. Se calcula que el estímulo tributario generó una creación de 242,000 puestos de trabajo mensuales entre los meses de Diciembre 2017 y Febrero 2018. El reporte de empleo a Febrero 2018 subió a 63.0\% la tasa de la población económicamente activa con respecto a la población total y la tasa de desempleo se ubicó en $4.1 \%$ (el nivel más bajo desde el año 2000), esto debido 
básicamente a la mayor demanda de trabajadores producto de una mayor inversión en la empresas.

Según proyecciones de la FED publicadas en Diciembre 2017 mostraron una ligera corrección al alza en el crecimiento y la inflación, mientras se revisaron a la baja el desempleo.

\subsubsection{Eurozona.}

La proyección de crecimiento de la Eurozona se revisa al alza para el 2018 manteniendo un pronóstico de de $2.1 \%$ a $2.3 \%$, y para el 2019 se preveé se aminore ligeramente la expansión (2.0\%), debido al brexit del Reino Unido, que lo ubicaría fuera de la Unión Europea.

El crecimiento se prevee que continúe con bajas tasa de inflación. A nivel de países se destaca la mejora de la economía alemana y española, aunque no es de la misma realidad para la economía italiana debido a incertidumbre política. Pese a ello, el consumo privado continúa creciendo debido a las ganancias de empleo y por la mejora de los ingresos de las familias.

Este escenario se mantendría en el tercer trimestre, el mayor crecimiento global han incrementado la confianza y se ha dado un impulso a la manufactura y servicios. Otro factor para el incremento de la confianza son los resultados electorales en Francia. Los países con mayor revisión al alza en la proyección de crecimiento para el 2017 son Alemania y España.

La inflación en la Eurozona se mantiene en $1.9 \%$ a Mayo 2018 y se espera un pronóstico del $2.0 \%$ para el 2019.

\subsubsection{Japón.}

La economía de Japón creció $1.7 \%$ en el 2017. Se aprecia una tasa de crecimiento del PBI de $1.1 \%$ a $1.3 \%$ para el 2018 , y de $1.0 \%$ para el 2019 , pronosticando un mayor dinamis mo en las exportaciones y en la inversión. en el segundo trimestre, tasa ligeramente menor a 
la del primer trimestre (1.5\%), destacando el dinamismo de la demanda interna. En Japón se mantiene la previsión de un retiro gradual del estímulo fiscal, aplicada desde el año 2012.

\subsubsection{China.}

La economía creció $6.5 \%$ en el primer trimestre del 2018, muy similar a los últimos trimestres del 2017. Esto debido a la evolución en el consumo, la inversión y las exportaciones. Se pronostica crecimiento al final del año 2018 de $6.6 \%$, y para el año 2019 un crecimiento que bordeará entre $6.3 \%$ y 6.4\%. Esta tendencia podría verse afectada debido a la guerra comercial con EE.UU. con el posible efecto en la producción industrial y las exportaciones.

\subsubsection{América Latina.}

En promedio desde el segundo trimestre del 2017 hasta el primer trimestre del 2018, la actividad económica se mantuvo a un ritmo positivo en todos los países de América Latina.

En la región se prevee un crecimiento de $2.2 \%$ para el 2018 y 2.9\% para el 2019.

La economía de Brasil mostró una ligera recuperación después de la turbulencia política del 2017, la cual mantuvo contraída su economía durante casi un año. En líneas generales todos los países de la región mantendrá una tendencia al alza del PBI, a excepción de Venezuela y Argentina, esta última por los ajustes financieras y fiscales llevadas a cabo por el gobierno de dicho país.

La economía de Chile se estima que crecerá en alrededor del 3.6\% para el 2018 y 3.5\% para el 2019, gracias al entorno de la economía externa y por consiguiente un recupero de la economía, a su vez que el consumo minorista se sigue manteniendo a ritmo constante.

La economía de Colombia se mantuvo impulsada por el entorno externo y política fiscal expansiva. Esta se ha recuperado luego de ser afectada por el incremento del impuesto al valor agregado (IVA) en el año 2017. Se prevee un crecimiento de 3.2\% para los años 2018 y 2019. 
La economía de México estima un crecimiento de 2.2\% para el 2018 y 2.3\% para el 2019. Este pronóstico se debe al crecimiento de EEUU por ser su principal socio comercial. El consumo interno es su principal impulso, así como una reducción de la inflación para el año 2018. Esta condición podría verse afectada con la renegociación del TLCAN con EEUU y Canadá.

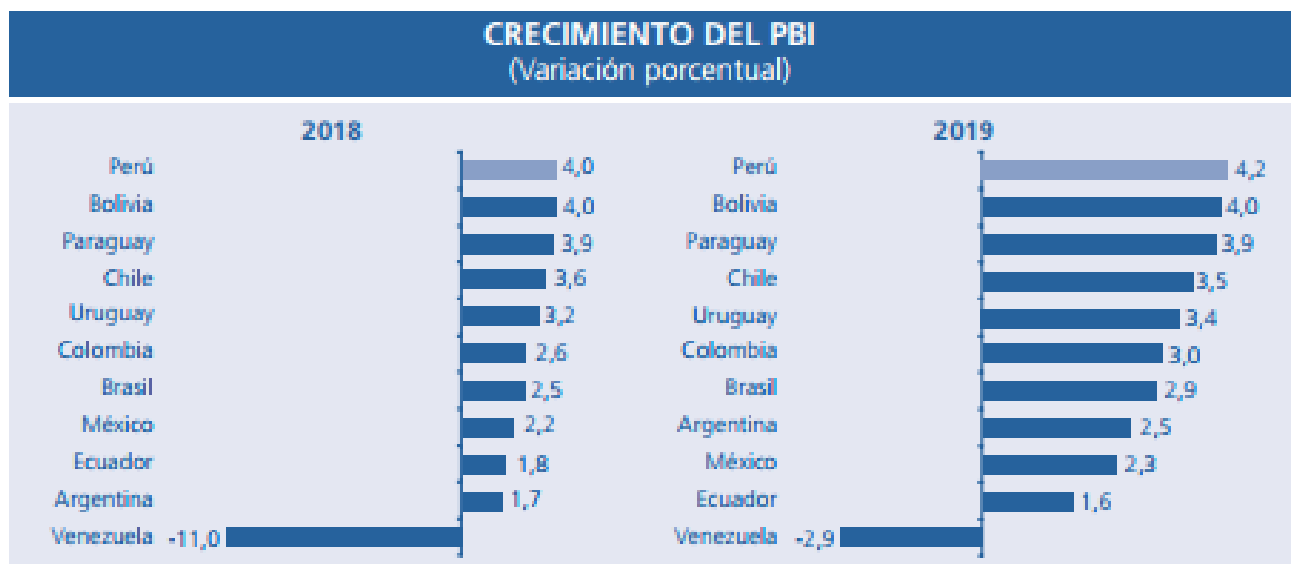

Figura 5. Crecimiento del PBI en América Latina (Variación porcentual), adaptado de: Reporte de Inflación BCRP, Junio 2018.

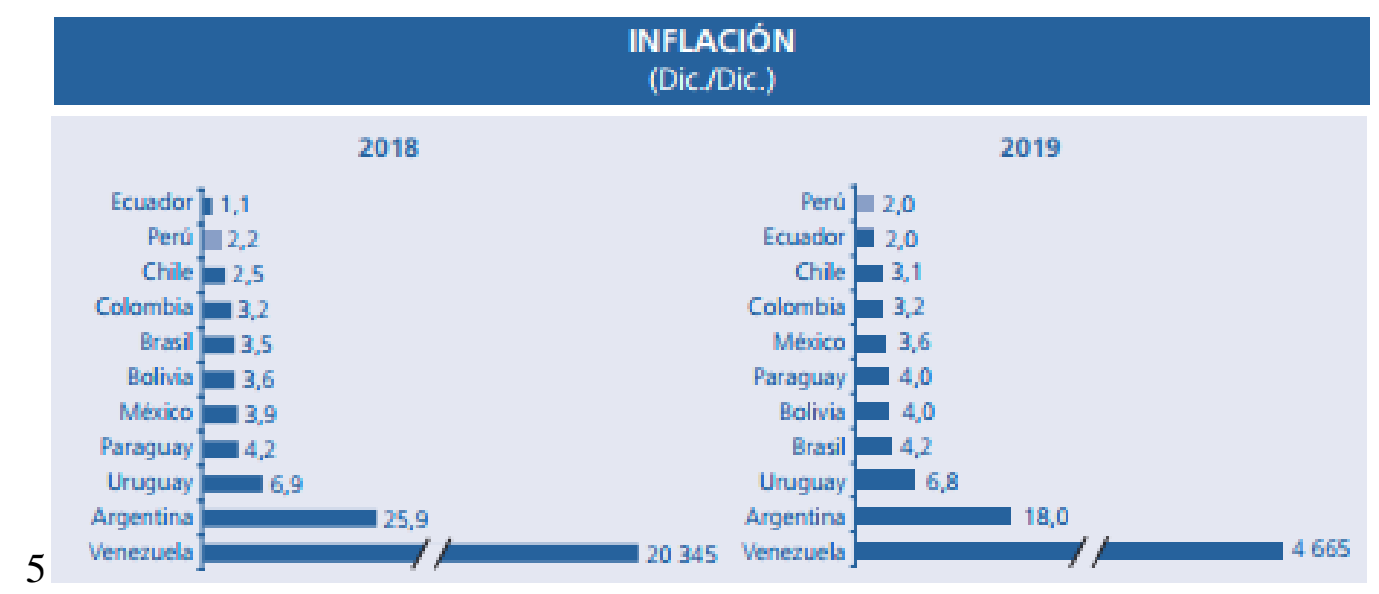

Figura 6. Inflación América Latina (2018 -2019), adaptado de: BCRP Reporte de Inflacion, Junio 2018. 


\subsubsection{Perú.}

En nuestro país la actividad económica se ha venido desacelerando desde el último trimestre del 2016 hasta llegar a un 4.0\%. Posteriormente se desaceleró aún más en el 2017 llegando a 2.5\%, debido a un menor impulso en el consumo interno y la inversión, sin dejar de mencionar el imacto del fenómeno del El Niño Costero. Por otro, la contracción de la inversión pública y privada, en parte debido a la paralización de proyectos en infraestructura a raíz de las investigaciones sobre casos de corrupción asociados a constructoras brasileñas.

Ya a principios del 2018 se ha observado recuperación de la demanda interna, en paralelo con la recuperación de la confianza empresarial que fue afectado por el caso Lava Jato (debido a la paralización de varios proyectos y reducción de la confianza de los inversionistas). Este mayor dinamismo del PBI se explica también por la inversión pública, la cual se da por el avance gradual de los Planes de Recostrucción y de las obras asociadas a los Juegos Panamericanos. En el caso de la inversión privada se ve afectada hasta la fecha por la disminución del empleo y caída de los ingresos familiares. Se tiene un crecimiento de las expectativas del consumidor, sin embargo, está todavía bajo en relación de hace 06 meses.

También debemos mencionar que la economía peruana se soporta en parte por el contexto internacional. Tal es el caso del precio de los commodities, el cual tiene impacto en la economía local y que tiene influencia porque el Perú es un país netamente exportador de dichos productos. Por consiguiente, esto impulsa en gran parte las inversiones del sector privado, explicado líneas abajo. Las exportaciones continúan siendo la principal fuente de crecimiento del PBI.

Revisemos el PBI de algunos sectores:

\subsubsection{Sector Agropecuario.}

Tuvo un crecimiento en el segundo trimestre del año 2018 de $5.7 \%$ gracias a la normalización de las condiciones climáticas, a la mayor expansión de las áreas agrícolas, sobre todo aquellas destinadas a la agroexportación, asi como la recuperación de las condiciones para mejor aprovechamiento de la tierra, la misma que fue afectada por el Fenómeno El Niño Costero. (café, uva, palta, cacao de la Selva y de productos orientados 
a la exportación como uva, aceituna, alcachofa y arándanos). Se prevee una proyección de $4.0 \%$ para el 2019 por aumento de la producción destinada a mercados externos.

\subsubsection{Sector Pesca.}

El sector pesca creció $3.4 \%$ debido a mayor pesca de anchoveta para el consumo industrial en el segundo trimestre debido a mayores desembarques de anchoveta, así como el incremento de la captura de otras especies como perico, jurel y bonito para consumo humano. Para el 2019 se espera una normalización de las condiciones para el desarrollo de la actividad pesquera similares a lo que ocurre en el 2018, es decir, no se esperan condiciones oceanográficas atípicas.

\subsubsection{Sector Hidrocarburos.}

La producción del sector cayó 5.9\% en el primer trimestre del 2018 debido a menor extracción de gas natural y líquidos de gas natural. Esto ocurre por la menor explotación del lote 56 (Pluspetrol) y menores demandas de gas por parte de las generadoras termoeléctricas (Afecta el lote 88 de Pluspetrol). Para el 2019 se espera un crecimie nto de $7.6 \%$ con la consiguiente recuperación de la producción de gas, así como se espera un incremento de la producción de petróleo en el Oleoducto Norperuano.

\subsubsection{Manufactura No Primaria.}

La producción se incrementó en 1.4\% en el primer trimestre del 2018 debido a mayor producción de bienes vinculados a exportaciones y consumo masivo.

Para el 2018 y 2019 se proyecta crecimiento de 3.5\% y 3.8\%, debido al mayor dinamis mo del lado de la demanda interna, lo que conlleva a mayor producción de bienes de consumo masivo, insumos y bienes de capital.

\subsubsection{Sector Minería Metálica.}

Este sector constituye uno de los sectores que más inversión genera en nuestro país. De acuerdo a proyecciones del BCRP, la inversión minera constituye un 39.1\% del total de inversiones en comparación con los otros sectores. Para el período se iniciarán importantes proyectos mineros. Existe en cartera proyectos en curso por más de US\$ 8 mil millones repartidos en proyectos mineros, como Mina Justa de Minsur, Pampa del Pongo, Quellaveco y Corani. Debemos mencionar la adjudicación de Proinversión del proyecto minero Michiquillay a Southern Peru. En cuanto al sector, el crecimiento del sector para el 2017 se registró a la baja 4.1\%, principalmente por la menor producción de 
cobre de Cerro Verde y Southern (problemas logísticos y laborales en el primer trimestre), por la menor producción de oro por leyes menores a las esperadas en Barrick y Yanacocha y por menor producción artesanal en Madre de Dios por interdicciones a mineros informales.

Para el 2018 el sector revisa a la baja por el orden de $2.4 \%$ a $0.8 \%$ principalmente por menor producción de oro y crecimiento menor esperado de producción de cobre, zinc y molibdeno. Para 2019 se estima un crecimiento de 4.3\%, se espera un aumento de proyección de oro por nuevos proyectos y una moderación del crecimiento de producción de cobre y zinc.

\begin{tabular}{lrrrrr}
\multicolumn{7}{c}{$\begin{array}{l}\text { PRODUCCIÓN MINERA } \\
\text { (Nariaciones porcentuales) }\end{array}$} \\
\hline Cobre & $\mathbf{2 0 1 5}$ & $\mathbf{2 0 1 6}$ & $\mathbf{2 0 1 7}$ & $\mathbf{2 0 1 8}$ & $\mathbf{2 0 1 9}^{*}$ \\
\hline Oro & 25,8 & 40,1 & 4,5 & 0,8 & 4,3 \\
Zinc & 4,8 & 4,2 & $-1,2$ & $-7,8$ & 1,0 \\
\hline
\end{tabular}

Figura 7. Variaciones Porcentuales Producción Minera, adaptado de : BCRP, Junio 2018.

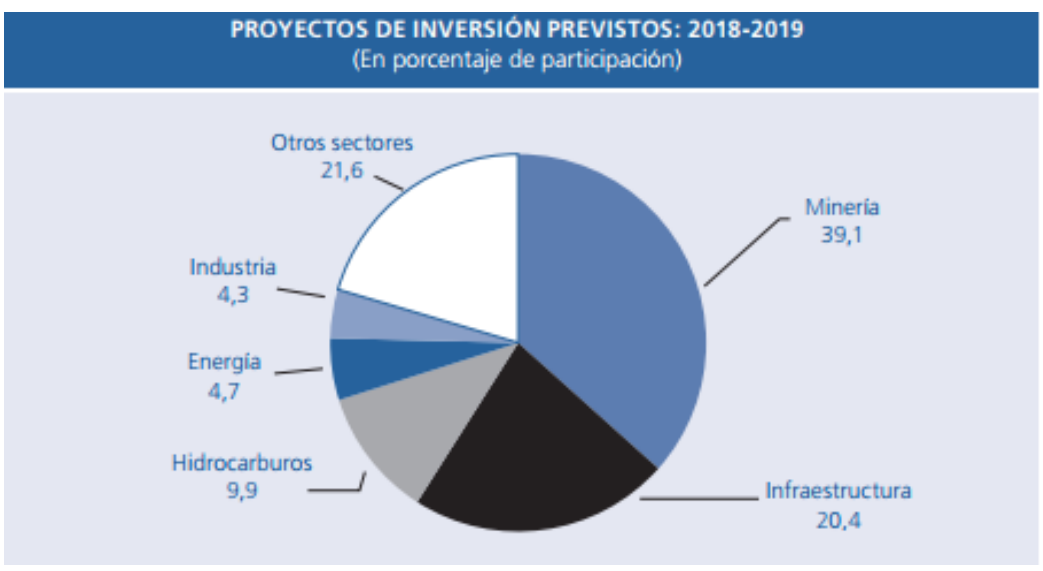

Figura 8. Proyectos de Inversión por Sectores, adaptado de : BCRP, Junio 2018. 


\begin{tabular}{|c|c|c|c|c|c|c|c|c|}
\hline \multicolumn{9}{|c|}{$\begin{array}{c}\text { Cuadro } 21 \\
\text { PBI POR SECTORES ECONÓMICOS } \\
\text { (Variaciones porcentuales reales) }\end{array}$} \\
\hline & \multirow{2}{*}{$\frac{2016}{\text { Año }}$} & \multicolumn{2}{|c|}{2017} & \multicolumn{3}{|c|}{ 2018* } & \multicolumn{2}{|c|}{ 2019* } \\
\hline & & I Trim. & Año & 1 Trim. & RI Mar.18 & RI Jun.18 & RI Mar. 18 & RI Jun. 18 \\
\hline Agropecuario & 2,7 & $-0,2$ & 2,8 & 5,7 & 4,0 & 4,8 & 4,0 & 4,0 \\
\hline Agricola & 1,8 & $-3,7$ & 3,0 & 7,8 & 4,3 & 5,1 & 4,1 & 4,1 \\
\hline Pecuario & 3,7 & 4,4 & 2,7 & 3,0 & 3,4 & 4,4 & 3,8 & 3,8 \\
\hline Pesca & $-10,1$ & 37,9 & 4,7 & 6,1 & 23,5 & 30,0 & 0,5 & $-4,2$ \\
\hline Mineria e hidrocarburos & 16,3 & 4,1 & 3,2 & 0,6 & 2,0 & 0,1 & 3,5 & 4,0 \\
\hline Mineria metálica & 21,2 & 3,9 & 4,2 & 1,7 & 2,4 & 0,5 & 3,0 & 3,5 \\
\hline Hidrocarburos & $-5,1$ & 5,3 & $-2,4$ & $-5,9$ & $-0,8$ & $-2,0$ & 7,6 & 7,6 \\
\hline Manufactura & $-1,4$ & 2,3 & $-0,2$ & 1,0 & 4,8 & 5,1 & 3,5 & 3,8 \\
\hline Recursos primarios & $-0,6$ & 11,7 & 1,9 & 0,1 & 9,9 & 9,9 & 4,1 & 4,1 \\
\hline Manufactura no primaria & $-1,6$ & $-0,5$ & $-0,9$ & 1,4 & 3,0 & 3,5 & 3,4 & 3,8 \\
\hline Electricidad y agua & 7,3 & 1,1 & 1,1 & 1,4 & 2,5 & 3,3 & 3,5 & 4,0 \\
\hline Construcción & $-3,1$ & $-5,2$ & 2,3 & 5,1 & 8,5 & 7,5 & 8,0 & 8,0 \\
\hline Comercio & 1,8 & 0,1 & 1,0 & 2,7 & 3,5 & 3,7 & 3,8 & 3,8 \\
\hline Servicios & 4,0 & 3,1 & 3,3 & 4,2 & 3,7 & 4,1 & 4,0 & 4,2 \\
\hline PRODUCTO BRUTO INTERNO & 4,0 & 2,3 & 2,5 & 3,2 & 4,0 & 4,0 & 4,0 & 4,2 \\
\hline \multicolumn{9}{|l|}{ Nota: } \\
\hline PBI primario & 10,0 & 4,6 & 3,0 & 1,8 & 3,8 & 2,9 & 3,6 & 3,8 \\
\hline PBI no primario & 2,4 & 1,6 & 2,3 & 3,6 & 4,0 & 4,3 & 4,2 & 4,3 \\
\hline
\end{tabular}

Figura 9. Variaciones porcentuales reales del PBI por sectores económicos, adaptado de: BCRP, segundo trimestre 2018.

En resumen, se mantiene la proyección del crecimiento del PBI para el 2018 en $4.0 \%$ y para el 2019 en 4.2\%. En el período 2018-2019 se proyecta una recuperación debido a la crisis generada por el impacto del fenómeno del Niño, para lo cual el gobierno ha incentivado bajando la tasa de referencia de BCR en 150 puntos básicos, a fin de estimular la reconstrucción y recuperación de la economía, conjuntamente con el destrabe de los proyectos de infraestructura. Para el 2018 también se espera recuperación en el sector agrícola debido a la normalización de condiciones climáticas. se espera recomposición a favor de la demanda interna, debido a la revisión al alza (3.3\%) el cual estaría asociado a una mayor recuperación del empleo e ingresos, como consecuencia de la expansión del sector construcción, la mejora de los términos de intercambio y el ingreso disponible, y la reversión del efecto riqueza negativo ocasionado por el Fenómeno El Niño Costero.

Por otro lado, BBVA Research, en su infografía presentación "Situación Perú. Segundo Trimestre 2018”, indica de igual manera una proyección baja de crecimiento para el 2018, todo supuestamente por un entorno de menor calma política e impulso fiscal. 
Por otro lado, también menciona de que el contexto internacional es más favorable al Perú debido básicamente a dos factores : el crecimiento de PBI mundial y al incremento del precio de los metales. Sin embargo, BBVA Research menciona un probable riesgo que podría afectar la guerra comercial USA y China como factor externo negativo, así como previsiones de crecimiento que nos indican son las externas como la desaceleración más marcada de la economía China y un proceso de auste de la FED más agresivo.

Además indican aquí que la inflación seguirá declinando en los siguientes meses y podría rozar el límite inferior del rango meta en el primer trimestre del 2018.

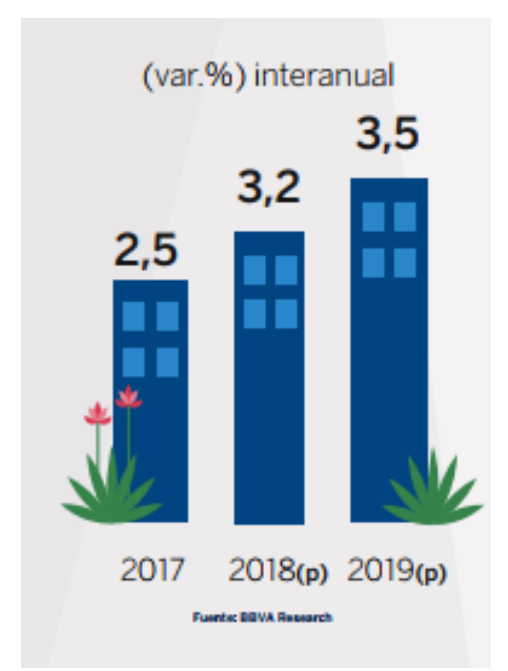

Figura 10. PBI (variación \% interanual), adaptado de: BBVA Research, Junio 2018.

\section{Proyecciones macroeconómicas}

\begin{tabular}{|c|c|c|c|c|c|c|c|c|}
\hline & 2012 & 2013 & 2014 & 2015 & 2016 & 2017 & 2018 (p) & $2019(p)$ \\
\hline PIB (var.\%) & 6.0 & 5.8 & 2.4 & 3.3 & 4.0 & 2.5 & 32 & 3.5 \\
\hline Demanda interna (excl. inv., var.\%) & 9.8 & 6.4 & 2.5 & 2.2 & 0.9 & 1.7 & 3.3 & 3.3 \\
\hline Gasto Privado (var.\%) & 6.5 & 7.2 & 1.9 & 2.7 & 1.3 & 2.0 & 3.3 & 3.3 \\
\hline Consumo Privedo (ver.\%) & 7.4 & 5.7 & 3.9 & 4.0 & 3.3 & 2.5 & 2.7 & 3.0 \\
\hline Inversión privada (var.\%) & 15.6 & 7.1 & -2.2 & 42 & -5.7 & 0.3 & 3.0 & 4.5 \\
\hline Gasto Público (var.\%) & 11.6 & 8.1 & 3.6 & 3.6 & -0.3 & -0.1 & 6.1 & 2.7 \\
\hline Consumo Público (ver.\%) & 8.1 & 6.7 & 6.0 & 9.8 & -0.5 & 1.0 & 6.1 & 2.3 \\
\hline mersión püblica (var.\%) & 19.5 & 11.1 & -1.1 & -9.5 & 0.2 & -2.8 & 6.0 & 3.8 \\
\hline Tipo de cambio (vs. USD, fdp) & 2.57 & 2.79 & 2.96 & 3.39 & 3.40 & 3.25 & 323 & 3.26 \\
\hline Inflaciōn (\% a/a, fdp) & 2.6 & 2.9 & 3.2 & 4.4 & 3.2 & 1.4 & 2.0 & 2.4 \\
\hline Tasas de interés * $(\%$, fdp) & 4.25 & 4.00 & 3.50 & 3.75 & 4.25 & 3.25 & 2.75 & 3.25 \\
\hline Resultado Fiscal (\% PIB) & 2.3 & 0.9 & -0.3 & -2.1 & -2.6 & -3.1 & -3.4 & -3.0 \\
\hline Cuenta Corriente (\% PIB) & -2.8 & 4.7 & -4.4 & 4.8 & -2.7 & -1.3 & -1.3 & -1.8 \\
\hline
\end{tabular}

Figura 11. Proyección de variables macroeconómicas Perú, adaptado de: BBVA Research, segundo trimestre 2018. 
En lo referente a la inflación BBVA Research prevee una proyección entre $2.0 \%$ a $2.4 \%$ para entre los años 2018 y 2019. Esto debido a cierta estabilidad en la paridad cambiaria, y la normalización de los precios, sobre todo alimentos (superado el impacto del Fenómeno del Niño Costero).

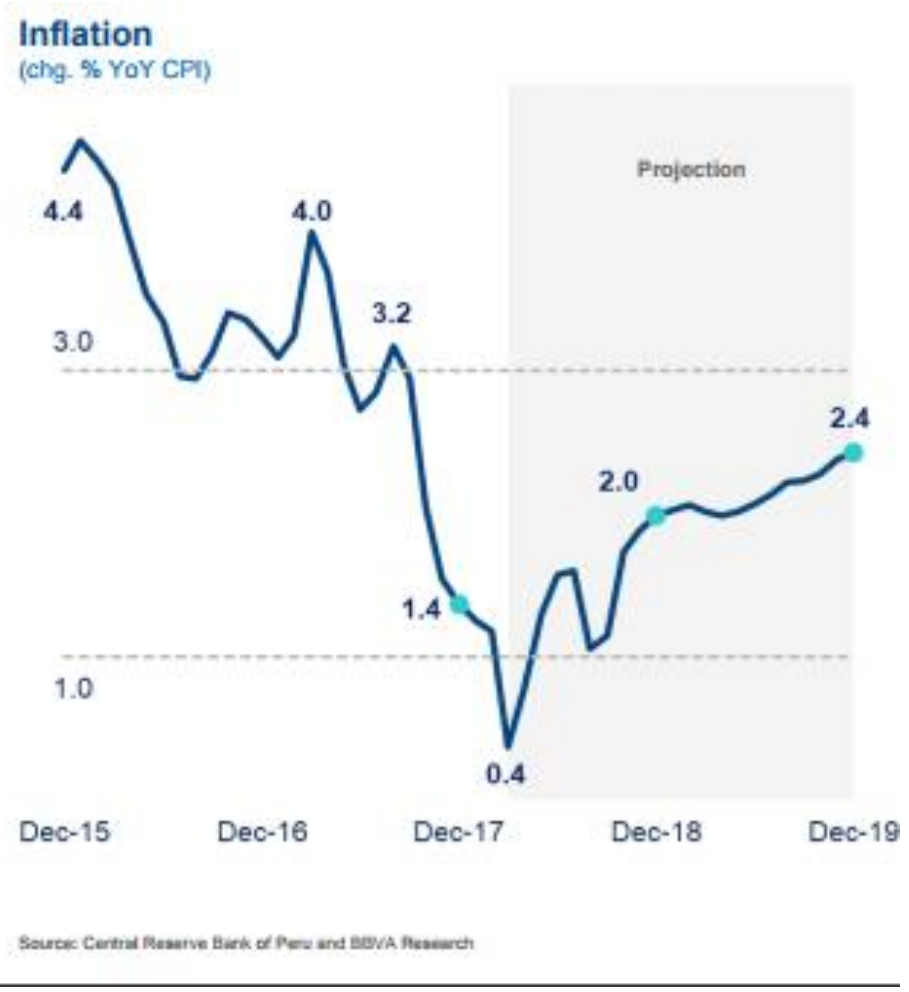

Figura 12. Tipo de Cambio Perú, adaptado de: BBVA Research, Junio 2018.

En cuanto a los Estudio Económicos del Scotiabank, en su Reporte Especial de Julio 2018, menciona un crecimiento del PBI del orden del 3.5\% para el 2018, y de $4.0 \%$ para el 2019. Así mismo, en diversos informes señala que el 2018 es en definitiva un año de transición, supuestamente porque ya no habría tantos efectos adversos como los que sí afectó en el 2017. Esto debido a que existen varios motivos a considerar. Así tenemos, por el lado de Proinversión (está trabajando en varios proyectos a licitar), se espera una ejecución de varios proyectos a ejecutar y que estuvieron contraídos durante 04 años anteriores al 2018, el incremento de los commodities y mayor estabilidad de precios. 
PRINCIPALES INDICADORES MACROECONÓMICOS

\begin{tabular}{|c|c|c|c|c|c|}
\hline & 2015 & 2016 & 2017 & $2018^{11}$ & $2019^{11}$ \\
\hline$\overline{\text { Sector Real (Var. \% real) }}{ }^{\not}$ & & & & & \\
\hline Producb Bruto Interno & 3.3 & 4.0 & 2.5 & 3.5 & 4.0 \\
\hline VAB Sectores Primarios & 6.9 & 10.0 & 3.0 & 2.5 & 3.2 \\
\hline VAB Sectores No Primarios & 2.4 & 2.4 & 2.3 & 3.7 & 4.2 \\
\hline
\end{tabular}

Figura 13. Principales Indicadores Económicos (variación porcentual real), adaptado de: Estudios Económicos-Scotiabank, Reporte Semanal Julio 2018.

\subsection{El Sector Minero en el Perú y su Entorno Internacional.}

Debido a su gran riqueza geológica, la disponibilidad de información catastral y geoló gica de alta calidad, la innumerable oferta de proveedores y además, un marco jurídico promotor de la inversión privada vigente en el país, convierten al Perú en uno de los destinos más atractivos para la inversión minera a nivel mundial. Tal es así que representa más del 50\% de las exportaciones peruanas, con cifras alrededor de los 4 mil millones de dólares al año.

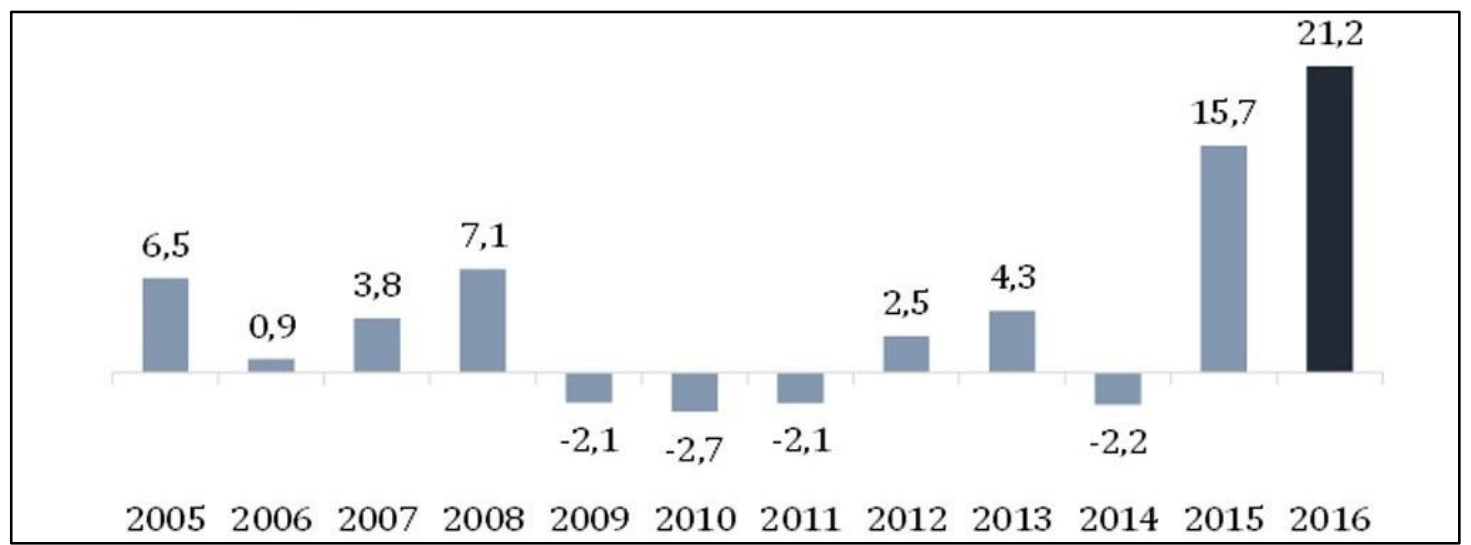

Figura 14. Estadística de la producción de la minería metálica anual (var \% real), adaptado de INEI y MINEM. 
Tabla 11: Posición del Perú en el ranking de reservas metálicas.

\begin{tabular}{|l|c|c|c|}
\hline \multicolumn{3}{|c|}{} & \\
\hline MINERAL & LATINOAMERICA & MUNDO & $\begin{array}{c}\text { RESERVAS } \\
\%\end{array}$ \\
\hline COBRE & 2 & 3 & $11.20 \%$ \\
\hline ZINC & 1 & 3 & $12.70 \%$ \\
\hline PLOMO & 1 & 4 & $7.10 \%$ \\
\hline
\end{tabular}

Nota. Elaboración propia en base a información del INEI y MINEM

\subsubsection{Producción, usos y perspectivas del zinc.}

Las perspectivas del precio es hacia el alza de este metal debido a altas expectativas de demanda aún fuertes en China. Así mismo, viniendo de una baja cotización en los años 2011-2016 ocasionó que se redujera la producción de este metal, razón por la cual ahora hizo que más o menos ocasionara un primer efecto al alza, así como en déficit en concentrados de zinc en el mercado global. Las perspectivas apuntan a un alza de acuerdo con pronósticos del banco mundial .

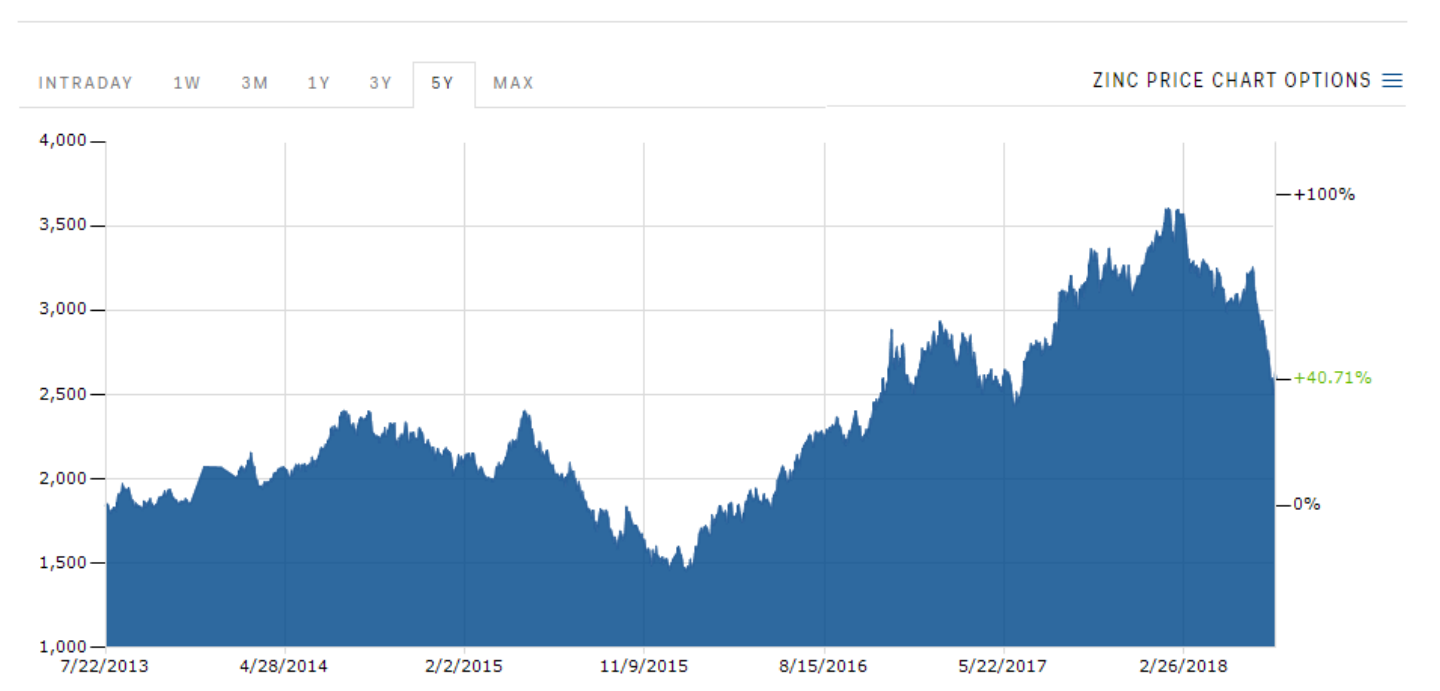

Figura 15. Evolución del precio del zinc en los últimos 05 años. Adaptado de Market Business Insider, Julio 2018. 


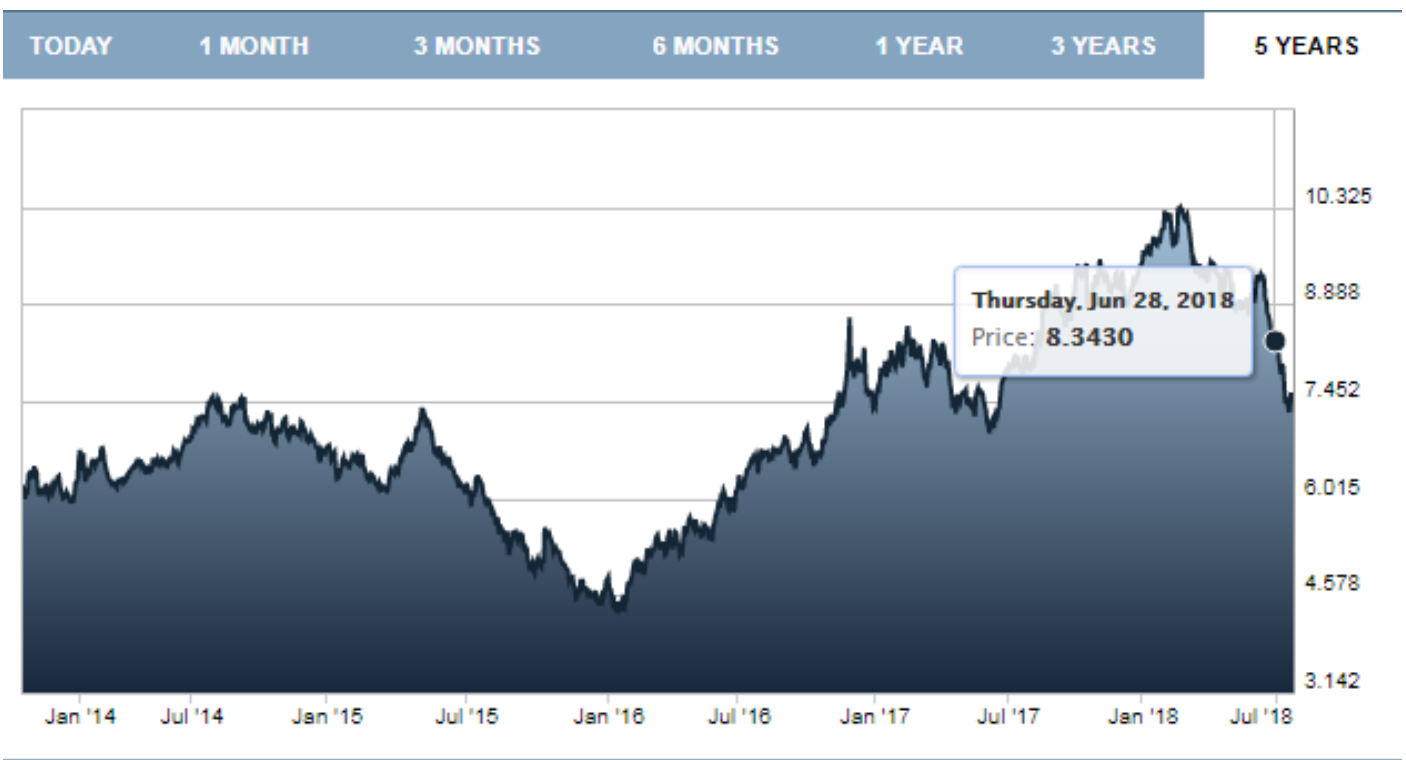

Figura 16. Evolución del Precio del Zinc en los últimos 05 años (USD x libra). Adaptado de london exchang market.com, Julio 2018.

Con relación a los usos del zinc, su aplicación abarca procesos tales como en galvanizado de aceros, industria de la fundición, aleaciones para la fabricación de latón y bronce, en la fabricación de pinturas, polvo de zinc para acumuladores o baterías, así como otras aplicaciones industriales (fabricación de maquinaria industrial, transporte y bienes consumibles, entre otros).

\subsubsection{Producción, usos y perspectivas del plomo.}

El comportamiento de este metal comenzó en el quinquenio 2011-2016 a la baja, ocasionado básicamente en la reducción de las ofertas a nivel mundial, por el cierre de minas en algunas partes del mundo, lo cual ocasionó que a mediados del 2016 el precio comenzara a subir. El alza del precio del plomo tiene una fuerte asociación al zinc en cuanto a las causas que ocasionan variaciones de precios en el mercado internacional. Los pronósticos apuntan al alza de acuerdo a estudios del Banco Mundial. 


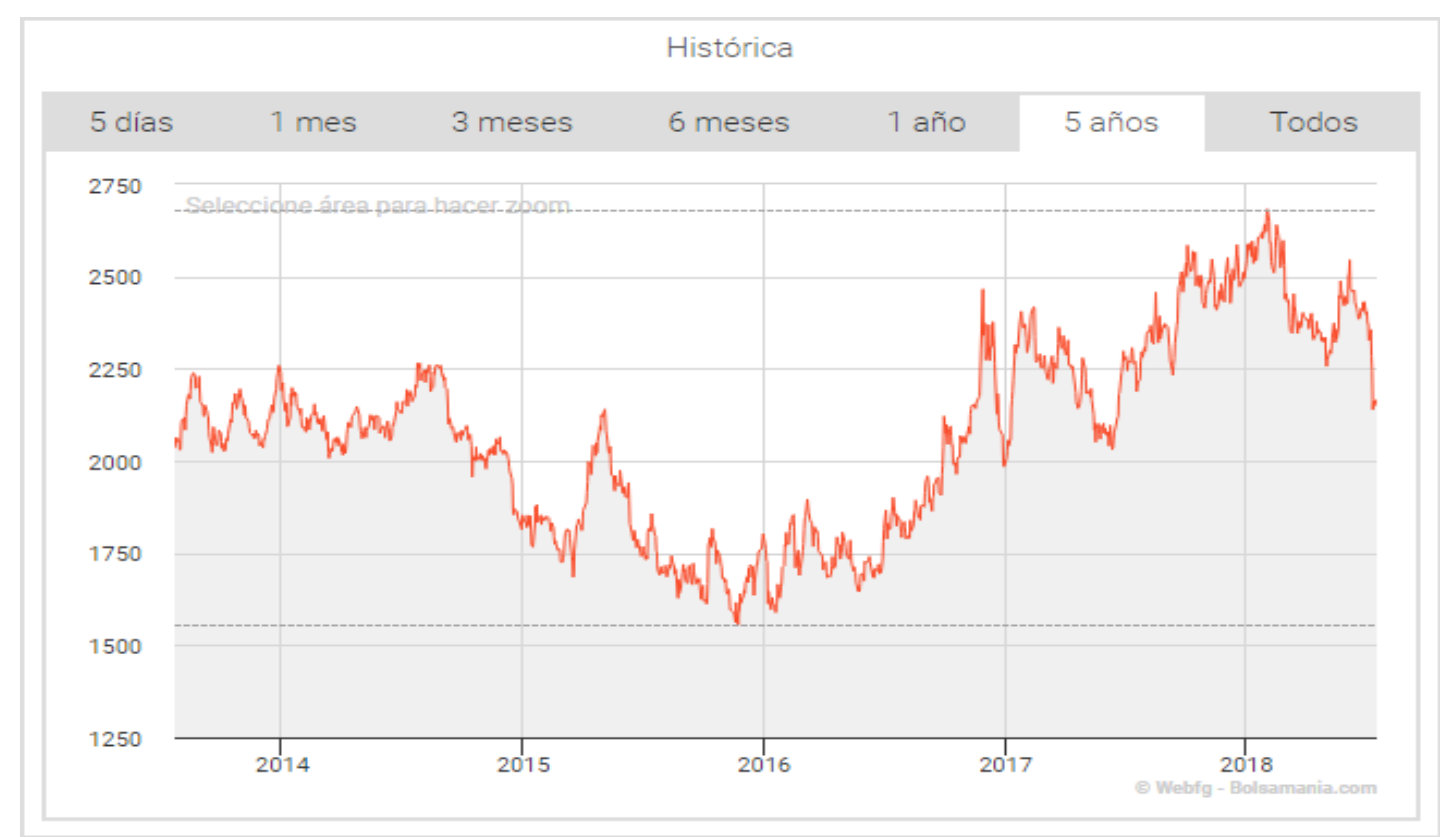

Figura 17. Evolución del precio del plomo en los últimos 05 años. Adaptado de www.bolsamania.com, Julio 2018.

En cuanto a los usos del plomo, tiene preponderante presencia en en la fabricación de acumuladores y baterías. También interviene en la industria de los laminados, en la fabricación de pigmentos, municiones, aleaciones, entre otros.

\subsubsection{Producción, usos y perspectivas del cobre.}

La demanda del cobre tiende al alza debido al comienzo de la reactivación china, como principal consumidor del cobre del mundo. Esto produjo una recuperación del precio después de una caída de su precio entre los años 2015-2016. Las causas de su incremento están asociadas al crecimiento de la economía a nivel mundial. El panorama también es alentador para los siguientes años en concordancia con los pronósticos del Banco Mundial. 


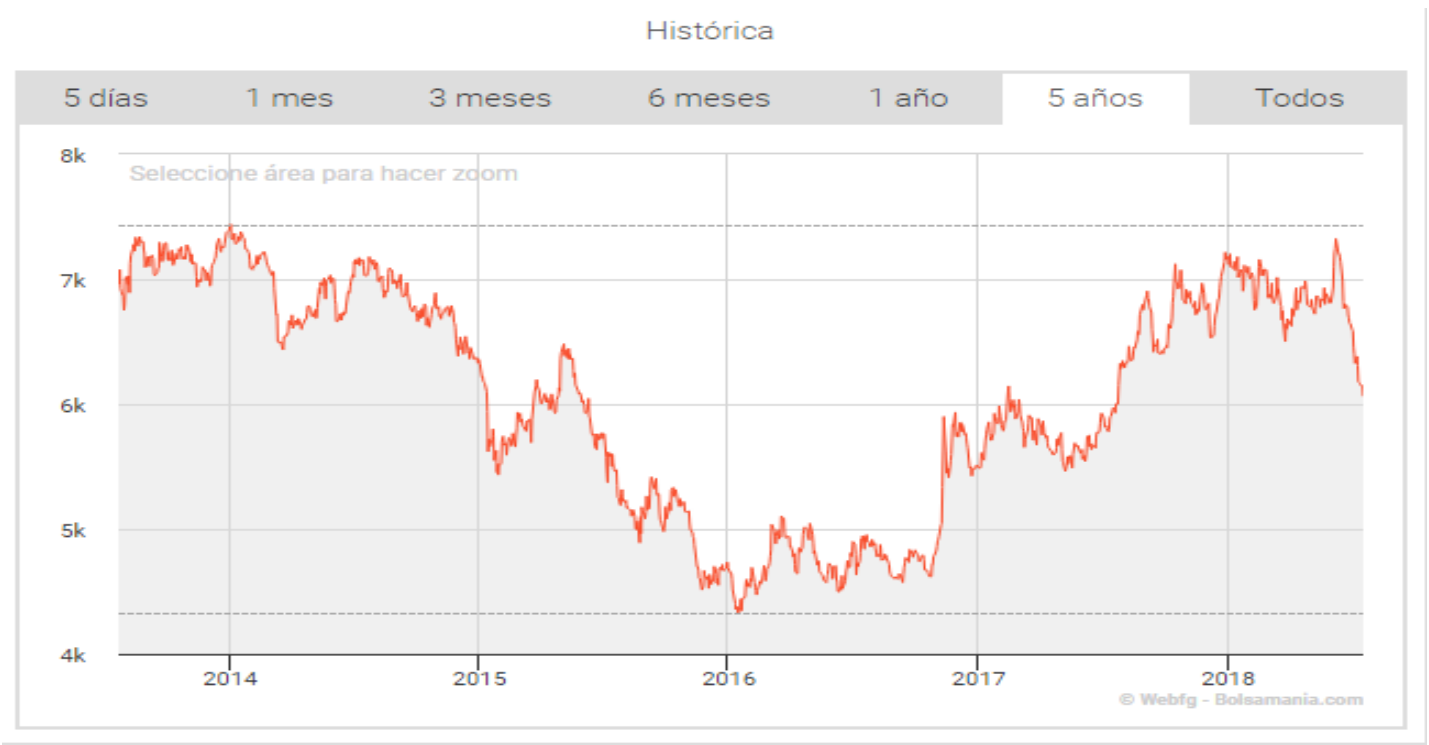

Figura 18. Evolución del precio del cobre en los últimos 05 años. Fuente: www.bolsamania.com, Julio 2018.

En lo relacionado a su uso, el cobre tiene muchas aplicaciones tales como en procesos de galvanizado, fabricación de pinturas y otros relacionados con la construcción, en la industria eléctrica y electrónica, en la elaboración de producos de consumo humano, en la fabricación de maquinaria industrial y equipos, entre otros.

\subsubsection{Entorno Minero en el Perú}

De acuerdo al estudio de inflación publicado por el BCRP segundo trimestre 2018, en general el sector minero experimentará un crecimiento debido al desarrollo de importantes proyectos en ejecución, tal es el caso de Mina Justa en el Sur, Pampa del Pongo, Quellaveco y Corani. El total de inversiones mineras en el Perú para el período 2018 y 2019, representaría un 39.1\% del total de inversiones previstos en todos los sectores del país. Esta tendencia también se ve reflejada en un crecimiento de $1.7 \%$ por mayor producción de cobre, zinc, molibdeno y hierro.

Por otra parte, de acuerdo a estudios de BBVA Research, también concuerda con un crecimiento en general debido a mayor dinamismo en la construcción e inversión privada (de gran impacto la inversión en el sector minero). El estudio prevee un crecimiento de 3.5\% para el 2019 impulsado por la mayor inversión minera (como Mina Justa, 
ampliación de Toromocho, adjudicación del proyecto minero Michiquillay a Southern Perú, entre otros).

Todas estas tendencias están también marcadas en el contexto internacional, ya que desde el año 2017 estuvo marcada por la recuperación significativa en la cotización de los metales industriales, principalmente el zinc y el cobre, sin dejar de mencionar las señales de crecimiento global mencionados líneas atrás, sobre todo China por ser el destino de mayor demanda de los metales industriales en los próximos años.

Por otro lado según dio a conocer en diciembre del 2017 el Instituto Nacional de Estadística e Informática (INEI) en cuanto al sector Minería e Hidrocarburos, este sector aumentó en $3.19 \%$ sustentada por la mayor actividad minero metálica principalmente por la producción de cobre, molibdeno, zinc y plata, el cual, según dicho estudio, también hace referencia de que dicho avance está asociado a la explotación de nuevas zonas con mejor calidad de mineral, recuperación de minerales, mayor volumenes de mineral procesado y contenido metálico.

El estudio del INEI hace mención que desde el año 2015, el dinamismo del sector viene creciendo initerrumpidamente, además de que la producción del cobre destaca como el principal impulsor de este crecimiento sectorial. El desarrollo de las operaciones cupríferas de gran envergadura tal es el caso de Las Bambas y de Chinalco Perú, explotación de unidades productivas de Cerro Verde, entre otros proyectos.

Sector Minería e Hidrocarburos: Diciembre 2017 (Año base 2007)

\begin{tabular}{c|c|c|c}
\hline \multirow{2}{*}{ Sector } & Ponde- & \multicolumn{2}{|c}{$\begin{array}{c}\text { Variación porcentual } \\
\text { 2017/2016 }\end{array}$} \\
\cline { 3 - 4 } & ración & \multicolumn{2}{|c}{} \\
\cline { 3 - 4 } & & Diciembre & Enero-Diciembre \\
\hline Sector Minería e Hidrocarburos & 100,00 & $\mathbf{5 , 5 5}$ & 3,19 \\
Minería Metálica & 84,64 & 6,60 & 4,20
\end{tabular}

Figura 19. Variación Anualizada del Valor Bruto de la Producción del Sector Minería e Hidrocarburos: 2016-2017, adaptado de: Instituto Nacional de Estadística e Informática, Diciembre 2017. 
Según el portal Semana Económica en su reporte del 01 de Mayo del 2018, las inversiones mineras alcanzaron un incremento en el primer trimestre del 2018, alrededor del $30.2 \%$ en comparación con el primer trimestre del año 2017. El incremento se produjo en todos los rubros de la ectividad minera : desarrollo y preparación, equipamiento minero, exploración, infraestructura, entre otros.

\subsection{Los Conflictos Sociales y su impacto en Milpo S.A.A.}

Para el caso de Milpo, en la zona de influencia de sus principales Unidades Mineras (Cerro de Pasco e ICA) existen a Febrero 2017, 04 conflictos Socioambientales activos. Estos datos contrastan significativamente si comparamos con otras regiones tales como las regiones de Ancash y Cuzco, los cuales tienen 20 y 12 conflictos socio ambientales activos respectivamente. Es decir, la probabilidad de riesgo por conflictos en las zonas de influencia de la UM Cerro Lindo, UM Atacocha y UM El Porvenir es mínimo. 


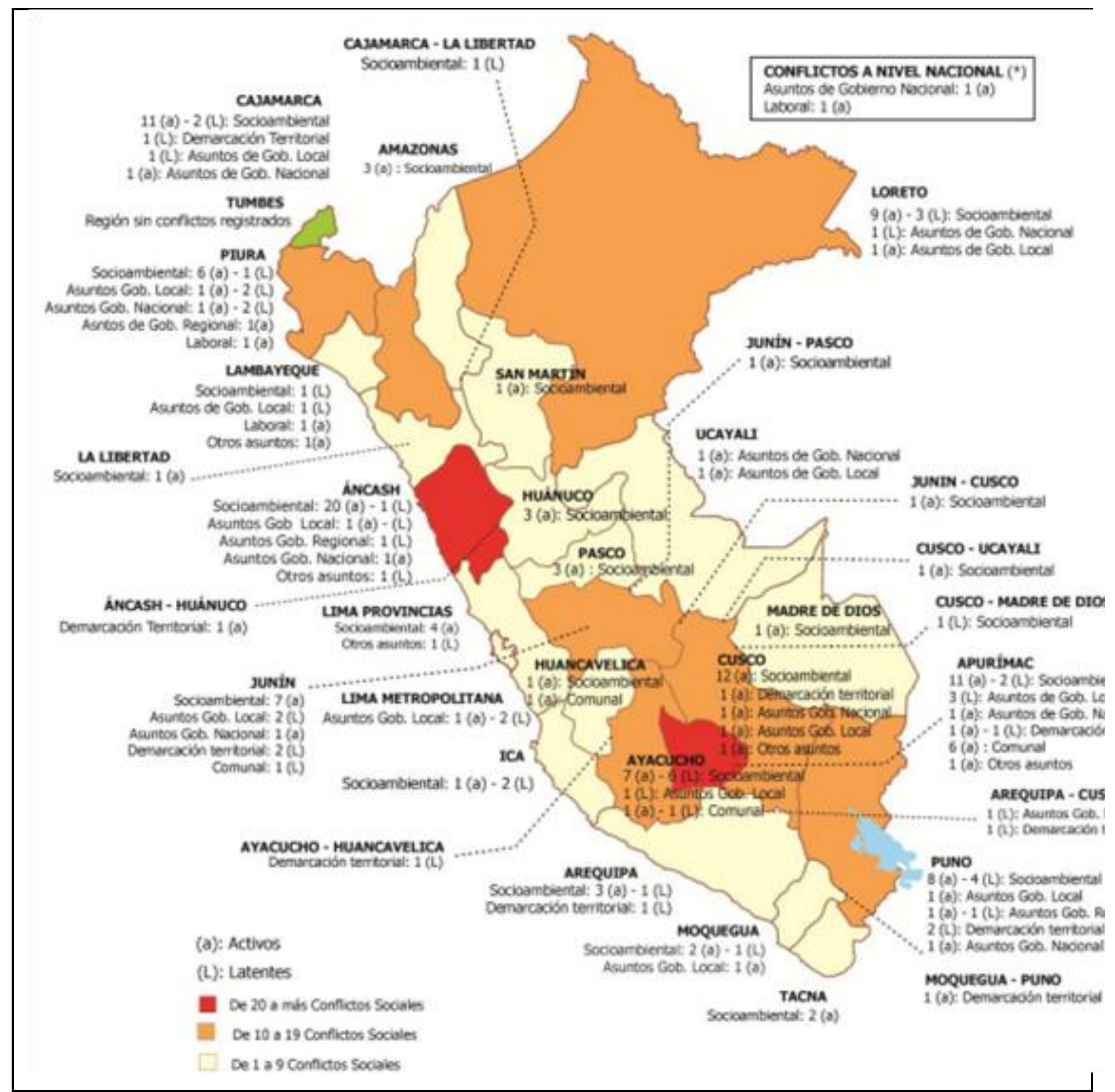

Figura 20. Conflictos sociales por Región y tipos de conflictos. Adaptado de Defensoría del Pueblo 2016. 


\section{Capítulo 4. Análisis financiero Milpo S.A.A. y estimación de la tasa de descuento.}

Para el presente trabajo, a fin de elaborar el análisis financiero correspondiente, se tomó para la empresa Milpo S.A.A. los Estados Financieros Auditados del 2008 - 2017 (ejercicios cerrados) y un corte a Marzo 2018, además de ello pudimos acceder a información pública obtenida de los informes de Gerencia en la página web de la compañía, así como información obtenida de la Superintendencia de Mercados y Valores (SMV), la que nos permitieron acceder a información financiera tanto de los ingresos, del Estado de resultados, el Estado de Situación Financiera y el Flujo de Efectivo; dicha información nos permitió obtener las aperturas necesarias para estimar nuestros drivers, obtener el detalle de los costos, gastos e ingresos; los cuales se convirtieron en herramientas claves para poder realizar las proyecciones de los Estados Financieros y obtener el valor de mercado de la empresa con una mayor exactitud.

\subsection{Análisis de la Empresa Milpo.}

El análisis de los ingresos de la empresa por en el periodo de análisis del 2014 al 2017 son los siguientes:

Tabla 12. Composición de Ventas Milpo S.A.A. (2014-2017).

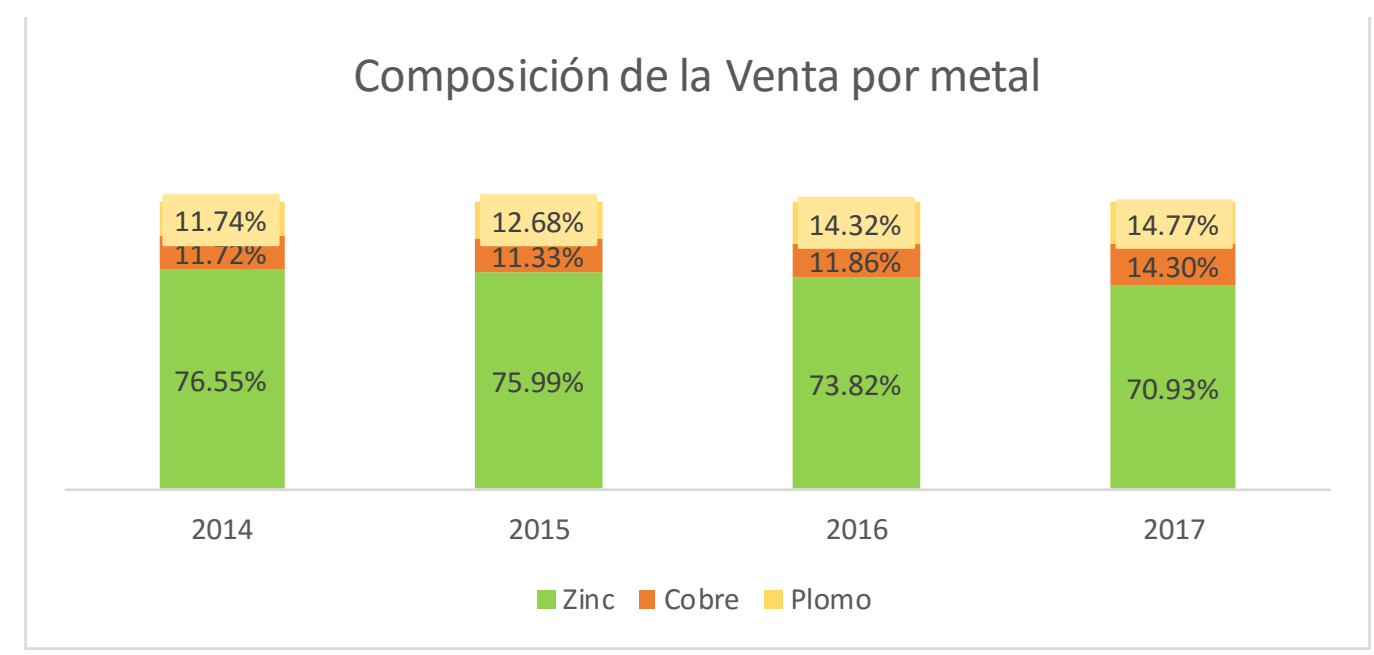

Nota: Elaboración propia en base a EEFF Milpo S.A.A. 
Tabla 13. Composición de la Venta por Unidad Minera Milpo S.A.A. (2014-2017).

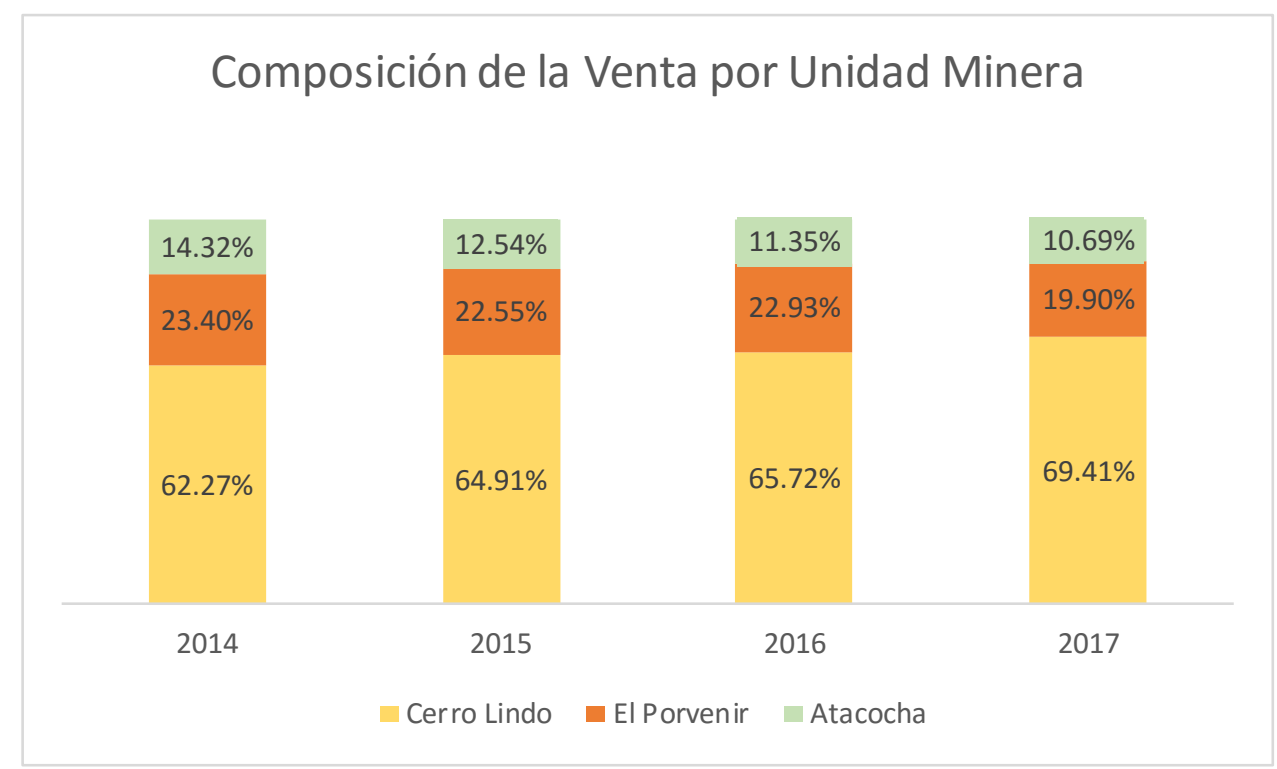

Nota: Elaboración propia en base a Informes de Gerencia Milpo S.A.A.

Con dicha información se puedo determinar la evolución del crecimiento de las distintas unidades de negocio de la empresa, así como también se puede apreciar el impacto que se tuvo sobre los ingresos de la Empresa debido a dos factores : uno externo relacionado con el precio de los metales, y otro interno, relacionado con el incremento de la producción de sus unidades mineras. También podemos apreciar que las productos con mayor participación en la composición de las ventas en los últimos años han sido mayormente a la venta del Zinc representando en promedio un $70.3 \%$, seguido del plomo y cobre con una participación del $14.77 \%$ y $14.30 \%$.

\subsection{Los Estados Financieros Milpo S.A.A.}

A continuación mostramos los Estados financieros de la empresa Milpo S.A.A. (Estado de Resultados y Estado de Situación Financiera) del 2011-2016, se pudo obtener información general de costos y gastos (detalle según dictámenes de Auditoría), Capex, entre otros. Información que nos permitió obtener los "drivers" para realizar la mejor estimación en la proyección de los estados financieros. 
Tabla 14. Estado de Resultados de Milpo S.A.A. (2008-2017).

\begin{tabular}{|c|c|c|c|c|c|c|c|c|c|c|}
\hline (millones de USD\$) & 2008 & 2009 & 2010 & 2011 & 2012 & 2013 & 2014 & 2015 & 2016 & 2017 \\
\hline Ventas & 308.38 & 400.92 & 586.35 & 737.89 & 690.97 & 720.16 & 758.12 & 625.56 & 714.70 & 911.75 \\
\hline Costo de Ventas & -225.77 & -212.97 & -249.67 & -422.06 & -451.03 & -447.49 & -459.10 & -447.82 & -436.02 & -492.27 \\
\hline Margen Bruto & 82.61 & 187.95 & 336.69 & 315.83 & 239.95 & 272.67 & 299.02 & 177.74 & 278.67 & 419.47 \\
\hline Gasto Adm y Ventas & -36.64 & -39.38 & -39.95 & -53.23 & -65.08 & -61.19 & -60.44 & -50.83 & -50.22 & -39.81 \\
\hline otros Ingresos/Gastos & -3.71 & -45.44 & -86.07 & -56.70 & -110.19 & -70.71 & -53.53 & -26.51 & -21.21 & -46.56 \\
\hline EBIT & 42.27 & 103.13 & 210.67 & 205.91 & 64.67 & 140.78 & 185.05 & 100.41 & 207.24 & 333.10 \\
\hline Ingresos Financieros & 2.73 & 0.86 & 1.28 & 1.78 & 2.30 & 2.59 & 2.85 & 3.50 & 4.57 & 11.62 \\
\hline Gastos Finacieros & -8.21 & -25.18 & -11.66 & -8.89 & -9.34 & -17.79 & -19.52 & -19.77 & -22.25 & -30.54 \\
\hline EBT & 36.80 & 78.81 & 200.28 & 198.80 & 57.64 & 125.58 & 168.39 & 84.14 & 189.56 & 314.17 \\
\hline Impuestos & -15.15 & -32.79 & -58.37 & -58.83 & -40.04 & -59.91 & -64.13 & -47.97 & -47.70 & -89.69 \\
\hline Utilidad Neta & 21.64 & 46.02 & 141.91 & 139.96 & 17.60 & 65.67 & 104.25 & 36.17 & 141.86 & 224.48 \\
\hline
\end{tabular}

Nota: Información financiera elaborada en base a información proporcionada por la empresa Milpo S.A. 
Tabla 15. Estado de Situación Financiera de Milpo S.A.A. (2008-2017).

\begin{tabular}{|c|c|c|c|c|c|c|c|c|c|c|}
\hline (millones de USD\$) & 2008 & 2009 & 2010 & 2011 & 2012 & 2013 & 2014 & 2015 & 2016 & 2017 \\
\hline Caja y Equivalentes de Efectivo & 51.93 & 113.51 & 170.16 & 198.23 & 113.70 & 342.41 & 436.69 & 440.20 & 751.07 & 527.59 \\
\hline Cuentas por Cobrar LP & 112.57 & 104.95 & 116.96 & 110.35 & 152.98 & 163.09 & 149.39 & 98.26 & 133.03 & 291.31 \\
\hline Existencias & 47.46 & 40.18 & 46.56 & 62.56 & 66.99 & 65.05 & 63.25 & 50.79 & 43.01 & 34.24 \\
\hline Otros Activos & 5.92 & 2.92 & 4.18 & 0.00 & 0.00 & 0.00 & 0.00 & 10.13 & 5.07 & 1.15 \\
\hline Total Activo CP & 217.87 & 261.56 & 337.86 & 371.14 & 333.66 & 570.54 & 649.33 & 599.38 & 932.18 & 854.30 \\
\hline Otros activos financieros & 6.83 & 0.46 & 2.90 & 0.00 & 0.00 & 0.00 & 0.00 & 58.02 & 18.02 & 0.00 \\
\hline Otros Activos L.P. & 118.60 & 22.04 & 17.97 & 27.76 & 20.69 & 21.74 & 23.85 & 20.23 & 35.26 & 38.11 \\
\hline Activo Fijo Neto & 482.13 & 392.93 & 414.65 & 403.64 & 514.00 & 460.90 & 435.83 & 418.72 & 395.51 & 368.35 \\
\hline Activo Intangibles & 197.47 & 182.98 & 184.06 & 170.75 & 164.78 & 156.97 & 201.56 & 174.29 & 228.91 & 228.30 \\
\hline Total Activo LP & 805.02 & 598.41 & 619.58 & 602.15 & 699.47 & 639.61 & 661.23 & 671.26 & 677.70 & 634.76 \\
\hline Total Activos & 1022.90 & 859.97 & 957.44 & 973.29 & 1033.13 & 1210.16 & 1310.57 & 1270.64 & 1609.88 & 1489.05 \\
\hline Otros Pasivos Fin. CP & 172.33 & 47.20 & 41.64 & 87.31 & 101.48 & 20.55 & 9.69 & 7.62 & 4.35 & 3.76 \\
\hline Cuentas por Pagar CP & 158.83 & 98.70 & 92.86 & 114.64 & 131.78 & 121.85 & 155.98 & 144.31 & 180.77 & 171.28 \\
\hline Otros pasivos CP & 0.00 & 32.51 & 58.64 & 46.44 & 47.75 & 49.17 & 42.21 & 20.28 & 46.55 & 61.52 \\
\hline Total Pasivo CP & 331.16 & 178.42 & 193.13 & 248.40 & 281.01 & 191.56 & 207.87 & 172.21 & 231.68 & 236.56 \\
\hline Cuentas por Pagar LP & 210.53 & 150.67 & 90.75 & 144.19 & 148.05 & 356.93 & 351.86 & 344.48 & 341.18 & 341.73 \\
\hline Otros Pasivos Fin. LP & 39.89 & 39.46 & 60.64 & 85.16 & 107.38 & 98.61 & 101.16 & 101.63 & 307.40 & 283.13 \\
\hline Total Pasivo LP & 250.41 & 190.13 & 151.40 & 229.35 & 255.43 & 455.54 & 453.02 & 446.11 & 648.58 & 624.86 \\
\hline Patrimonio Neto & 441.33 & 491.42 & 612.91 & 495.55 & 496.70 & 563.06 & 649.68 & 652.33 & 729.62 & 627.64 \\
\hline Total Pasivo + Patrimonio & 1022.89 & 859.97 & 957.44 & 973.29 & 1033.13 & 1210.16 & 1310.57 & 1270.64 & 1609.88 & 1489.05 \\
\hline
\end{tabular}

Nota: Información financiera proporcionada por la empresa Milpo S.A.A. 


\subsection{Análisis del Ebitda, Ebit, Patrimonio, Depreciación y Amortización.}

A continuación, en este cuadro podemos observar la evolución del Ebitda, de la utilidad operativa (Ebit) y de los márgenes de rentabilidad de la empresa en los últimos años:

Tabla 16. Indicadores Financieros de Rentabilidad Milpo SAA (2008-2017).

\begin{tabular}{|c|c|c|c|c|c|c|c|c|c|c|}
\hline (millones de USD\$) & 2008 & 2009 & 2010 & 2011 & 2012 & 2013 & 2014 & 2015 & 2016 & 2017 \\
\hline Ebitda & 60.97 & 149.75 & 260.96 & 289.46 & 166.24 & 250.14 & 273.13 & 184.01 & 280.10 & 401.96 \\
\hline Margen Ebitda & $19.77 \%$ & $37.35 \%$ & $44.51 \%$ & $39.23 \%$ & $24.06 \%$ & $34.73 \%$ & $36.03 \%$ & $29.42 \%$ & $39.19 \%$ & $44.09 \%$ \\
\hline D\&A & 18.70 & 46.63 & 50.29 & 83.55 & 101.57 & 109.36 & 88.08 & 83.61 & 72.86 & 68.87 \\
\hline Ebit & 45.98 & 148.57 & 296.73 & 262.61 & 174.87 & 211.49 & 238.58 & 126.91 & 228.45 & 379.66 \\
\hline Margen Ebit & $14.91 \%$ & $37.06 \%$ & $50.61 \%$ & $35.59 \%$ & $25.31 \%$ & $29.37 \%$ & $31.47 \%$ & $20.29 \%$ & $31.96 \%$ & $41.64 \%$ \\
\hline Utilidad Neta & 21.64 & 46.02 & 141.91 & 139.96 & 17.60 & 65.67 & 104.25 & 36.17 & 141.86 & 224.48 \\
\hline Margen Neto & $7.02 \%$ & $11.48 \%$ & $24.20 \%$ & $18.97 \%$ & $2.55 \%$ & $9.12 \%$ & $13.75 \%$ & $5.78 \%$ & $19.85 \%$ & $24.62 \%$ \\
\hline Patrimonio & 441.33 & 491.42 & 612.91 & 495.55 & 496.70 & 563.06 & 649.68 & 652.33 & 729.62 & 627.64 \\
\hline
\end{tabular}

Nota: Elaboración propia mediante Información de los Estados Financieros proporcionados por la empresa Milpo S.A.A.

Como se muestra en la Tabla 16 el Ebitda entre los años 2008 - 2017 Milpo SAA tuvo índices de crecimiento promedio que han ido en forma consistente (un promedio de $34.8 \%$ ), lo cual se debe básicamente a una optimización de las operaciones, es decir, mejora en la cadena de valor (combina los recursos energéticos y la cercanía a las las principales vías de comunicación (acceso al puerto del Callao) lo que permitieron marginar en forma considerable. Además de ello, se integraron las unidades operativas El Porvenir y Atacocha, haciendo que el uso de recursos sean compartidos y aprovechados simultáneamente por ambas, con la consecuente reducción en los costos (tanto en el ámbito energético como logístico).

\subsection{Análisis financiero: Ratios de Liquidez, de Gestión y Rentabilidad.}

Ratios de Liquidez: La Empresa, en paralelo con la baja de los precios de los metales, tuvo una disminución de la liquidez en los períodos 2009-2012, produciéndose posteriormente una recuperación a partir del año 2013, elevándose en adelante hasta el presente. Además, durante el período de reducción hubo también una contracción en las inversiones a consecuencia de la disminución mencionada inicialmente. Con todo ello, 
mantiene un saldo corriente suficiente para así poder afrontar sus compromisos al corto plazo.

Ratios de Solvencia: Se aprecia un efecto en el incremento del endeudamiento patrimonial en el período de disminución en la reducción de los precios de los metales, lo cual afectó en general a todo el sector minero. Pese a este escenario, mantuvo resultados favorables sobre todo en el apalancamiento financiero, así como en los indicadores de endeudamiento patrimonial de corto y largo plazo a partir del año 2012 en adelante.

Ratios de Gestión: Se mantiene un comportamiento regular en los ratios de períodos medio de cobranza y de inmovilización de existencias, sin embargo, sí hubo una disminución en los ratios de rotación de activos (activos totales y activos fijos), lo cual se debió principalmente a la disminución de las ventas en los períodos de reducción del precio de los metales que afectó a la industria (de USD 210 millones en el 2012 a USD 184 millones en el 2015).

Ratios de Rentabilidad: En el ROA y ROE podemos apreciar un aumento sobre todo en el año 2016 debido a una ligera recuperación de las ventas, el cual impacta directamente en la utilidad neta de le empresa. Así mismo, la empresa puso en marcha varias estrategias en la reducción de los costos ocasionado principalmente por la coyuntura de la disminución de los metales.

En cuanto a los Riesgos, la Empresa presenta los siguientes:

- Riesgos de Tipo de Cambio: La Compañía realiza sus ventas en dólares estadounidenses, lo cual le permite hacer frente a sus obligaciones en esa moneda. El riesgo de tipo de cambio surge de los saldos mantenidos en Nuevos soles tales como el efectivo y equivalentes de efectivo, los créditos fiscales del impuesto general a las ventas e impuesto a las ganancias. La Gerencia ha aceptado el riesgo de su posición neta, por lo que no ha efectuado operaciones de derivados para su cobertura. Sin embargo, a fin de medir este riesgo, la empresa realiza un anális is de sensibilidad con un margen de más o menos $10 \%$ a fin de medir esta variación en los resultados antes de los impuestos. 
- Riesgo crediticio: El riesgo de crédito de la empresa se origina de la incapacidad de los deudores de poder cumplir con sus obligaciones. La Gerencia considera que el riesgo crediticio se encuentra mitigado debido a que las entidades relacionadas son de reconocido prestigio internacional y a la política de la empresa evaluar continuamente su historia de crédito y su condición financiera para cumplir con los pagos. Así también, la empresa coloca sus excedentes de liquidez en instituciones financieras de prestigio $\mathrm{y} / \mathrm{o}$ entidades relacionadas, establecen políticas de crédito conservadoras y evalúan constantemente las condiciones existentes en el mercado en el que operan. En consecuencia, la Compañía no prevé pérdidas significativas que surjan de este riesgo.

- Riesgo de liquidez: La administración es prudente frente al riesgo de liquidez y busca mantener efectivo y equivalente al efectivo para cubrir sus operaciones; así también, mantiene la posibilidad de comprometer y/o tener comprometido financiamiento a través de fuentes de crédito.

En tal sentido, la empresa realiza monitoreo a través de sus ratios de liquidez, así como realiza un análisis de los pasivos financieros a fin de medir el anticuamie nto de dichas obligaciones.

- Riesgo político: Es el riesgo que se presentaría ante alguna turbulencia por algún cambio en las leyes tributarias o en época de turbulencia política, sobre todo cada vez que se realiza un cambio de gobierno.

- Riesgo Socio-Ambiental: La empresa realiza constantemente capacitaciones y programas de proyección en las comunidades adyacentes a las zonas de explotación, a fin de mejorar la calidad de vida de los habitantes. Con ello, mitiga la probabilidad de que se produzca conflictos sociales. De igual forma, al infringir alguna norma medioambiental, existe la posibilidad de que la empresa sea sancionada ya sea con una multa y/o hasta con la suspensión de sus actividades .

- Volatilidad de los precios de los Metales: Debido a la variación de los precios de los commodities a nivel internacional, una variación de los precios en el forecast tiene impacto en la valorización de la empresa. 
Tabla 17. Ratios Financieros de Liquidez-Rentabilidad y Endeudamiento de Milpo SAA (2008-2017).

\begin{tabular}{|c|c|c|c|c|c|c|c|c|c|c|}
\hline Liquidez & 2008 & 2009 & 2010 & 2011 & 2012 & 2013 & 2014 & 2015 & 2016 & 2017 \\
\hline Activo Corriente & 0.66 & 1.47 & 1.75 & 1.49 & 1.19 & 2.98 & 3.12 & 3.48 & 4.02 & 5.19 \\
\hline Prueba Acida & 0.51 & 1.24 & 1.51 & 1.24 & 0.95 & 2.64 & 2.82 & 3.19 & 3.84 & 4.94 \\
\hline Capital de trabajo & -113281 & 83146 & 144725 & 122741 & 52655 & 378982 & 441462 & 427174 & 700504 & 738326 \\
\hline Fondo de maniobra con Activo Total (Capital de Trabajo/Activo Total) & -0.11 & 0.10 & 0.15 & 0.13 & 0.05 & 0.31 & 0.34 & 0.34 & 0.44 & 0.45 \\
\hline Prueba de Tesorería & 0.16 & 0.64 & 0.88 & 0.80 & 0.40 & 1.79 & 2.10 & 2.56 & 3.24 & 4.32 \\
\hline Ratios de Solvencia o Apalancamiento & 2008 & 2009 & 2010 & 2011 & 2012 & 2013 & 2014 & 2015 & 2016 & 2017 \\
\hline Apalancamiento Financiero (Total Activo/Total Patrimonio) & 2.33 & 1.75 & 1.56 & 1.96 & 2.08 & 2.15 & 2.02 & 1.95 & 2.21 & 1.67 \\
\hline Endeudamiento Total (Total Pasivo/Total Activo) & 0.57 & 0.43 & 0.36 & 0.49 & 0.52 & 0.53 & 0.50 & 0.49 & 0.55 & 0.38 \\
\hline Endeudamiento Activo Fijo (Total Pasivo No Corriente/Activo Fijo) & 0.52 & 0.48 & 0.37 & 0.57 & 0.50 & 0.99 & 1.04 & 1.07 & 1.64 & 1.13 \\
\hline Endeudamiento Patrimonial (Total Pasivo/Total Patrimonio) & 1.33 & 0.75 & 0.56 & 0.96 & 1.08 & 1.15 & 1.02 & 0.95 & 1.21 & 0.63 \\
\hline Cobertura de Gastos Financieros (Ganancia Act. Operación/Gtos. Financ.) & 5.15 & 4.10 & 18.06 & 23.17 & 6.93 & 7.92 & 9.48 & 5.48 & 10.62 & 15.96 \\
\hline Ratios de Gestión & 2008 & 2009 & 2010 & 2011 & 2012 & 2013 & 2014 & 2015 & 2016 & 2017 \\
\hline Período medio de Cobranzas & 90 & 99 & 69 & 56 & 70 & 80 & 75 & 72 & 59 & 39 \\
\hline Período medio de Inmovilización de Exist & 68 & 75 & 63 & 47 & 52 & 54 & 51 & 46 & 39 & 32 \\
\hline Período medio de pago & 114 & 113 & 52 & 61 & 83 & 89 & 99 & 116 & 161 & 111 \\
\hline Rotación Activo Fijo & 0.22 & 0.23 & 0.36 & 0.45 & 0.38 & 0.37 & 0.42 & 0.37 & 0.44 & 0.58 \\
\hline Rotación Activo Total & 0.11 & 0.11 & 0.16 & 0.19 & 0.17 & 0.16 & 0.15 & 0.12 & 0.12 & 0.14 \\
\hline Ratios de Rentabilidad & 2008 & 2009 & 2010 & 2011 & 2012 & 2013 & 2014 & 2015 & 2016 & 2017 \\
\hline Margen Bruto & $26.79 \%$ & $46.88 \%$ & $57.42 \%$ & $42.80 \%$ & $34.73 \%$ & $37.86 \%$ & $39.44 \%$ & $28.41 \%$ & $38.99 \%$ & $46.01 \%$ \\
\hline Margen Operativo & $13.71 \%$ & $25.72 \%$ & $35.93 \%$ & $27.90 \%$ & $9.36 \%$ & $19.55 \%$ & $24.41 \%$ & $16.05 \%$ & $29.00 \%$ & $34.17 \%$ \\
\hline Margen Neto & $4.76 \%$ & $11.48 \%$ & $24.20 \%$ & $18.97 \%$ & $2.55 \%$ & $9.12 \%$ & $13.75 \%$ & $5.78 \%$ & $19.85 \%$ & $21.47 \%$ \\
\hline Rentabilidad respecto a Activo y Patrimonio & 2008 & 2009 & 2010 & 2011 & 2012 & 2013 & 2014 & 2015 & 2016 & 2017 \\
\hline ROA & $1.44 \%$ & $5.35 \%$ & $14.82 \%$ & $14.38 \%$ & $1.70 \%$ & $5.43 \%$ & $7.95 \%$ & $2.85 \%$ & $8.81 \%$ & $12.04 \%$ \\
\hline ROE & $3.34 \%$ & $9.37 \%$ & $23.15 \%$ & $28.24 \%$ & $3.54 \%$ & $11.66 \%$ & $16.05 \%$ & $5.54 \%$ & $19.44 \%$ & $20.11 \%$ \\
\hline Dupont ROA & $1.44 \%$ & $5.35 \%$ & $14.82 \%$ & $14.38 \%$ & $1.70 \%$ & $5.43 \%$ & $7.95 \%$ & $2.85 \%$ & $8.81 \%$ & $12.04 \%$ \\
\hline Dupont ROE & $3.34 \%$ & $9.37 \%$ & $23.15 \%$ & $28.24 \%$ & $3.54 \%$ & $11.66 \%$ & $16.05 \%$ & $5.54 \%$ & $19.44 \%$ & $20.11 \%$ \\
\hline Utilidad Neta\Ventas & $4.76 \%$ & $11.48 \%$ & $24.20 \%$ & $18.97 \%$ & $2.55 \%$ & $9.12 \%$ & $13.75 \%$ & $5.78 \%$ & $19.85 \%$ & $21.47 \%$ \\
\hline Ventas\Total Activo Promedio & $10.68 \%$ & $10.65 \%$ & $16.13 \%$ & $19.11 \%$ & $17.22 \%$ & $16.05 \%$ & $15.04 \%$ & $12.12 \%$ & $12.41 \%$ & $14.09 \%$ \\
\hline
\end{tabular}

Nota: Elaboración propia en base a información de los Estados Financieros de la empresa Milpo S.A.A.

En cuanto al análisis financiero pudimos obtener los indicadores financieros de creación de valor como el EVA, el ROIC y el capital invertido. Podemos observar que en el anális is realizado se obtuvo un EVA negativo en el 2015, en consecuencia ocasionó una reducción de valor en dicho año. Esta situación se presentó de manera aislada para efecto de anális is ya que debe entenderse la situación expansiva y de alta inversión en los proyectos Greenfield y Brownfield (es decir, de exploración en otras zonas) lo que ocasionó que el costo de ventas del 2016 fuera similar al del 2015. En vista de ello, es mejor analizar los EVAs en su conjunto (obtener los EVAs de los últimos años y traerlos a valor presente, a fin de determinar correctamente la creación o destrucción de valor de la compañía). 
Tabla 18. Ratios de Creación de Valor de Milpo S.A.A. (2012-2016).

\begin{tabular}{|c|c|c|c|c|c|}
\hline Ratios Financieros & $\mathbf{2 0 1 2}$ & $\mathbf{2 0 1 3}$ & $\mathbf{2 0 1 4}$ & $\mathbf{2 0 1 5}$ & $\mathbf{2 0 1 6}$ \\
\hline NOPAT & 132,024 & 146,238 & 168,592 & 73,819 & 175,286 \\
\hline Capital Invertido & 746,225 & 940,530 & $1,011,222$ & $1,004,429$ & $1,075,152$ \\
\hline ROIC & $17.92 \%$ & $17.34 \%$ & $17.28 \%$ & $7.32 \%$ & $16.86 \%$ \\
\hline WACC & $9.01 \%$ & $9.10 \%$ & $9.58 \%$ & $9.05 \%$ & $10.77 \%$ \\
\hline EVA & 66,537 & 77,529 & 77,848 & $-17,334$ & 65,408 \\
\hline
\end{tabular}

Nota: Elaboración Propia mediante información de los Estados Financieros proporcionados por Milpo S.A.A.- Se obtiene el EVA mediante la fórmula: ROIC - WACC * Capital Invertido; el Capital Invertido es: Activos Totales - Pasivos Espontáneos y el WACC es el Costo promedio ponderado de Capital que se determinó para periodos anteriores en $9.03 \%$. 


\subsection{Estimación del CAPM y WACC.}

Para la determinación de la tasa de descuento a fin de descontar los flujos de caja en la valorización de Milpo S.A.A, el modelo utilizado para poder estimar el costo de oportunidad del accionista (COK) fue el modelo CAPM. Se obtuvo un WACC de 9.03\% y un COK de $10.29 \%$, resultados obtenidos de la siguiente forma:

Tabla 19. Determinación del CAPM de Milpo S.A.A.

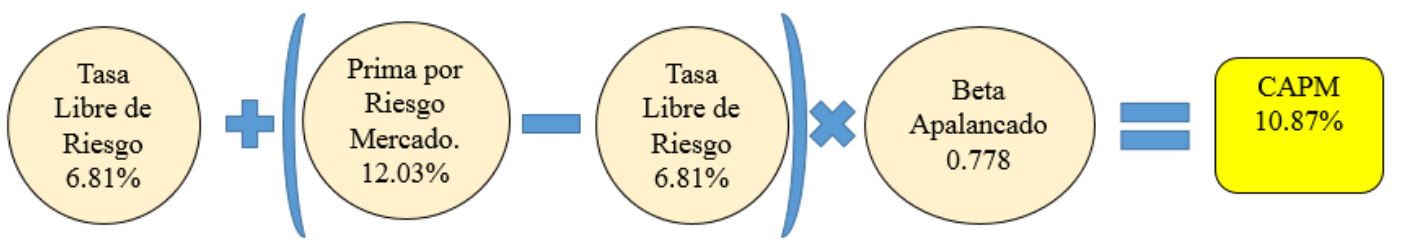

Nota: Elaboración propia

Tabla 20. Determinación del WACC de Milpo S.A.A.

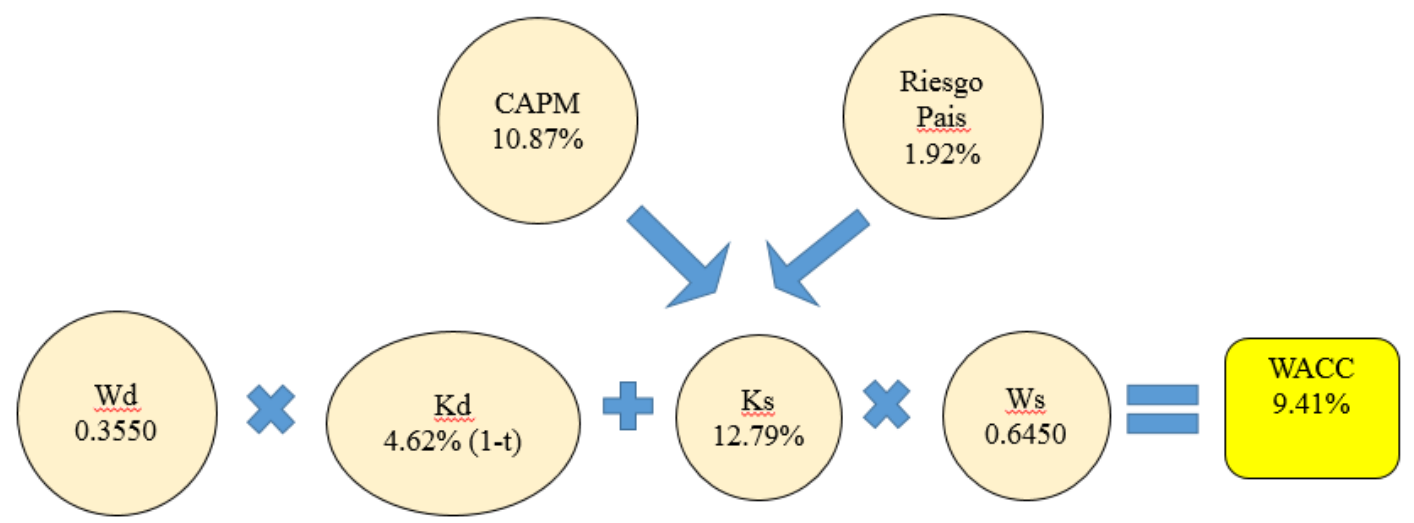

Nota: Elaboración propia

\subsection{Estimación de la Tasa Libre de Riesgo.}

La tasa libre riesgo es esencial para la determinación de la tasa de descuento, el porcentaje considerado fue de $6.81 \%$ y se determinó al escoger la rentabilidad que paga un T-bond en el periodo de 30 años promediando cada uno de los datos obtenidos a fin de suavizar la tendencia (información obtenida de Damodaran On Line - Annual Returns on Stock, T.Bonds and T.Bills : $1928-2017$ ) 
Tabla 21. Información de la Rentabilidad de los T-Bonds de los últimos 30 años. Adaptado de Información financiera del Dr. Aswath Damodaran en su web site:http://www.damodaran.com.

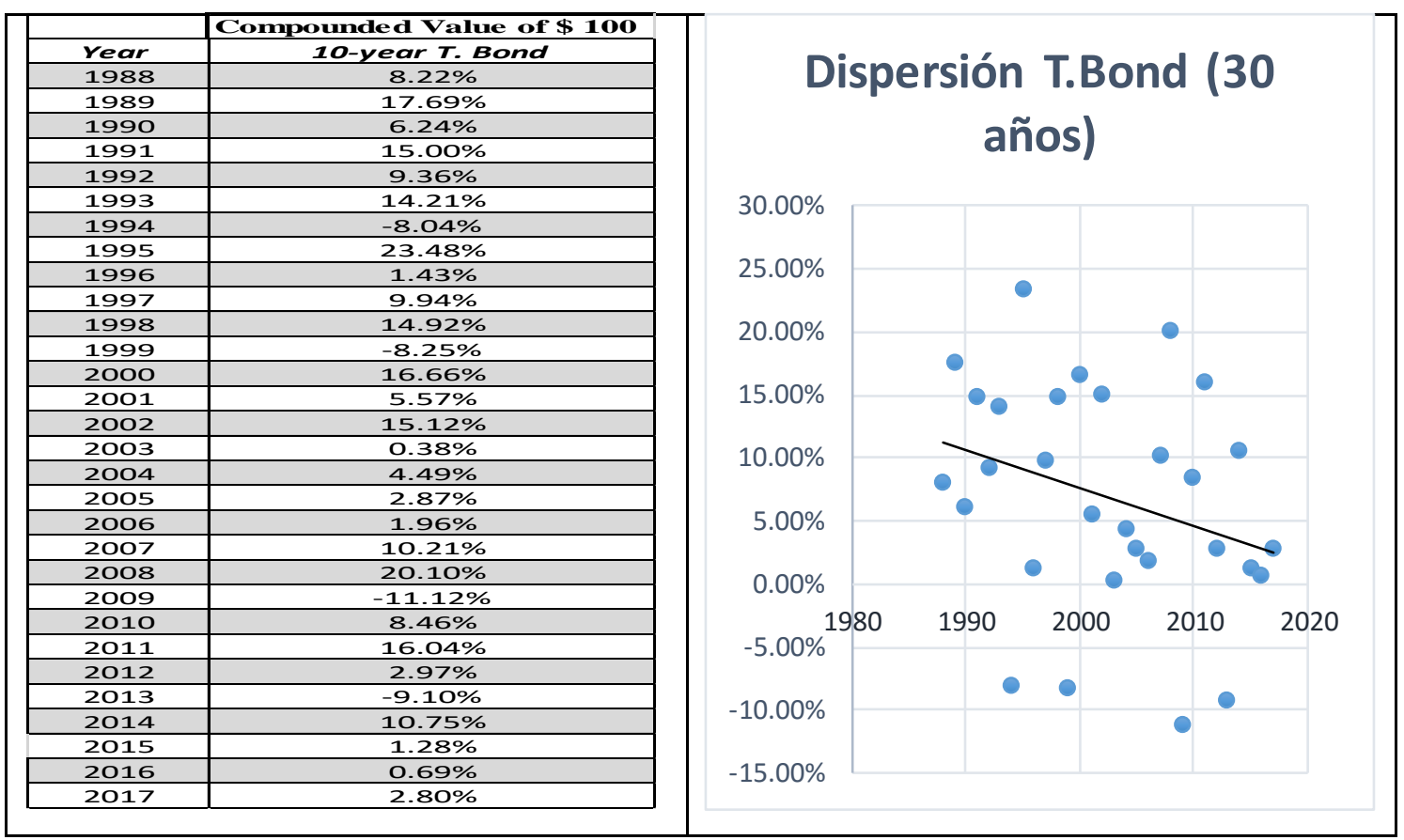

\subsection{Estimación de la Prima de Riesgo.}

Para la estimación de la Prima de riesgo de mercado, de acuerdo a la fórmula de CAPM, se determinó la tasa de $5.22 \%$ como resultado de la diferencia entre la prima de riesgo del mercado y la tasa libre de riesgo (T-Bond) explicada en el punto anterior.

Para el caso de la prima de riesgo del mercado se determinó de acuerdo a lo siguiente : 
Tabla 22. Determinación de la prima de riesgo de mercado. Adaptada de la Información financiera del Dr. Aswath Damodaran en su web site:http://www.damodaran.com.

\begin{tabular}{|c|c|}
\hline & Annual Returns on Investments in \\
\hline Year & S\&P 500 \\
\hline 1988 & $16.54 \%$ \\
\hline 1989 & $31.48 \%$ \\
\hline 1990 & $-3.06 \%$ \\
\hline 1991 & $30.23 \%$ \\
\hline 1992 & $7.49 \%$ \\
\hline 1993 & $9.97 \%$ \\
\hline 1994 & $1.33 \%$ \\
\hline 1995 & $37.20 \%$ \\
\hline 1996 & $22.68 \%$ \\
\hline 1997 & $33.10 \%$ \\
\hline 1998 & $28.34 \%$ \\
\hline 1999 & $20.89 \%$ \\
\hline 2000 & $-9.03 \%$ \\
\hline 2001 & $-11.85 \%$ \\
\hline 2002 & $-21.97 \%$ \\
\hline 2003 & $28.36 \%$ \\
\hline 2004 & $10.74 \%$ \\
\hline 2005 & $4.83 \%$ \\
\hline 2006 & $15.61 \%$ \\
\hline 2007 & $5.48 \%$ \\
\hline 2008 & $-36.55 \%$ \\
\hline 2009 & $25.94 \%$ \\
\hline 2010 & $14.82 \%$ \\
\hline 2011 & $2.10 \%$ \\
\hline 2012 & $15.89 \%$ \\
\hline 2013 & $32.15 \%$ \\
\hline 2014 & $13.52 \%$ \\
\hline 2015 & $1.38 \%$ \\
\hline 2016 & $11.77 \%$ \\
\hline 2017 & $21.64 \%$ \\
\hline
\end{tabular}

Con esta información se determinó la prima de riesgo según el rendimiento Aritmético de los T-Bonds de los últimos 30 años:

Tabla 23. Datos finales de la prima de riesgo de mercado y la tasa libre de riesgo.

\begin{tabular}{|c|c|c|}
\hline Year & Stocks & T.Bonds \\
\hline $1988-2017$ & $12.03 \%$ & $6.81 \%$ \\
\hline
\end{tabular}

Nota: Elaboración propia 


\subsection{Estimación del Beta.}

Se determinó el beta de la empresa Milpo S.A.A. en $\mathbf{0 . 7 7 8}$ accediendo a información brindada por Bloomberg (beta ajustado).

Tabla 24. Determinación del Beta desapalancado de la Empresa Milpo SAA.

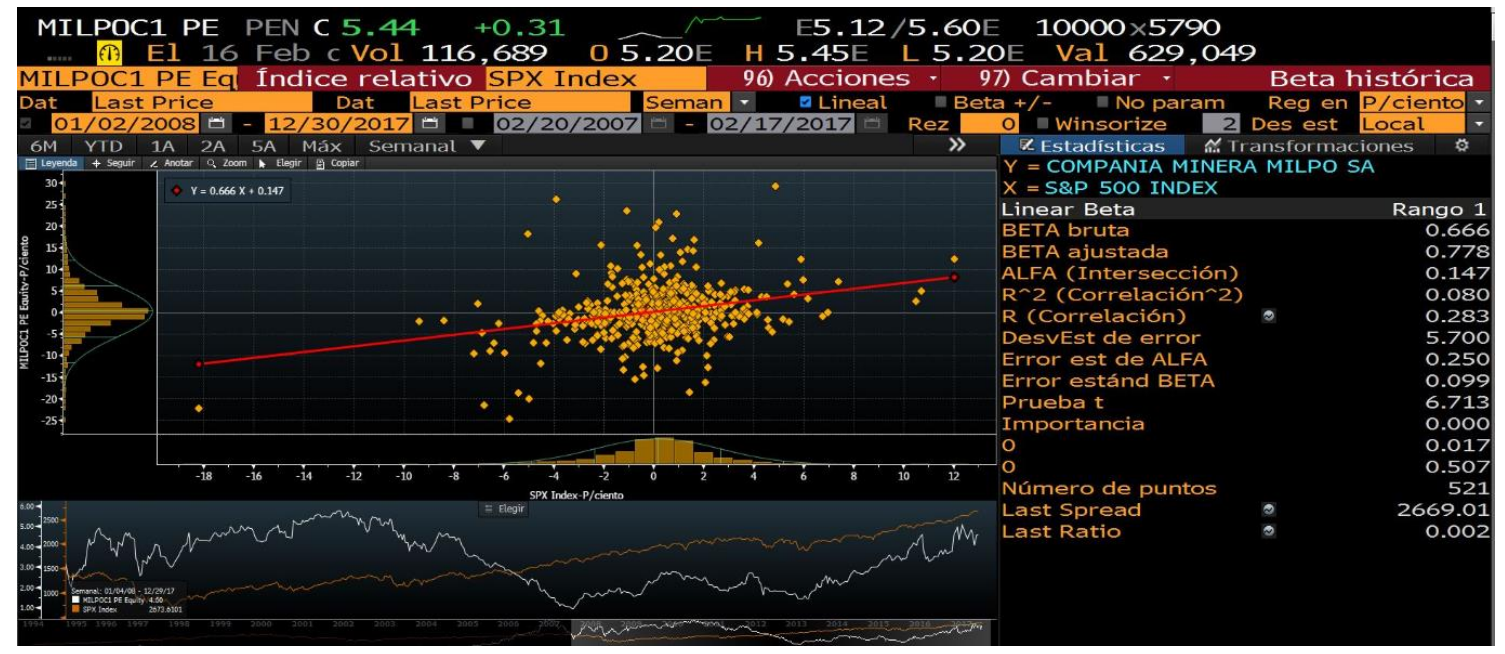

Nota: Información financiera obtenida de Bloomberg.

\subsection{Estimación del Riesgo País.}

El riesgo país determinado para la estimación de la tasa de descuento es de $1.92 \%$, riesgo país obtenido del promedio de 120 meses (10 años) del Spread EMBIG Perú PBS elaborado por el BCRP (período 2008-2017). 
Tabla 25. Determinación del Riesgo País (Perú).

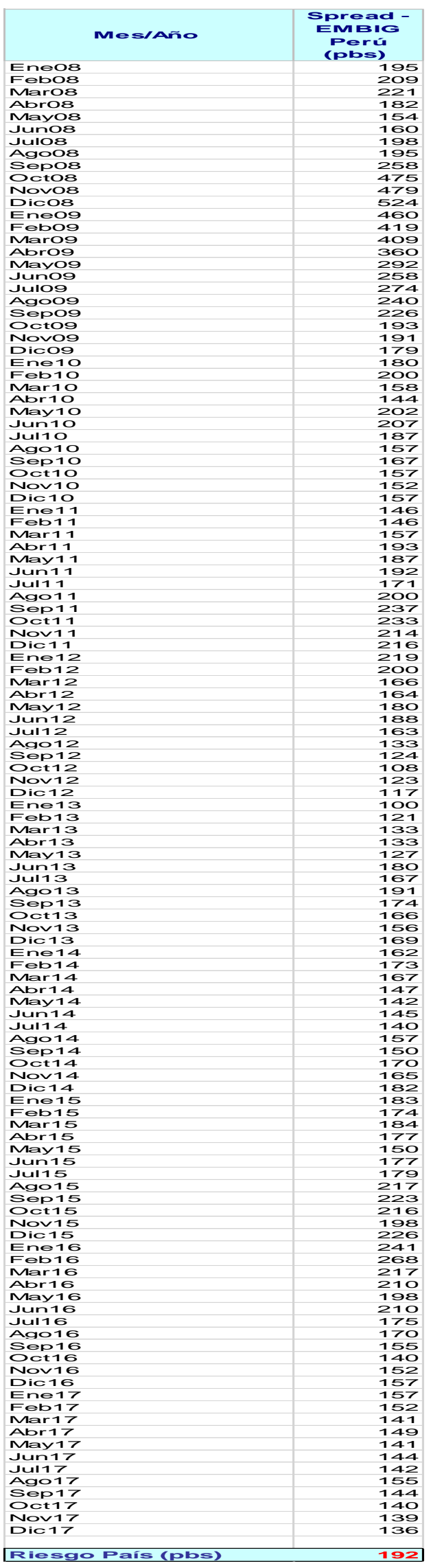

Nota: Información financiera obtenida de Banco Central de Reserva del Perú 


\subsection{Estimación del COK.}

Al analizar y proyectar Estados financieros de Milpo S.A.A. que se encuentran en Moneda Extranjera el efecto de obtener el COK Se tomó en cuenta principalmente la colocación total de los bonos internacionales corporativos por USD 346 millones en el mercado de capitales internacional a una tasa de $4.625 \%$ al valor cierre 2017.

Para el cálculo final del CAPM (kd) se consideró los siguientes valores:

\begin{tabular}{|c|c|}
\hline Total Deuda (miles de USD) & 345,485 \\
\hline Patrimonio Neto (miles de USD) & 627,638 \\
\hline
\end{tabular}

El Cok obtenido es de $10.29 \%$ a aplicar la fórmula: $\mathrm{COK}=\mathrm{r}_{\mathrm{f}}+\beta^{*}\left(\mathrm{r}_{\mathrm{m}}-\mathrm{r}_{\mathrm{f}}\right)$ (modelo CAPM) 


\section{Capítulo 5. Valorización.}

\subsection{Supuestos y sustentos para las proyecciones.}

\subsubsection{Proyección de las Ventas.}

Para el caso de la estimación de las ventas, se trabajó sobre 03 factores: el precio de los metales, la producción estimada y un factor de ajuste.

Para el caso de los precios de los metales, se consideró como base la proyección estimada de los precios de los commodities del Banco Mundial, con una proyección de 10 años para la presente valoración.

Tabla 26. Proyección de los Precios de los Commodities período 2018-2027.

\begin{tabular}{|c|c|c|c|c|c|c|c|c|c|c|c|}
\hline & & \multicolumn{10}{|c|}{ Proyección } \\
\hline Commodity & Unit & 2018 & 2019 & 2020 & 2021 & 2022 & 2023 & 2024 & 2025 & 2026 & 2027 \\
\hline \multicolumn{12}{|c|}{ Metals and Minerals } \\
\hline Copper & $\$ / \mathrm{mt}$ & 6,118 & 6,187 & 6,257 & 6,328 & 6,399 & 6,471 & 6,571 & 7,000 & \begin{tabular}{|l|}
6,921 \\
\end{tabular} & 6,916 \\
\hline Lead & $\$ / \mathrm{mt}$ & 2,500 & 2,483 & 2,465 & 2,448 & 2,431 & 2,415 & 2,415 & 2,415 & \begin{tabular}{l|}
2,405 \\
\end{tabular} & 2,381 \\
\hline Zinc & $\$ / \mathrm{mt}$ & 3,000 & 2,945 & 2,890 & 2,837 & 2,785 & 2,734 & 2,734 & 2,734 & 2,714 & 2,449 \\
\hline
\end{tabular}

Nota: Elaboración propia en base a Información proporcionada por el Banco Mundial

Para el caso de las proyecciones de producción, asumimos que en el horizonte de valoración las unidades mantienen sus actuales capacidades de producción, leyes vigentes sobre el mineral tratado, así como los actuales niveles de recuperación. La producción considerada para su venta se tomó como referencia la producción de los últimos 10 años y se asume constante. Así mismo, al verificar variaciones fuertes en los diferentes años de producción, se estableció considerar una media móvil a fin de suavizar las tendencias.

Por último, para el factor de ajuste se consideró como base los porcentajes aplicados para establecer tanto las leyes de cada metal, así como el porcentaje de recuperación de los mismos. Se determinó un valor de ajuste debido a que ésta no es información pública de la Compañía. 


\subsubsection{Proyección del Costo de Ventas.}

Para el caso de los costos de ventas operativamente la Compañía los ha ido disminuye ndo. Tal es así que en los últimos años se generaron proyectos para optimizar recursos como la integración operativa de las UM Atacocha y El Porvenir, el cual implica una optimización de los servicios y tarifas, reducción de los gastos de personal y planes energéticos, implementándose algunas de esta medidas a partir del año 2017. Y a partir de este año se asume constante los costos para los siguientes años.

Tabla 27. Proyección del Costo de Ventas período 2018-2027.

\begin{tabular}{|c|c|c|c|c|c|c|c|c|c|c|c|c|c|}
\hline Costo de Ventas (en miles de USD) & 2015 & 2016 & 2017 & 2018 & 2019 & 2020 & 2021 & 2022 & 2023 & 2024 & 2025 & 2026 & 2027 \\
\hline Saldo Inicial de Concentrados & 1,526 & 744 & 3,258 & 5,168 & 5,353 & 5,328 & 5,302 & 5,277 & 5,253 & 5,229 & 5,256 & 5,370 & 5,329 \\
\hline \multirow[t]{2}{*}{ Saldo Inicial de Productos en proceso } & 509 & 559 & 1,321 & 1,351 & 3,361 & 3,345 & 3,329 & 3,314 & 3,298 & 3,283 & 3,300 & 3,372 & 3,346 \\
\hline & 2,035 & 1,303 & 4,579 & 6,519 & 8,714 & 8,673 & 8,631 & 8,591 & 8,551 & 8,512 & 8,556 & 8,742 & 8,676 \\
\hline \multicolumn{14}{|l|}{ Costo de Producción } \\
\hline Repuestos y suministros diversos utilizados & 93,921 & 86,198 & 103,301 & 106,422 & 106,006 & 105,569 & 105,156 & 104,739 & 104,336 & 104,790 & 106,720 & 106,036 & 102,795 \\
\hline Gastos de Personal & 53,756 & 62,908 & 75,777 & 78,066 & 77,761 & 77,441 & 77,137 & 76,832 & 76,536 & 76,870 & 78,285 & 77,783 & 75,406 \\
\hline Sertvicios Prestados por contratistas mineros & 215,802 & 217,939 & 242,828 & 260,722 & 252,707 & 247,382 & 242,116 & 236,555 & 230,815 & 227,888 & 230,382 & 222,826 & 251,244 \\
\hline \multirow[t]{2}{*}{ Depreciación y Amortización } & 83,607 & 72,257 & 72,308 & 66,833 & 70,980 & 74,589 & 78,236 & 82,164 & 86,329 & 91,116 & 96,313 & 100,927 & 39,546 \\
\hline & 447,086 & 439,302 & 494,214 & 512,043 & 507,454 & 504,981 & 502,645 & 500,289 & 498,016 & 500,664 & 511,701 & 507,571 & 468,991 \\
\hline (-)Saldo Final de Concentrados & -744 & $-3,258$ & $-5,168$ & $-5,353$ & $-5,328$ & $-5,302$ & $-5,277$ & $-5,253$ & $-5,229$ & $-5,256$ & $-5,370$ & $-5,329$ & $-5,137$ \\
\hline \multirow[t]{2}{*}{ (-)Saldo Final de Productos en Proceso } & -559 & $-1,321$ & $-1,351$ & $-3,361$ & $-3,345$ & $-3,329$ & $-3,314$ & $-3,298$ & $-3,283$ & $-3,300$ & $-3,372$ & $-3,346$ & $-3,226$ \\
\hline & 447,818 & 436,026 & 492,274 & 509,849 & 507,495 & 505,023 & 502,685 & 500,330 & 498,055 & 500,620 & 511,515 & 507,637 & 469,304 \\
\hline
\end{tabular}

Nota: Elaboración propia en base a información real de los Estados Financieros de Milpo SAA

\subsubsection{Valor Terminal.}

El Valor Terminal incluye las provisiones por cierre de mina y pasivos ambientales. Para la determinación del valor terminal se parte del supuesto que, debido a los constantes trabajos de exploración de nuevos recursos, el tiempo de vida de las minas tenderá a mantenerse. Razón por la cual la Empresa mantendrá un principio de continuidad en el futuro. Hemos asumido un $\mathrm{G}=2.40 \%$, el cual es un valor conservador, tomando en consideración que la variación porcentual del PBI minero según estadísticas publicadas por el BCR en el período 1980-2017 fue de $2.52 \%$.

\subsubsection{Producción.}

No existe información oficial concreta relacionada a planes de ampliación de su actual capacidad de producción, por lo que las actuales unidades mineras se han asumido que mantendrán sus actuales capacidades y reservas existentes. 
La vida de cada unidad minera se calcula según a la capacidad de producción y el tiempo que se dedicaría en explotar las reservas y recursos existentes. Además, los niveles de producción se verán afectados conforme llega al fin de su vida útil. En función a ello, las tres Unidades Mineras tendrán una vida útil en un tiempo mayor al período de proyección, el mismo que detallamos líneas arriba.

Tabla 28. Proyección de la Producción de Metales período 2018-2027 de Milpo SAA.

\begin{tabular}{|l|r|r|r|r|r|r|r|r|r|r|r|}
\hline \multirow{2}{*}{ Concentrado } & \multicolumn{10}{|c|}{ Producción Provectada } \\
\cline { 2 - 14 } & \multicolumn{1}{|c|}{2018} & \multicolumn{1}{c|}{2019} & \multicolumn{1}{c|}{2020} & \multicolumn{1}{c|}{2021} & \multicolumn{1}{c|}{2022} & \multicolumn{1}{c|}{2023} & \multicolumn{1}{c|}{2024} & \multicolumn{1}{c|}{2025} & \multicolumn{1}{c|}{2026} & \multicolumn{1}{c|}{2027} \\
\hline Zinc & miles de Tms & 226.92 & 222.76 & 218.60 & 214.59 & 210.66 & 206.80 & 206.80 & 206.80 & 205.29 & 185.24 \\
\hline Cobre & miles de Tms & 43.82 & 44.31 & 44.81 & 45.32 & 45.83 & 46.34 & 47.06 & 50.13 & 49.57 & 49.53 \\
\hline Plomo & miles de Tms & 49.22 & 48.88 & 48.53 & 48.19 & 47.86 & 47.54 & 47.54 & 47.54 & 47.35 & 46.87 \\
\hline
\end{tabular}

Nota: Proyección expresados en TMS (toneladas métricas secas).

\subsubsection{Cierre de Mina y Pasivos Ambientales}

De acuerdo a lo que indica en los Estados Financieros auditados, la empresa ha implementado en el flujo de caja plan de cierre de minas y la constitución de garantías ambientales, de acuerdo a las provisiones reveladas en los EEFF de la compañía. Para efectos de ser considerado en el Flujo de Caja Descontado, este rubro forma parte de la proyección del CAPEX a 10 años.

\subsection{Estimación de los Gastos Administrativos y de Ventas.}

Para la estimación de los costos y gastos de la empresa se analizó el comportamiento histórico de cada partida, tomando en cuenta los rubros generales obtenidos de los Estados Financieros Auditados de la Empresa. Con ello se pudo obtener información detallada para así estimar el driver correcto que se aplicará en la proyección de cada Gasto.

En el caso de los gastos administrativos se comparó el gasto sobre la venta proyectada del año, ajustándolo con el promedio histórico de los últimos 10 años para así suavizar la variabilidad. El mismo tratamiento se consideró para el caso de los gastos de ventas.

\subsubsection{Estimación de los Gastos Administrativos.}

Tabla 29. Proyección de los Gastos Administrativos período 2018-2027 de Milpo SAA. 


\begin{tabular}{|c|c|c|c|c|c|c|c|c|c|c|}
\hline Gastos de Administración (en miles de USD) & 2018 & 2019 & 2020 & 2021 & 2022 & 2023 & 2024 & 2025 & 2026 & 2027 \\
\hline Gastos de Personal & $6,612.55$ & $6,288.70$ & $6,220.69$ & $6,159.10$ & $6,097.10$ & $6,038.18$ & $6,120.81$ & $6,325.75$ & $6,094.57$ & $5,546.85$ \\
\hline Servicios Prestados por Terce & $9,285.55$ & $8,830.79$ & $8,735.29$ & $8,648.81$ & $8,561.73$ & $8,479.00$ & $8,595.03$ & $8,882.82$ & $8,558.19$ & $7,789.06$ \\
\hline Remuneraciones al Directorio & $3,603.58$ & $3,427.10$ & $3,390.03$ & $3,356.47$ & $3,322.68$ & $3,290.57$ & $3,335.60$ & $3,447.29$ & $3,321.30$ & $3,022.82$ \\
\hline \begin{tabular}{|l|} 
Diversos \\
\end{tabular} & 127.94 & 121.68 & 120.36 & 119.17 & 117.97 & 116.83 & 118.43 & 122.39 & 117.92 & 107.32 \\
\hline & $19,629.62$ & $18,668.27$ & $18,466.38$ & $18,283.55$ & $18,099.48$ & $17,924.58$ & $18,169.87$ & $18,778.24$ & $18,091.98$ & $16,466.04$ \\
\hline
\end{tabular}

Nota: Elaboración propia en base a información real de los Estados Financieros de Milpo SAA.

\subsubsection{Estimación de los Gastos de Ventas.}

Tabla 30. Proyección de los Gastos de Ventas período 2018-2027 de Milpo SAA.

\begin{tabular}{|l|r|r|r|r|r|r|r|r|r|r|}
\hline Gastos de Ventas (en miles de USD) & \multicolumn{1}{c|}{2018} & \multicolumn{1}{c|}{2019} & \multicolumn{1}{c|}{2020} & \multicolumn{1}{c|}{2021} & \multicolumn{1}{c|}{2022} & \multicolumn{1}{c}{2023} & \multicolumn{1}{c}{2024} & \multicolumn{1}{c|}{2025} & \multicolumn{1}{c}{2026} & \multicolumn{1}{c}{2027} \\
\hline Transporte y Almacenamiento & $16,492.71$ & $15,684.99$ & $15,515.36$ & $15,361.75$ & $15,207.09$ & $15,060.14$ & $15,266.23$ & $15,777.39$ & $15,200.80$ & $13,834.69$ \\
\hline Servicios de Laboratorio y Anál. De Conc. & 522.82 & 497.21 & 491.84 & 486.97 & 482.06 & 477.41 & 483.94 & 500.14 & 481.86 & 438.56 \\
\hline & $17,015.53$ & $16,182.20$ & $16,007.20$ & $15,848.72$ & $15,689.16$ & $15,537.55$ & $15,750.17$ & $16,277.53$ & $15,682.66$ & $14,273.25$ \\
\hline
\end{tabular}

Nota: Elaboración propia en base a información real de los Estados Financieros de Milpo SAA.

\subsubsection{Estimación del Capex.}

El Capex para efectos de la valorización se consideró información de los movimientos de activos fijos contenidos en los informes auditados de la empresa Milpo SA, la misma que mostró variabilidad sobre todo en equipos diversos, el cual está correlacionado con la coyuntura en el precio de los metales. Para nuestro objetivo se procedió a usar el CAPEX promedio de las variaciones de los 10 años anteriores a la valorización. Este promedio expresado en porcentaje, se procedió con la estimación de las inversiones en activos fijos necesarios para la continuidad y crecimiento del negocio. No se obtuvo una proyección de parte de la compañía en este rubro, por al razón tomamos el valor más conservador posible.

Tabla 31. Proyección de las Inversiones en Activos Fijos (Capex) período 2018-2027 de Milpo SAA.

\begin{tabular}{|c|c|c|c|c|c|c|c|c|c|c|}
\hline $\begin{array}{l}\text { INVERSIONES CAPEX } \\
\text { en miles de USD\$ }\end{array}$ & 2018 & 2019 & 2020 & 2021 & 2022 & 2023 & 2024 & 2025 & 2026 & 2027 \\
\hline TERRENOS & 95.82 & 64.97 & 68.83 & 68.49 & 68.16 & 35.64 & 33.96 & 32.36 & 31.84 & 31.33 \\
\hline EDIFICIOS & $6,403.46$ & $5,700.06$ & $5,672.93$ & $5,639.41$ & $3,377.58$ & $3,361.28$ & $3,361.28$ & $3,704.77$ & $4,299.85$ & $4,990.50$ \\
\hline MAQUINARIA Y EQUIPO & $8,479.63$ & $8,088.56$ & $8,457.25$ & $7,066.53$ & $7,094.11$ & $7,529.08$ & $8,427.74$ & $8,137.66$ & $8,306.63$ & $8,479.12$ \\
\hline MUEBLES Y ENSERES & 77.72 & 66.99 & 37.79 & 49.79 & 4.90 & 4.48 & 4.48 & 16.93 & 19.17 & 21.70 \\
\hline UNIDAD DE TRANSPORTE & 141.02 & 7.69 & 8.05 & 5.58 & 6.62 & 6.46 & 6.69 & 5.22 & 3.60 & 2.48 \\
\hline OBRAS EN CURSO & $1,780.80$ & 912.19 & $1,403.98$ & $2,001.33$ & $2,742.98$ & $1,264.69$ & $1,067.67$ & $1,684.21$ & $1,008.01$ & 603.29 \\
\hline EQUIPOS DE COMPUTO & 33.00 & 32.76 & 33.28 & 39.49 & 19.23 & 17.34 & 15.79 & 14.96 & 11.00 & 8.09 \\
\hline EQUIPOS DIVERSOS & $20,907.51$ & $24,334.14$ & $25,789.32$ & $29,714.00$ & $33,791.23$ & $43,889.50$ & $48,326.06$ & $49,513.01$ & $52,492.03$ & $55,650.29$ \\
\hline \multirow[t]{2}{*}{ CIERRE DE MINA } & $2,612.64$ & $3,355.79$ & $5,138.34$ & $5,377.49$ & $7,833.91$ & $7,326.08$ & $7,455.37$ & $7,563.11$ & $7,401.79$ & $7,243.91$ \\
\hline & $40,531.61$ & $42,563.16$ & $46,609.76$ & $49,962.11$ & $54,938.71$ & $63,434.56$ & $68,699.04$ & $70,672.25$ & $73,573.92$ & $77,030.71$ \\
\hline
\end{tabular}


Nota: Elaboración Propia en base a las inversiones de Milpo SAA. Para efectos de la proyección del flujo de caja descontado, se consideró el promedio de los 10 años, el cual arroja el importe de miles de US 52,583 .

\subsubsection{Proyección de los Estados Financieros.}

Con las proyecciones de ingresos, costos, gastos, depreciación, amortización y Capex procedimos a proyectar las Estados Financieros de la empresa relacionados entre sí, de tal forma que los Estados Financieros mantenan los efectos de las variaciones entre si y cada resultado o movimiento en las cuentas contables afecte al flujo de efectivo y por tanto al Estado de Situación financiera. Con ello se busca estimar las necesidades de financiamiento y disposición de efectivo. No estamos considerando proyecciones ni reservas en etapas de exploración, únicamente en las 03 UM mencionadas. Tamién hemos incidido en la proyeccion en producción, costos y ventas de los 03 metales más importantes que produce Milpo SAA, como son el zinc, plomo y cobre.

\subsubsection{Proyección del Estado de Resultados}

Tabla 32. Proyección del Estado de Resultados Anual período 2018- 2027 de Milpo SAA.

\begin{tabular}{|l|r|r|r|r|r|r|r|r|r|r|r|r|r|}
\hline (millones de USD\$) & $\mathbf{2 0 1 5}$ & $\mathbf{2 0 1 6}$ & $\mathbf{2 0 1 7}$ & $\mathbf{2 0 1 8}$ & $\mathbf{2 0 1 9}$ & $\mathbf{2 0 2 0}$ & $\mathbf{2 0 2 1}$ & $\mathbf{2 0 2 2}$ & $\mathbf{2 0 2 3}$ & $\mathbf{2 0 2 4}$ & $\mathbf{2 0 2 5}$ & $\mathbf{2 0 2 6}$ & $\mathbf{2 0 2 7}$ \\
\hline Ventas & 625.56 & 714.70 & 911.75 & 972.41 & 924.79 & 914.79 & 905.73 & 896.61 & 887.95 & 900.10 & 930.24 & 896.24 & 835.27 \\
\hline Costo de Ventas & -447.82 & -436.02 & -492.27 & -509.85 & -507.49 & -505.02 & -502.68 & -500.33 & -498.05 & -500.62 & -511.52 & -507.64 & -469.30 \\
\hline Margen Bruto & $\mathbf{1 7 7 . 7 4}$ & $\mathbf{2 7 8 . 6 7}$ & $\mathbf{4 1 9 . 4 7}$ & $\mathbf{4 6 2 . 5 6}$ & $\mathbf{4 1 7 . 2 9}$ & $\mathbf{4 0 9 . 7 6}$ & $\mathbf{4 0 3 . 0 4}$ & $\mathbf{3 9 6 . 2 8}$ & $\mathbf{3 8 9 . 8 9}$ & $\mathbf{3 9 9 . 4 8}$ & $\mathbf{4 1 8 . 7 2}$ & $\mathbf{3 8 8 . 6 0}$ & $\mathbf{3 6 5 . 9 7}$ \\
\hline Gasto Adm y Ventas & -50.83 & -50.22 & -86.38 & -80.49 & -76.55 & -75.72 & -74.97 & -74.22 & -73.50 & -74.50 & -77.00 & -74.18 & -67.52 \\
\hline otros Ingresos/Gastos & -26.51 & -21.21 & -21.59 & -18.37 & -26.39 & -23.14 & -20.86 & -22.90 & -21.00 & -17.88 & -15.90 & -13.36 & -13.36 \\
\hline EBIT & $\mathbf{1 0 0 . 4 1}$ & $\mathbf{2 0 7 . 2 4}$ & $\mathbf{3 1 1 . 5 1}$ & $\mathbf{3 6 3 . 7 0}$ & $\mathbf{3 1 4 . 3 5}$ & $\mathbf{3 1 0 . 9 1}$ & $\mathbf{3 0 7 . 2 1}$ & $\mathbf{2 9 9 . 1 6}$ & $\mathbf{2 9 5 . 3 9}$ & $\mathbf{3 0 7 . 0 9}$ & $\mathbf{3 2 5 . 8 2}$ & $\mathbf{3 0 1 . 0 5}$ & $\mathbf{2 8 5 . 0 8}$ \\
\hline Ingresos Financieros & 3.50 & 4.57 & 2.33 & 2.34 & 2.55 & 2.86 & 1.92 & 2.00 & 2.05 & 2.11 & 2.73 & 2.30 & 2.30 \\
\hline Gastos Finacieros & -19.77 & -22.25 & -19.52 & -18.32 & -19.52 & -17.79 & -9.34 & -8.89 & -11.66 & -10.58 & -14.25 & -14.29 & -14.29 \\
\hline EBT & $\mathbf{8 4 . 1 4}$ & $\mathbf{1 8 9 . 5 6}$ & $\mathbf{2 9 4 . 3 2}$ & $\mathbf{3 4 7 . 7 3}$ & $\mathbf{2 9 7 . 3 9}$ & $\mathbf{2 9 5 . 9 8}$ & $\mathbf{2 9 9 . 8 0}$ & $\mathbf{2 9 2 . 2 7}$ & $\mathbf{2 8 5 . 7 8}$ & $\mathbf{2 9 8 . 6 2}$ & $\mathbf{3 1 4 . 3 0}$ & $\mathbf{2 8 9 . 0 7}$ & $\mathbf{2 7 3 . 1 0}$ \\
\hline Impuestos & -47.97 & -47.70 & -98.60 & -116.49 & -99.63 & -99.15 & -100.43 & -97.91 & -95.74 & -100.04 & -105.29 & -96.84 & -91.49 \\
\hline Utilidad Neta & $\mathbf{3 6 . 1 7}$ & $\mathbf{1 4 1 . 8 6}$ & $\mathbf{1 9 5 . 7 2}$ & $\mathbf{2 3 1 . 2 4}$ & $\mathbf{1 9 7 . 7 6}$ & $\mathbf{1 9 6 . 8 2}$ & $\mathbf{1 9 9 . 3 7}$ & $\mathbf{1 9 4 . 3 6}$ & $\mathbf{1 9 0 . 0 4}$ & $\mathbf{1 9 8 . 5 8}$ & $\mathbf{2 0 9 . 0 1}$ & $\mathbf{1 9 2 . 2 3}$ & $\mathbf{1 8 1 . 6 1}$ \\
\hline
\end{tabular}

Nota: Elaboración Propia con Información financiera de la empresa. 


\subsubsection{Indicadores Financieros obtenidos luego de la proyección}

Tabla 33. Indicadores Financieros Proyectados período 2018- 2027 de Milpo SAA.

\begin{tabular}{|c|c|c|c|c|c|c|c|c|c|c|}
\hline Liquidez & 2018 & 2019 & 2020 & 2021 & 2022 & 2023 & 2024 & 2025 & 2026 & 2027 \\
\hline Activo Corriente & 4.85 & 3.94 & 3.90 & 2.89 & 2.86 & 2.92 & 2.76 & 2.07 & 2.64 & 2.41 \\
\hline Prueba Acida & 4.61 & 3.74 & 3.70 & 2.76 & 2.72 & 2.76 & 2.61 & 1.97 & 2.47 & 2.26 \\
\hline Capital de trabajo & 712500 & 655674 & 630354 & 607445 & 575155 & 542320 & 521060 & 499531 & 449308 & 403700 \\
\hline Fondo de maniobra con Activo Total (Capital de Trabajo/Activo Total) & 0.44 & 0.40 & 0.38 & 0.35 & 0.33 & 0.32 & 0.30 & 0.26 & 0.26 & 0.23 \\
\hline Prueba de Tesorería & 4.00 & 3.21 & 3.13 & 2.36 & 2.29 & 2.27 & 2.13 & 1.65 & 1.90 & 1.68 \\
\hline Ratios de Solvencia o Apalancamiento & 2018 & 2019 & 2020 & 2021 & 2022 & 2023 & 2024 & 2025 & 2026 & 2027 \\
\hline Apalancamiento Financiero (Total Activo/Total Patrimonio) & 1.62 & 1.68 & 1.68 & 1.79 & 1.79 & 1.77 & 1.78 & 1.95 & 1.77 & 1.80 \\
\hline Endeudamiento Total (Total Pasivo/Total Activo) & 0.38 & 0.41 & 0.41 & 0.44 & 0.44 & 0.43 & 0.44 & 0.49 & 0.44 & 0.44 \\
\hline Endeudamiento Activo Fijo (Total Pasivo No Corriente/Activo Fijo) & 1.09 & 1.05 & 1.01 & 0.98 & 0.95 & 0.92 & 0.89 & 0.86 & 0.83 & 0.81 \\
\hline Endeudamiento Patrimonial (Total Pasivo/Total Patrimonio) & 0.62 & 0.68 & 0.68 & 0.79 & 0.79 & 0.77 & 0.78 & 0.95 & 0.77 & 0.80 \\
\hline Cobertura de Gastos Financieros (Ganancia Act. Operación/Gtos. Financ.) & 19.86 & 16.11 & 17.48 & 32.91 & 33.66 & 25.33 & 29.02 & 22.86 & 21.07 & 19.96 \\
\hline Ratios de Gestión & 2018 & 2019 & 2020 & 2021 & 2022 & 2023 & 2024 & 2025 & 2026 & 2027 \\
\hline Período medio de Cobranzas & 29 & 32 & 33 & 35 & 37 & 39 & 40 & 40 & 44 & 50 \\
\hline Período medio de Inmovilización de Exist & 31 & 32 & 32 & 32 & 32 & 32 & 32 & 31 & 32 & 34 \\
\hline Período medio de pago & 111 & 116 & 122 & 127 & 134 & 140 & 146 & 150 & 159 & 88 \\
\hline Rotación Activo Fijo & 0.61 & 0.56 & 0.53 & 0.50 & 0.47 & 0.45 & 0.44 & 0.43 & 0.40 & 0.35 \\
\hline Rotación Activo Total & 0.15 & 0.14 & 0.14 & 0.13 & 0.13 & 0.13 & 0.13 & 0.13 & 0.12 & 0.12 \\
\hline Ratios de Rentabilidad & 2018 & 2019 & 2020 & 2021 & 2022 & 2023 & 2024 & 2025 & 2026 & 2027 \\
\hline Margen Bruto & $47.57 \%$ & $45.12 \%$ & $44.79 \%$ & $44.50 \%$ & $44.20 \%$ & $43.91 \%$ & $44.38 \%$ & $45.01 \%$ & $43.36 \%$ & $43.81 \%$ \\
\hline Margen Operativo & $37.40 \%$ & $33.99 \%$ & $33.99 \%$ & $33.92 \%$ & $33.37 \%$ & $33.27 \%$ & $34.12 \%$ & $35.03 \%$ & $33.59 \%$ & $34.13 \%$ \\
\hline Margen Neto & $23.78 \%$ & $21.38 \%$ & $21.52 \%$ & $22.01 \%$ & $21.68 \%$ & $21.40 \%$ & $22.06 \%$ & $22.47 \%$ & $21.45 \%$ & $21.74 \%$ \\
\hline Rentabilidad respecto a Activo y Patrimonio & 2018 & 2019 & 2020 & 2021 & 2022 & 2023 & 2024 & 2025 & 2026 & 2027 \\
\hline ROA & $14.14 \%$ & $12.03 \%$ & $11.98 \%$ & $11.37 \%$ & $11.15 \%$ & $11.06 \%$ & $11.37 \%$ & $10.79 \%$ & $11.08 \%$ & $10.41 \%$ \\
\hline ROE & $22.91 \%$ & $20.25 \%$ & $20.15 \%$ & $20.34 \%$ & $19.91 \%$ & $19.54 \%$ & $20.21 \%$ & $21.02 \%$ & $19.64 \%$ & $18.73 \%$ \\
\hline Dupont ROA & $14.14 \%$ & $12.03 \%$ & $11.98 \%$ & $11.37 \%$ & $11.15 \%$ & $11.06 \%$ & $11.37 \%$ & $10.79 \%$ & $11.08 \%$ & $10.41 \%$ \\
\hline Dupont ROE & $22.91 \%$ & $20.25 \%$ & $20.15 \%$ & $20.34 \%$ & $19.91 \%$ & $19.54 \%$ & $20.21 \%$ & $21.02 \%$ & $19.64 \%$ & $18.73 \%$ \\
\hline Utilidad Neta|Ventas & $23.78 \%$ & $21.38 \%$ & $21.52 \%$ & $22.01 \%$ & $21.68 \%$ & $21.40 \%$ & $22.06 \%$ & $22.47 \%$ & $21.45 \%$ & $21.74 \%$ \\
\hline Ventas|Total Activo Promedio & $14.92 \%$ & $14.10 \%$ & $13.92 \%$ & $13.33 \%$ & $12.82 \%$ & $12.83 \%$ & $12.99 \%$ & $12.62 \%$ & $12.20 \%$ & $12.00 \%$ \\
\hline
\end{tabular}

Nota: Elaboración Propia en base a información financiera de la empresa. 


\subsubsection{Proyección del Estado de Situación Financiera (Balance General)}

Tabla 34. Proyección del Estado de situación Financiera período 2018- 2027 de Milpo SAA.

\begin{tabular}{|c|c|c|c|c|c|c|c|c|c|c|}
\hline (millones de USD\$) & 2018 & 2019 & 2020 & 2021 & 2022 & 2023 & 2024 & 2025 & 2026 & 2027 \\
\hline Caja y Equivalentes de Efectivo & 740.08 & 717.00 & 681.84 & 757.92 & 707.95 & 644.09 & 629.21 & 772.96 & 521.75 & 481.14 \\
\hline Cuentas por Cobrar LP & 108.17 & 112.50 & 116.99 & 121.67 & 127.15 & 132.87 & 138.85 & 145.79 & 153.08 & 160.74 \\
\hline Existencias & 44.31 & 44.14 & 43.96 & 43.78 & 43.61 & 43.44 & 43.63 & 44.43 & 44.15 & 42.80 \\
\hline Otros Activos & 5.07 & 5.07 & 5.07 & 5.07 & 5.07 & 5.07 & 5.07 & 5.07 & 5.07 & 5.07 \\
\hline Total Activo CP & 897.63 & 878.71 & 847.85 & 928.44 & 883.77 & 825.47 & 816.76 & 968.26 & 724.05 & 689.74 \\
\hline Otros activos financieros & 58.02 & 58.02 & 58.02 & 58.02 & 58.02 & 58.02 & 58.02 & 58.02 & 58.02 & 58.02 \\
\hline Otros Activos L.P. & 35.81 & 36.15 & 36.50 & 36.87 & 37.30 & 37.75 & 38.22 & 38.76 & 39.34 & 39.94 \\
\hline Activo Fijo Neto & 405.30 & 423.57 & 442.67 & 462.63 & 483.49 & 505.29 & 528.08 & 551.89 & 576.77 & 602.78 \\
\hline Acti & 238.07 & 247.59 & 257.50 & 267.80 & 279.85 & 292.44 & 305.60 & 320.88 & 336.92 & 353.77 \\
\hline Tota & 737.20 & 765.34 & 794.69 & 825.32 & 858.66 & 893.50 & 929.91 & 969.55 & 1011.05 & 1054.50 \\
\hline Total Activos & 1634.82 & 1644.04 & 1642.55 & 1753.76 & 1742.43 & 1718.97 & 1746.68 & 1937.81 & 1735.10 & 1744.25 \\
\hline Otro & 7.62 & 9.69 & 20.55 & 101.48 & 87.31 & 41.64 & 47.20 & 170.25 & 5.14 & 5.14 \\
\hline Cuentas por Pagar $\mathrm{CP}$ & 147.08 & 181.71 & 164.05 & 185.30 & 185.55 & 204.14 & 209.45 & 257.48 & 226.55 & 235.71 \\
\hline Otros pasivos $\mathrm{CP}$ & 30.42 & 31.64 & 32.90 & 34.22 & 35.76 & 37.37 & 39.05 & 41.00 & 43.05 & 45.20 \\
\hline Total Pasivo CP & 185.13 & 223.03 & 217.50 & 321.00 & 308.62 & 283.15 & 295.70 & 468.73 & 274.74 & 286.04 \\
\hline Cuentas por Pagar LP & 341.18 & 341.18 & 341.18 & 341.18 & 341.18 & 341.18 & 341.18 & 341.18 & 341.18 & 341.18 \\
\hline Otros Pasivos Fin. LP & 99.20 & 103.16 & 107.29 & 111.58 & 116.60 & 121.85 & 127.33 & 133.70 & 140.39 & 147.40 \\
\hline Total Pasivo LP & 440.38 & 444.34 & 448.47 & 452.76 & 457.78 & 463.03 & 468.51 & 474.88 & 481.57 & 488.58 \\
\hline Patrimonio Neot & 1009.32 & 976.67 & 976.58 & 980.00 & 976.03 & 972.79 & 982.46 & 994.20 & 978.79 & 969.62 \\
\hline Total Pasivo + Patrimonio & 1634.82 & 1644.04 & 1642.55 & 1753.76 & \begin{tabular}{|l|}
1742.43 \\
\end{tabular} & 1718.97 & \begin{tabular}{|l|}
1746.68 \\
\end{tabular} & 1937.81 & \begin{tabular}{|l|}
1735.10 \\
\end{tabular} & 1744.25 \\
\hline
\end{tabular}

Nota: Elaboración Propia en base a información financiera de la empresa

\subsubsection{Proyección del Flujo de Efectivo}

Tabla 35. Proyección del Flujo de Efectivo período 2018- 2027 de Milpo SAA.

\begin{tabular}{|c|c|c|c|c|c|c|c|c|c|c|}
\hline (millones de USD\$) & 2018 & 2019 & 2020 & 2021 & 2022 & 2023 & 2024 & 2025 & 2026 & 2027 \\
\hline $\mathrm{FC} \mathrm{O}$ & 290. & 244.5 & 233.3 & 222.8 & 208.5 & 197.5 & 200.0 & 206.4 & 172.8 & 196.9 \\
\hline $\mathrm{FC} \mathrm{d}$ & -340.5 & -342.6 & -346.6 & -48.7 & -51.5 & -157.1 & -158.3 & -162.9 & -165.0 & 167.3 \\
\hline $\mathrm{FC} \mathrm{F}$ & -18.3 & -19.5 & -17.8 & -9.3 & -8.9 & -11.7 & -10.6 & -14.3 & -14.3 & -14.3 \\
\hline Variac. Efec & -68.0 & -117.6 & -131.0 & 164.8 & 148.1 & 28.7 & 31.1 & 29.3 & -6.5 & 15.4 \\
\hline & 643.5 & 575.5 & 457.9 & 326.9 & 491.7 & 639.8 & 668.5 & 699.6 & 728.9 & 722.4 \\
\hline Caja Final & 575.5 & 457.9 & 326.9 & 491.7 & 639.8 & 668.5 & 699.6 & 728.9 & 722.4 & 737.8 \\
\hline
\end{tabular}




\subsubsection{Estimación de la perpetuidad para la valonización}

Se aplicó la fórmula de la Perpetuidad con crecimiento para el flujo del último año: (FCL año $2028 *(1+g) /($ WACC-g)), obtenido el monto de : USD \$ 1,824,775 (miles de USD).

\subsubsection{Valorización de la empresa Milpo S.A.A.}

$\mathrm{Al}$ construir el modelo de valorización se obtuvo como dato final, el importe de miles de USD \$ 1,824,775 como el valor de la empresa Milpo SAA. Los valores determinados han sido determinados utilizando la tasa de descuento (WACC) de $9.03 \%$ y una tasa de crecimiento de $\mathbf{2 . 4 0 \%}$ (información considerada al comparar este porcentaje con el crecimiento estimado del PBI en el período 1980-2017, el cual fue de 2.55\%).

\subsubsection{Estimación del Free Cash Flow para la Compañía}

Tabla 36. Modelo de Valorización de Milpo SAA.

\begin{tabular}{|c|c|c|c|c|c|c|c|c|c|c|c|}
\hline n miles de dólares americanos & 1 & 2 & 3 & 4 & 5 & 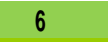 & 7 & 8 & . & 10 & Perpetuo \\
\hline Concepto & 2018 & 2019 & 2020 & 2021 & 2022 & 2023 & 2024 & 2025 & 2026 & 2027 & 2028 \\
\hline Ingresos de Actividades Ordinarias & 972,411 & 924,787 & 914,786 & 905,729 & 896,611 & 887,946 & 900,097 & 930,235 & 896,239 & 815,693 & 835,270 \\
\hline Total de IngresOS ACTIVIDADES ORDINARIAS & 972,411 & 924,787 & 914,786 & 905,729 & 896,611 & 887,946 & 900,097 & 930,235 & 896,239 & 815,693 & 835,270 \\
\hline Costo de Ventas & $(509,849)$ & $(507,495)$ & $(505,023)$ & $(502,685)$ & $(500,330)$ & $(498,055)$ & $(500,620)$ & $(511,515)$ & $(507,637)^{\prime \prime}$ & $(469,304)$ & 480,56 \\
\hline Total Costos Operacion & $(509,849)$ & $(507,495)$ & $(505,023)$ & $(502,685)$ & $(500,330)$ & $(498,055)$ & $(500,620)$ & $(511,515)$ & $(507,637)$ & $(469,304)$ & $(480,568)$ \\
\hline Utilidad Bruta & 462,562 & 417,293 & 409,763 & 403,044 & 396,281 & 389,892 & 399,477 & 418,720 & 388,602 & 346,389 & 354,702 \\
\hline Gastos & $(36,645)$ & $(34,850)$ & $(34,4$ & $(34,132)$ & & & $(33,920)$ & & & & 11,4 I \\
\hline Gastos de Administración & $(43,845)$ & $(41,697)$ & $(41,247)$ & $(40,838)$ & $(40,427)$ & $(40,036)$ & $(40,584)$ & $(41,943)$ & 0) & $(36,779)$ & $37,661)$ \\
\hline Utilidad Operativa (EBIT) & 382,072 & 340,745 & 334,043 & 328,074 & 322,065 & 316,393 & 324,973 & 341,721 & 314,417 & 278,871 & 285,5 \\
\hline las utilidades & $(127,230)$ & $(113,468)$ & $(111,236)$ & $(109,249)$ & $(107,248)$ & $(105,359)$ & $(108,216)$ & & & & $(95,093)$ \\
\hline NOPAT & 254,842 & 227,277 & 222,807 & 218,825 & 214,817 & 211,034 & 216,757 & 227,928 & 209,716 & 186,007 & 190,471 \\
\hline Deprecia & 66,833 & 70,980 & 74,589 & 78,236 & 82,164 & 86,329 & & 96,313 & 100,927 & 39,546 & 40,4 \\
\hline mbio & $(24,423)$ & $(25,250)$ & $(26,105)$ & $(26,988)$ & $(31,389)$ & $(32,5$ & $(33,825)$ & & $(40,666)$ & $(42,386)$ & $(43,404$ \\
\hline Inversiones (CAPEX) & $(52,583)$ & $(52,583)$ & $(52,583)$ & $(52,583)$ & $(52,583)$ & $(52,583)$ & $(52,583)$ & $(52,583)$ & $(52,583)$ & $(52,583)$ & $(52,58$ \\
\hline FLUJO DECAJA LIBRE & 244,669 & 220,424 & 218,709 & 217,491 & 213,009 & 212,196 & 221,465 & 232,644 & 217,395 & 130,584 & 133,718 \\
\hline
\end{tabular}

Nota: Elaboración Propia con Información financiera de la empresa 


\subsubsection{Resultados de la Valorización:}

Tabla 37. Cálculo del Valor Terminal de Milpo SAA.

\begin{tabular}{|l|r|}
\hline G & $2.40 \%$ \\
\hline WACC & $9.41 \%$ \\
\hline FCL Perpetuo en miles de USD\$ & $1,907,589$ \\
\hline
\end{tabular}

Nota. Elaboración propia

Tabla 38. Cálculo del Valor Final de Milpo SAA.

\begin{tabular}{|l|r|}
\hline Valor Actual de los Flujos en miles de USD\$ & $1,367,326$ \\
\hline Valor Actual de FCL Perpetuo en miles de USD\$ & 776,109 \\
\hline Valor de las Operaciones en miles de USD\$ & $2,143,435$ \\
\hline (-) Deuda en mles de USD\$ & 345,531 \\
\hline Valorización Total en miles de USD\$ & $\mathbf{1 , 7 9 7 , 9 0 4}$ \\
\hline
\end{tabular}

Nota. Elaboración propia

Tabla 39. Determinación del Margen con Relación al Valor de Mercado de la Acción Milpo SAA.

\begin{tabular}{|l|r|}
\hline Acciones MILPOC1 \\
\hline $\mathrm{N}^{\circ}$ Acciones Comunes sin derecho a voto & $1,309,748,288$ \\
\hline Precio Acción Calculado al T/C 3.36 S/. & 4.458 \\
\hline Precio de la Acción Mercado (30/07/18)S/. & 4.590 \\
\hline Margen & $-2.87 \%$ \\
\hline
\end{tabular}

Nota: Elaboración Propia 


\section{Capítulo 6. Análisis de riesgos.}

\subsection{Análisis de Sensibilidad de la Valorización.}

\subsubsection{Sensibilidad del precio de los metales.}

De acuerdo al resultado obtenido al sensibilizar las principales variables obtenemos lo siguiente:

- El precio de largo plazo del plomo tendría que aumentar (en forma independiente) $0.11 \%$ respectivamente para que el valor final calculado sea mucho más cercano al precio final actual (S/. 4.590).

- Los precios de largo plazo del cobre y zinc hay un margen mucho más estrecho en cuanto a variación de la sensibilidad, lo cual casi no se muestra con respecto al precio final actual.

Tabla 40. Sensibilidad en el Precio del Cobre.

\begin{tabular}{|r|r|r|}
\hline Cu (USD x Ton) & Precio S/. & Upside/Downside \\
\hline $7,607.60$ & 5.152 & $12.24 \%$ \\
\hline $7,261.80$ & 4.805 & $4.68 \%$ \\
\hline $\mathbf{6 , 9 1 6 . 0 0}$ & $\mathbf{4 . 4 5 8}$ & $\mathbf{- 2 . 8 7 \%}$ \\
\hline $6,743.10$ & 4.285 & $-6.64 \%$ \\
\hline $6,570.20$ & 4.112 & $-10.41 \%$ \\
\hline $6,397.30$ & 3.938 & $-14.20 \%$ \\
\hline $6,224.40$ & 3.765 & $-17.97 \%$ \\
\hline
\end{tabular}

Nota: Elaboración Propia 
Tabla 41. Sensibilidad en el Precio del Plomo.

\begin{tabular}{|r|r|r|}
\hline Pb (USD x Ton) & Precio S/. & Upside/Downside \\
\hline $2,619.10$ & 4.732 & $3.09 \%$ \\
\hline $2,500.05$ & 4.595 & $0.11 \%$ \\
\hline $\mathbf{2 , 3 8 1 . 0 0}$ & $\mathbf{4 . 4 5 8}$ & $\mathbf{- 2 . 8 7 \%}$ \\
\hline $2,321.48$ & 4.390 & $-4.36 \%$ \\
\hline $2,261.95$ & 4.322 & $-5.84 \%$ \\
\hline $2,202.43$ & 4.253 & $-7.34 \%$ \\
\hline $2,142.90$ & 4.185 & $-8.82 \%$ \\
\hline
\end{tabular}

Nota: Elaboración Propia

Tabla 42. Sensibilidad en el Precio del Zinc.

\begin{tabular}{|r|r|r|}
\hline Zc (USD x Ton) & Pre cio S/. & Upside/Downside \\
\hline $2,693.90$ & 6.118 & $33.29 \%$ \\
\hline $2,571.45$ & 5.288 & $15.21 \%$ \\
\hline $\mathbf{2 , 4 4 9 . 0 0}$ & $\mathbf{4 . 4 5 8}$ & $\mathbf{- 2 . 8 7 \%}$ \\
\hline $2,387.78$ & 4.043 & $-11.92 \%$ \\
\hline $2,326.55$ & 3.628 & $-20.96 \%$ \\
\hline $2,265.33$ & 3.213 & $-30.00 \%$ \\
\hline $2,204.10$ & 2.798 & $-39.04 \%$ \\
\hline
\end{tabular}

Nota: Elaboración Propia

\subsubsection{Sensibilidad de la tasa de descuento.}

Al sensibilizar la tasa de descuento (WACC) sobre el resultado obtenido (WACC: 9.03\%) tenemos los siguientes resultados:

Tabla 43. Sensibilidad en el Costo Promedio Ponderado del Capital. 


\begin{tabular}{|c|c|c|}
\hline WACC & Precio S/. & Upside/Downside \\
\hline $9.97 \%$ & 4.147 & $-9.65 \%$ \\
\hline $9.83 \%$ & 4.221 & $-8.04 \%$ \\
\hline $9.69 \%$ & 4.297 & $-6.38 \%$ \\
\hline $9.55 \%$ & 4.376 & $-4.66 \%$ \\
\hline $9.41 \%$ & 4.458 & $-2.87 \%$ \\
\hline $9.27 \%$ & 4.543 & $-1.02 \%$ \\
\hline $9.13 \%$ & 4.632 & $0.92 \%$ \\
\hline $8.99 \%$ & 4.724 & $2.92 \%$ \\
\hline $8.85 \%$ & 4.820 & $5.01 \%$ \\
\hline
\end{tabular}

Nota: Elaboración Propia

En base a ello podemos determinar que se necesita una tasa de descuento WACC de 9.19\% para que el valor final calculado de la acción sea muy similar al valor actual (S/. 4.590).

\subsubsection{Sensibilidad de la tasa de crecimiento.}

Al sensibilizar la tasa de crecimiento $(\mathrm{G})$ sobre el resultado obtenido ( G: 2.40\%) tenemos los siguientes resultados:

Tabla 44. Sensibilidad en la tasa de Crecimiento.

\begin{tabular}{|r|r|r|}
\hline G & Precio S/. & Upside/Downside \\
\hline $2.54 \%$ & 4.503 & $-1.90 \%$ \\
\hline $2.51 \%$ & 4.492 & $-2.14 \%$ \\
\hline $2.47 \%$ & 4.481 & $-2.37 \%$ \\
\hline $2.44 \%$ & 4.469 & $-2.64 \%$ \\
\hline $\mathbf{2 . 4 0 \%}$ & $\mathbf{4 . 4 5 8}$ & $\mathbf{- 2 . 8 7 \%}$ \\
\hline $2.36 \%$ & 4.447 & $-3.12 \%$ \\
\hline $2.33 \%$ & 4.436 & $-3.36 \%$ \\
\hline $2.29 \%$ & 4.426 & $-3.57 \%$ \\
\hline $2.26 \%$ & 4.415 & $-3.81 \%$ \\
\hline
\end{tabular}

Nota: Elaboración Propia

En base también a estos resultados, podemos determinar que se necesita una tasa de crecimiento $\mathrm{G}$ de $2.81 \%$ para que el valor final calculado de la acción sea muy similar al valor actual (S/. 4.590). 


\section{Capitulo 7. Conclusiones.}

Luego de nuestra valorización, podemos concluir lo siguiente:

El valor estimado producto de la valorización de Milpo S.A.A. asciende a $\$ 1,797,904$ miles de USD, con un valor por acción de S/. 4.458 soles (al cambio de \$ 1.373 dólares), cifra levemente menor al valor negociado en la Bolsa de Valores de Lima al 30 de Julio de 2018 por S/. 4.590 (-2.87\%). De acuerdo a este resultado, lo más aconsejable es vender y/o mantener las acciones de la compañía porque hay una alta probabilidad de obtener márgenes de ganancia mayores en el futuro. Los probables escenarios a futuro expuestos en el presente trabajo, confirma la tendencia a la recuperación de la Acción de Milpo S.A.A. en los próximos meses y/o años conforme se vayan obteniendo resultados.

También se puede apreciar de que el valor final calculado es muy sensible con relación al pronóstico en el precio de los metales del modelo, sobre todo en el precio del zinc, que representan más del $70 \%$ de sus ingresos.

Así mismo, el valor fundamental es también dependiente principalmente de la Unidad Minera de Cerro Lindo, el cual representar más del $65 \%$ de sus ingresos totales.

Sin embargo, aún cuando existe concentración de la producción en un solo commodity y/o Unidad Minera, la compañía cuenta con márgenes de utilidad sólidos y consistentes a lo largo de su operación, márgenes que se iran incrementando a los largo del tiempo por la eficiencia operativa de la empresa. Esto le permitirá sostener su posición competitiva en el largo plazo, bajo condiciones razonables del comportamiento futuro de dichos márgenes. 


\section{Capítulo 8. Recomendaciones y conceptos adicionales.}

Finalmente recomendamos lo siguiente: Para los inversionistas que pudieran estar interesados, la recomendación principal es vender como primera opción, o en todo caso mantener las acciones de la compañía, ya que, de acuerdo con nuestro análisis, existe un margen de depreciación de $-2.87 \%$ con relación al valor bursátil al 30.07.2018.

La segunda recomendación radica en que, dada la volatilidad de los precios de los metales, en el mercado internacional, o en caso existan cambios normativos importantes, se sugiere revisar periódicamente la vigencia de los supuesto empleados en la presente valorización. Por el momento se prevee un incremento en el precio de los metales, con lo cual sería otra causal en el aumento del precio de la acción en el mediano plazo.

La tercera recomendación, es definitivamente la diversificación de los proyectos, para así minimizar la dependencia mayoritaria de una sola Unidad Minera, sobre todo si representa más del 50\% de los ingresos totales. Por al razón se debe tomar en cuenta de su impacto en el caso que ocurriese algún suceso que afecte su funcionamiento (huelgas, conflictos sociales etc.).

Para efectos del presente estudio, no está considerado eventos externos no controlados por la compañía, como por ejemplo: interrupción de las vías de comunicación y/o falta de acceso a los puertos, conflictos y/o estallidos sociales, crisis internacional, etc. 


\section{Capítulo 9. Bibliografía.}

1. Julio Panez Meza y Carmela Ishida de Panez. Diccionario de contabilidad, Economía y Finanzas. Iberoamericana de Editores, segundo tomo CH-L.

2. Isidro Chambergo Guillermo. Costos para Gerenciar Organizaciones Por Sectores Económicos, Instituto Pacífico S.A.C. (Primera Edición- Julio 2016).

3. Pearson Educational Limited (2001). Longman Business English Dictionary, (Fourth Impression).

4. Fina Alemany, Carolina Alvarez, María José Arasa, Monserrat Casanovas, entre otros. (2012). MBA Práctico, Guía Práctica para valoración de Empresas, Luppa Solutions.

5. Directorio Minero.pe Empresas y Proveedores Minero del Peru (2017). Recuperado de http://directoriominero.pe/empresa-minera-los-quenuales-s-a/. [Consulta: $12 \mathrm{de}$ diciembre de 2017].

6. Chu Rubio Manuel, Finanzas Aplicadas: Teoría y práctica, FINANCIAL ADVISORY PARTNERS S.A.C. (Segunda Edición Agosto 2011).

7. World Bank Commodities Price Forecast (nominal US dollars), Released Octubre 2017 y Abril 2018. [Fecha de consulta 16/12/2017 y 20/07/2018].

8. Bravo Orellana Sergio. (2010). Teoria Financiera y Costo de Capital, UNIVERSIDAD ESAN, 2008. (Primera Reimpresión Octubre 2010).

9. Barrionuevo Canto Francisco J., (2014). Metodo de Valoración de Empresas, FUNDACION NOVASOFT (Género : Ensayo, Materia : Teoría y comportamie ntos Organizativos) (publicado el 31 de Mayo de 2014).

10. Molina A. Hércules, (2004). La Tasa de Descuento en la Evaluación de Proyectos y Negocios Empresariales, UNIVERSIDAD NACIONAL MAYOR DE SAN MARCOS, Industrial Data - Revista de Investigación : Volumen (7) 1 : pp 42-54.

11. Ibboton Roger G., Kaplan Paul D., Peterson James D. (1997). Estimates of smallstocks betas are too much low. The Journal of Portfolio Managmnent Summer pp 104-111.

12. BBVA Research. (2018). Situación Perú. Segundo Trimestre 2018. Recuperado de https $/ /$ www.bbvaresearch.com/ publicaciones/situacion-peru-segundo-trimestre2018/ [Consulta: 20 de julio de 2018].

13. Bravo, Sergio. (2004). El costo de capital en sectores regulados y mercados emergentes: metodología y casos aplicativos. (Documento de investigación, $\mathrm{N}^{\circ} 13$, Escuela de administración de negocios para graduados - ESAN. Lima: Perú).

14. Bustamante, R. (2014). Métodos de valorización de empresas mineras: un análisis para el caso peruano 2008 - 2013. (Documento de Investigación, Universidad Nacional Mayor de San Marcos - UNMSM, Lima: Perú).

15. Copeland, T., Koller, T. \& Murrin, J. (2004). Valoración: medición y gestión del valor. Barcelona: Ediciones Deusto. 
16. Court, E. (2009). Aplicaciones para finanzas empresariales. Estado de México: Pearson Educación de México.

17. Damodaran, A. (2006). Damodaran on valuation - security analysis for investment and corporate finance. New Jersey: John Wiley \& Sons, Inc.

18. EY - Perú. ¿Su empresa está al tanto de las últimas prácticas de valorización en el mercado? Recuperado de http//www.ey.com/Publication/vwLUAssets/EY-ultimaspracticas-valorizacion-mercado/\$File/EY-ultimas-practicas-valorizacionmercado.pdf [Consulta: 05 de julio de 2018].

19. Fernandez, P. (2008). Métodos de Valoración de Empresas. (Documento de investigación, IESE Business School - Universidad de Navarra. Madrid: España).

20. Forsyth, J. (2012). Finanzas empresariales: rentabilidad y valor. Lima: Tarea Asociación Gráfica Educativa.

21. Herrera Garcia Beatriz. (2008). Acerca de la Tasa de Descuento en Proyectos. UNIVERSIDAD NACIONAL MAYOR DE SAN MARCOS, Revista Quipucamayoc, volumen $15 \mathrm{~N}^{\circ} 29 \mathrm{pp}$ 101-108.

22. Aswath Damodaran: "Uno de los mayores errores es asumir que el crecimiento de una compañía es gratis o muy barato". [Entrevista] Sintetia.com. Recuperado de https $/ /$ www.sintetia.com/aswath-damodaran-stern-finance/ [Consultado: $07 \mathrm{de}$ agosto de 2017].

23. Compendio Estadístico Peru 2016, Minería e Hidrocarburos. Recuperado de https $/ /$ www.inei.gob.pe/media/MenuRecursivo/publicaciones_digitales/Est/Lib137 5/ cap14 /cap14.pdf. [Consultado: 17 de diciembre de 2017].

24. Ministerio de Energia y Minas - Dirección General de Minería. Recuperado de http://www.minem.gob.pe /_estadistica.php?idSector=1\&idEstadistica=11299. [Consultado: 17 de diciembre de 2017].

25. Superintendencia de Mercados y Valores. Fecha de consulta 19/12/2017. Recuperado de: http://www.smv.gob.pe/ConsultasP8/temp/ Grupo\%20Glencore\%20en\%20el \%20Per\%C3\%BA_Diagrama\%2014.9.17.pdf. [Consultado: 19 de diciembre de 2017].

26. Mineria con Futuro. Recuperado de http:// mineriaconfuturo.com.pe Inoticias/produccion-de-mineria-metalica-logra-record-de-crecimiento-mineria-confuturo-pro-duccion - de-cobre. [Consultado: 20 de diciembre de 2017].

27. Sociedad Nacional de Minería y Petróleo, memoria anual 2016. Fuente de información: http://www.snmpe.org.pe/informes-y-publicaciones /memoriasinstitucionales/4503-memoria-anual-2016.html.

28. Osinergmin: La industria de la minería en el Perú. Recuperado de: http://www.osinergmin.gob.pe/seccion/centro_documental/Institucional/Estudios_E conomicos/Libros/Osinergmin-Industria-Mineria-Peru-20anios.pdf. $\quad$ Fecha de publicación: Febrero/2017.

29. Mineria con Futuro. Recuperado de: http://mineriaconfuturo.com.pe/ noticias/defensoria-del-pueblo-reporto-78-conflic tos-activos-relacionados-al-sectorminero-peru [Consultado: 22 de diciembre de 2017].

30. Osinergmin: La industria de la minería en el Perú. Recuperado de: http://www.osinergmin.gob.pe/seccion /centro_documental/Institucional/ 
Estudios_Economicos/Libros/Osinergmin-Industria-Mineria-Peru-20anios.pdf. Fecha de publicación: Febrero/2017.

31. Annual Reports on Investments: Annual Returns on Stock, T.Bonds and T.Bills: 1928 - Current, Damodaran. Recuperado de: http://pages.stern.nyu. edu/ adamodar/ New_Home_Page/ datafile/ histretSP.html. [Consultado: 07 de enero de 2018].

32. Betas by Sector (US). Recuperado de : http://pages.stern.nyu.edu / adamodar / New_Home_Page/datafile/Betas.html. [Consultado: 07 de enero de 2018].

33. Bolsa de Valores de Lima, cotización acciones comunes Milpo S.A.A. MILPOC1. Recuperado de : http://www.bvl.com.pe/ inf_cotizaciones62000_TUIMUE9DMQ. html. [Consultado: 30 de junio de 2018].

34. Investing.Com Datos históricos de S\&P Lima General SPBLGPT. Recuperado de : https:/es.investing.com/indices/lima-stock-exchange-general-historical-data. [Consultado: 14 de enero de 2018].

35. Investing Com Resument consolidado del ejercicio MILPO (MIL). Recuperado de : https:/es.investing.com/equities/milpo-cash-flow. [Consultado: 24 de enero de 2018].

36. Ministerio de Energía y Minas Glosario Técnico Minero, Republica de Colombia, ministerio de Energía y minas. Edición Mayo de 2015. Recuperado de : https $/ /$ www.minminas.gov.co/documents/10180/698204/[Consultado: 21 de enero de 2018].

37. Derecho y Sociedad (02 de Junio de 2008). La Regulación del Sector Minero del Perú : Reflexiones y Propuestas desde una Visión Admnistrativa. Recuperado de http://blog.pucp.edu.pe/blog/derysoc/2008/06/02/la-regulacion-del-sector-mineroen-el-peru-reflexiones-y-propuestas-desde-una-vision-administrativista/. [Consulta : 06 de Julio de 2017].

38. Reporte de Estudios Económicos Julio 2018 Scotiabank. Recuperado de : https $/ /$ www.scotiabank.com.pe/Acerca-de/Scotiabank-Peru/Mas-informacion/ reportes-de-estudios-economicos/reportes-en-linea/reporte-semanal-2014 [Consulta : 13 de Julio de 2017].

39. BBVA Research - Presentation Peru Economic Outlook. Second Quarter 2018. Recuperado de : https://www.bbvaresearch.com/en/publicaciones/presentation-perueconomic-outlook-second-quarter-2018/ [Consulta : 13 de Julio de 2017].

40. Scotiabank Perú SAA - Reporte de Estudios Económicos. (2017). Reporte Especial. La economía 2018: Saliendo del Shock. Recuperado de : https $/ /$ scotiabankfiles. azureedge. net/scotiabank-peru/PDFs/reportes/ macroeconomico/20170907_mac_es.pdf [Consulta: 09 de Julio de 2018].

41. London stock exchange . Datos históricos cotización del zinc. Recuperado de : https $/ /$ www.londonstock exchange.com/exchange/prices-and- markets/ETPs /company-summary/GB00B15K Y872JEUSDETCS.html [Consulta: 09 de Julio de 2018].

42. Bolsamanía. Com. Datos históricos cotización del plomo. Recuperado de : https $/ /$ www.bolsamania.com/materia-prima/plomo/historico-precios. [Consulta: 09 de Julio de 2018].

43. Bolsamanía. Com. Datos históricos cotización del cobre. Recuperado de : http://www.bolsamania.com/materia-prima/cobre [Consulta: 09 de Julio de 2018]. 
44. De Lara Haro, Alfonso (2012). Medición y control de riesgos financieros. Editorial Limusa SA de CV, Grupo Noriega Editores, tercera Edición.

45. BCRP, Ministerio de Economía y Finanzas - Gerencia Central de Estudios Económicos. Cuadros de PBI, Balanza de Pagos y Esportaciones Recuperado de : http://www.bcrp.gob.pe/ estadisticas/cuadros-anuales-historicos [Consulta: 09 de Julio de 2018].

46. Ministerio de Economía y Finanzas. Informe de Actualización de Proyecciones Macroecnómicas 2018-2021. Recuperado de : https://www.mef.gob.pe /contenidos/pol_econ/marco_macro/IAPM_2018_2021.pdf [Consulta: 09 de Julio de 2018].

47. Portal Bloomberg. Informe de Beta Milpo [Consulta: 17 de Febrero de 2018]. 